NAA-SR-5415

REACTOR TECHNOLOGY

110 PAGES

KINETIC EXPERIMENTS ON WATER BOILERS

"A" CORE REPORT - PART I

PROGRAM HISTORY, FACILITY DESCRIPTION,

AND EXPERIMENTAL RESULTS

\author{
Edirors: \\ JOHN W. FLORA \\ ROBERT K. STITT \\ Report Written By: \\ JOHN W. FLORA \\ EDWARD L. GARDNER \\ MOSES A. GREENFIELD (Consultant) \\ JOHN H. ROECKER \\ ROBERT K. STITT
}

\title{
ATOMICS INTERNATIONAL
}
A DIVISION OF NORTH AMERICAN AVIATION, INC.
P.O. BOX 309 CANOGA PARK, CALIFORNIA

CONTRACT: AT(11-1)-GEN -8

ISSUED:

MAR 301962 


\section{DISCLAIMER}

This report was prepared as an account of work sponsored by an agency of the United States Government. Neither the United States Government nor any agency Thereof, nor any of their employees, makes any warranty, express or implied, or assumes any legal liability or responsibility for the accuracy, completeness, or usefulness of any information, apparatus, product, or process disclosed, or represents that its use would not infringe privately owned rights. Reference herein to any specific commercial product, process, or service by trade name, trademark, manufacturer, or otherwise does not necessarily constitute or imply its endorsement, recommendation, or favoring by the United States Government or any agency thereof. The views and opinions of authors expressed herein do not necessarily state or reflect those of the United States Government or any agency thereof. 


\section{DISCLAIMER}

Portions of this document may be illegible in electronic image products. Images are produced from the best available original document. 


\section{DISTRIBUTION}

This report has been distributed according to the category "Reactor Technology" as given in "Standard Distribution Lists for Unclassified Scientific and Technical Reports" TID-4500 (16th Ed.), December 15, 1960. A total of 650 copies were printed.

\section{ACKNOWLEDGMENT}

This report summarizes the experiment phase of nearly four years of activity in the KEWB program. There were obviously notable and valuable contributions made by others than the authors and editors of this report, and it is with pleasure that these contributions are gratefully acknowledged below:

Grant Schumann

Bernard R. Moskowitz

Dean P. Gamble

Gerl C. Murphy

Daniel R. Muller

John C. Moore

Eugene B. Hecker

Sidney G. Barnes

Robert E. Wimmer

John B. Williams

Robert J. Allen
July, 1955- Reactor installation, operation, and testing.

Oct., 1955- Reactor installation and Sept., 1956 initial testing.

Sept., 1956- Data analysis.

Apr., 1960

Jan., 1957- Data reduction.

June, 1960

June, 1956- Program planning and

Aug., 1959 directing reactor operation.

Sept., 1957- Instrumentation for reactor July, 1960 tests.

Sept., 1955- Instrumentation installation May, 1958 and reactor testing.

Aug., 1958- Instrumentation development. Apr., 1961

Oct., 1956- Data analysis.

Aug., 1958

Oct., 1954June, 1956

Design of facility and reactor components.

July, 1956Nov., 1956
Instrumentation installation and testing. 


\section{PREFACE}

This is Part I in a series of five reports concerning the developments which occurred during the first (" $A$ " core) phase of Kinetic Experiments on Water Boilers (KEWB) program. The reader interested in further details of this program will undoubtedly find other reports in the series helpful. These reports are designated as:

NAA-SR-5416 - M. S. Dunenfeld, et al.

Kinetic Experiments on Water Boile $\overline{r s}$, "A" Core ReportPart II, Analysis of Results.

NAA-SR-5417 - R. N. Cordy.

Kinetic Experiments on Water Boilers, "A" Core ReportPart III, Pile Oscillator Results.

NAA-SR-5418 - M. A. Greenfield.

Kinetic Experiments on Water Boilers, "A" Core ReportPart IV, Containment Aspects of Hydrogen-Oxygen Explosions.

NAA-SR-5419-M.A. Greenfield.

Kinetic Experiments on Water Boilers, "A" Core ReportPart V, Containment Aspects of Pressure Waves from Initial Solution Expansion. 


\begin{abstract}
The Kinetic Experiments on Water Boilers, an AEC Reactor Safety program, included the experimental testing of a small spherical aqueous homogeneous core. Approximately 900 power excursions were initiated during the testing of this core. Parameters such as initial fuel temperature, system pressure, power, and void volume were found to have little effect on the dynamic behavior of the assembly. Ramp reactivity insertions arising from the simultaneous withdrawal of all control rods $(\$ 0.16 \Delta \rho / \mathrm{sec})$ gave rise to a mild transient having a peak power of about $3 \mathrm{Mw}$. This excursion had a minimum period of $50 \mathrm{msec}$; no pressure was generated. The only parameter of significance in determining the severity of meaningful bursts, in terms of radiological safety, was the amount of reactivity injected as a step input. The reactivity had to exceed that required to produce a $10-\mathrm{msec}$ period $(\$ 1.70 \Delta \rho)$ if pressures of more than a few pounds per square inch were to be generated. The largest burst had a maximum power of $773 \mathrm{Mw}$ and an inertial pressure of 620 psi. These latter results were obtained with the core vessel completely filled with fuel solution and the reactor on a period of $1.8 \mathrm{msec}$. The hydrogenoxygen explosions initiated by the gas recombination system were found to offer no greater hazard than the fuel expansion pressures.
\end{abstract}




\section{CONTENTS}

Page

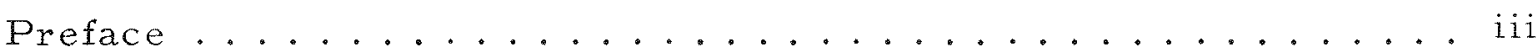

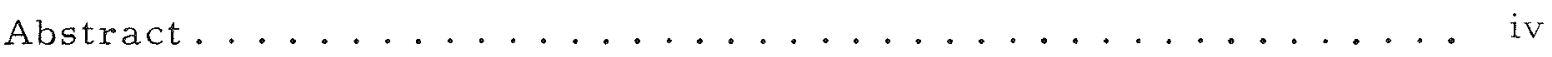

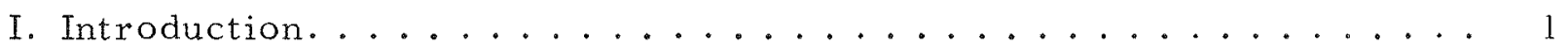

II. Summary of Experimental Data and Conclusions. . . . . . . . . . 4

A. Complete and Sudden Release of all Installed Reactivity--\$4 . . 6

B. Lesser Reactivity Insertions. ................... 11

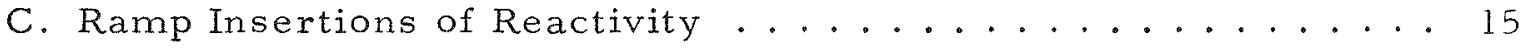

D. Effect of Operating Parameters. .............. 17

E. Reservations on Application of Data Available ......... 19

III. Description of KEWB Facility and Instrumentation . . . . . . . . 21

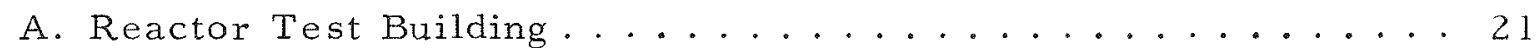

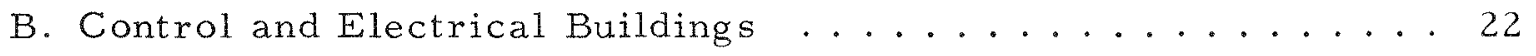

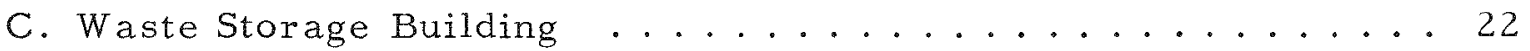

D. Description of KEW B Reactor System. . . . . . . . . . 24

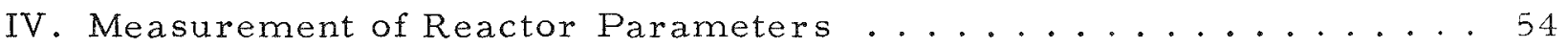

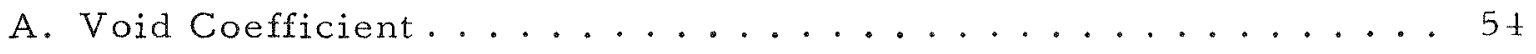

B. Temperature Coefficient of Reactivity .............. 56

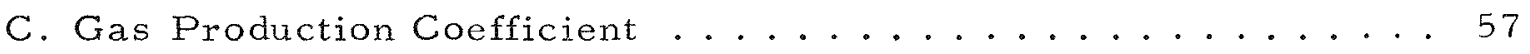

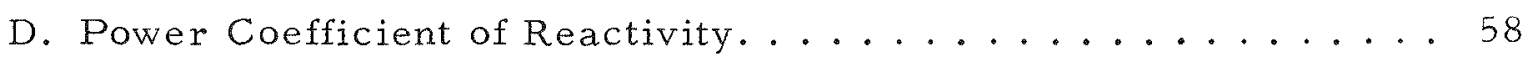

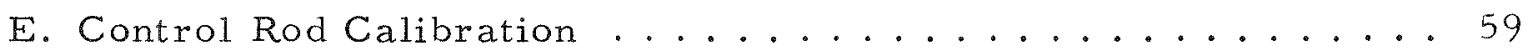

F. Transient Power Recorder Calibration ............. 64

G. Pressure Transducer Calibration ................ 64

H. Flux Traverses in Core and Reflector ........... 65

I. Thermal Power Calibration ................. 67

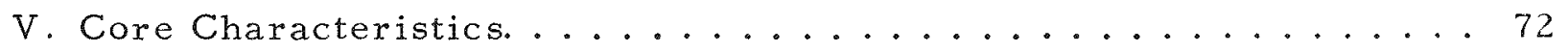

VI. Details of Experimental Data ................... 74

A. Step Reactivity Insertions. . . . . . . . . . . . . . . 74

B. Ramp Reactivity Insertions. . . . . . . . . . . . . . 90

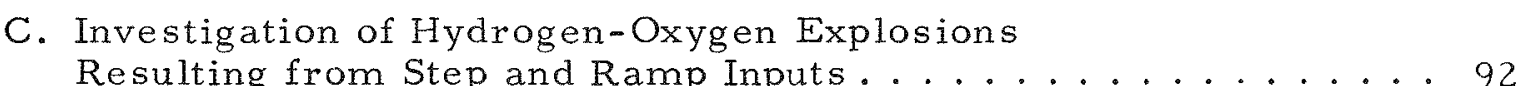

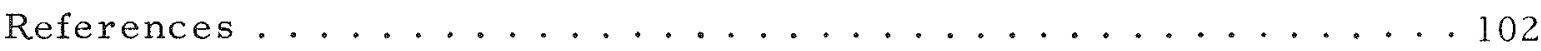




\section{TABLES}

Page

I. Coolant Thermal Power Calibration Data . . . . . . . . . . . 70

II. KEWB Spherical Core Characteristics................... 73

III. Summary of Data for Step Input Transients, 85\% Full Core . . . . . 77

IV. Summary of Data for Step Input Transients, Full Core . . . . . . 78

V. Summary of Data for Effects of Initial Euel Temperature on Step Input Transients, $85 \%$ Full Core .............. 82

VI. Summary of Data for Effects of Initial Reactor Power on Step Input Transients, $85 \%$ Full Core .............. 88

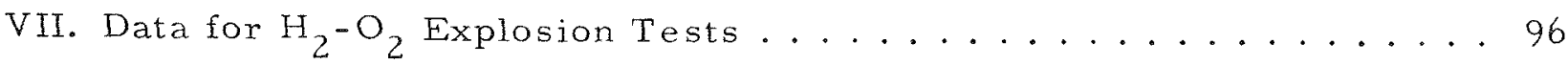

\section{FIOURES}

1. Cutaway View of KEWB Reactor .................... 5

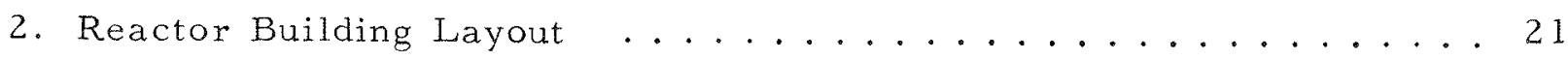

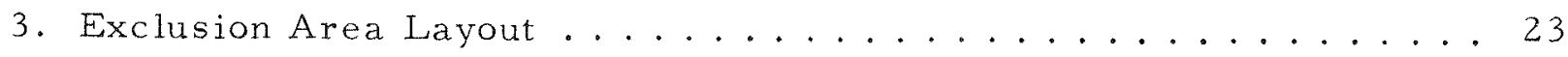

4. Layout Drawing and Photograph of Core Vessel

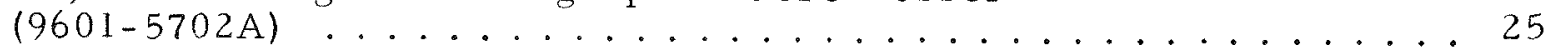

5. Cooling Coils Mounted in One-half of Core Vessel before

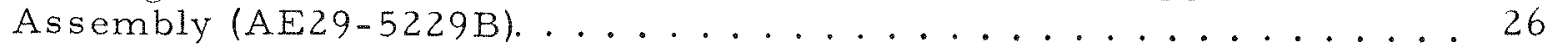

6. Elevation View of Piping and Vessels for Reactor System

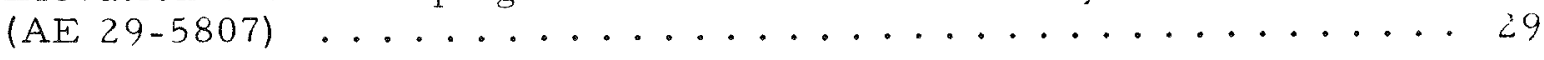

7. KEWB Conventional Reactor Control Instrumentation Block

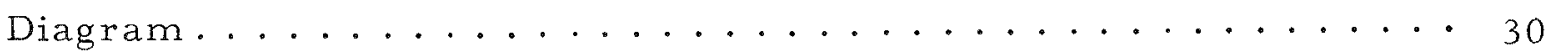

8. KEW B Transient Instrumentation Block Diagram .......... 33

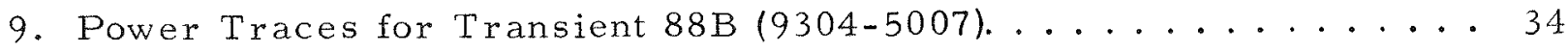

10. Circuit Diagram for Electrometer Head . . . . . . . . . . 36

11. Circuit Diagram for Electrometer Head Power Supply. . . . . . . . 37

12. Revised Linear Power Recording System . . . . . . . . . . . . . . . . . . . . .

13. Block Diagram of Fast Pressure Recording Channel ........ 39

14. Pressure Record for 2-msec Transient . . . . . . . . . . . 4 41

15. Pressure Record for a Hydrogen-Oxygen Explosion in the Core Vessel Following a Power Transient. . . . . . . . . . . . . 42

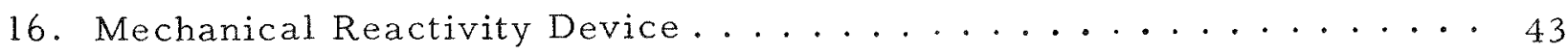

17. Layout Drawing of Pneumatic Reactivity Device. . . . . . . . . 45

18. Poison Rod Position and Resulting Reactivity

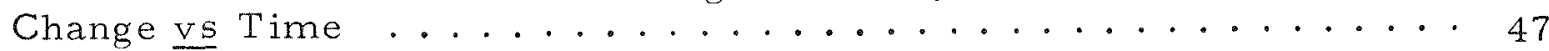




\section{FIGURES}

Page

19. Typical Power Transient Oscillogram . . . . . . . . . . . 48

20. Thermocouple Fabrication Sequence ............... 50

21. Digital Oscillogram Readout System (9304-1854) ........ 51

22. Readout Head Showing Linear Potentiometer and Cursor

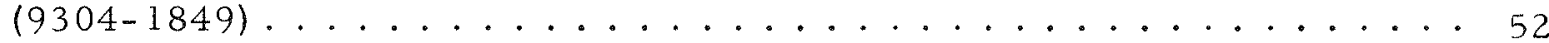

23. Reactivity Consumed in Calibrated Voids .............. . . 54

24. Void Coefficient of Reactivity vs Void Volume ........... . . 55

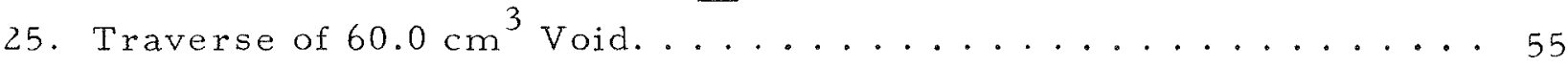

26. Temperature Coefficient vs Temperature for $85 \%$ Full

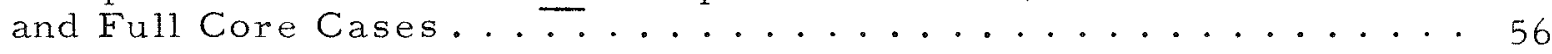

27. "G" Value vs Final Core Pressure ................. . . 58

28. Reactivity Consumed vs Reactor Power Level . . . . . . . . . . 59

29. Subcritical Control Rod Calibration Curve, Rod 4.........6 61

30. Control Rod Calibration Curves, 85\% Full Core.......... 62

31. Control Rod Calibration Curves, Full Core ........... 62

32. Ganged Four-Rod Calibration Curve, Full Core. . . . . . . . . 63

33. Ganged Four-Rod Calibration Curve, 85\% Full Core ....... 63

34. Steady-State Flux Distribution in Air-Filled Horizontal Through-Tube using Indium Wire................... 65

35. Steady-State Flux Distribution in Moderator-Filled Horizontal Through-Tube using Indium Wire........... 66

36. Transient and Steady-State Thermal Flux Distribution in Air-Filled Horizontal Through-Tube using $1 \mathrm{~cm}^{2}$ Au Foils . . . . . 67

37. Transient and Steady-State Thermal Flux Distribution in Horizontal Exposure Facility using $1 \mathrm{~cm}^{2}$ Au Foils . . . . . . . 68

38. Cadmium Ratio in Horizontal Through-Tube and Exposure Facility for 3.2 msec $\operatorname{Transient} \ldots \ldots \ldots \ldots 68 \ldots \ldots \ldots \ldots$

39. Cadmium Ratio in Horizontal Through-Tube and Exposure

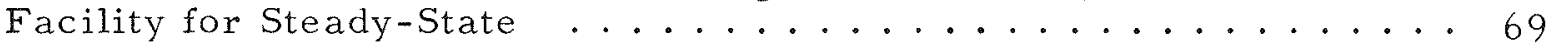

40. Coolant Thermal Power Calibration Plot ............. . 71

41. Typical Transient Recordings (9304-4544).................. 75

42. Peak Power vs Reactor Period (9304-4540) ............. . 76

43. Peak Pressure vs Period (9304-4554) ................ 80

44. Peak Power vs Initial Temperature, Core Vessel $85 \%$ Full of Fuel Solution $(9304-4542) \ldots \ldots \ldots 1$ 


\section{FIGURES}

45. Peak Power vs Initial Temperature, Core Vessel

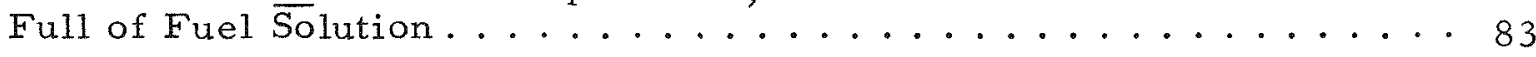

46. Energy Release vs Stable Period (9304-4539). . . . . . . . . . 84

47. Oscillogram for Transient No. 249B, Stable Period 0.98 sec ... 84

48. Oscillogram for Transient No. 202BR, Stable Period $200 \mathrm{msec}$. . 85

49. Oscillogram for Transient No. 204B, Stable Period 153 msec ... 85

50. Oscillogram for Transient No. 234B, Stable Period $51.1 \mathrm{msec} . . .85$

51. Oscillogram for Transient No. 226B, Stable Period $3.8 \mathrm{msec}$. . . 86

52. Oscillogram for Transient No. 190B, Stable Period $2.12 \mathrm{msec}$. . . 86

53. Peak Power vs Initial Power (9304-4543) . . . . . . . . . . . 89

54. Peak Power vs Minimum Period, Ramp Inputs (9304-4548) . . . . . 91

55. Plot of Unit Step and Indicial Admittance, A(t) . . . . . . . . . 97

56. Signal $S(t)$ vs Response $R(t) \ldots \ldots \ldots 9$

57. Plot of Equation $R_{m}=x^{\frac{x}{1-x}} \ldots \ldots \ldots \ldots$ 


\section{INTRODUCTION}

The Kinetic Experiments on Water Boilers program represents a comprehensive effort to gain a thorough understanding of the dynamic behavior of small aqueous homogeneous reactors. The program has included an extensive series of experimental tests on a representative reactor system, an analytical effort devoted to interpretation of the results of the experiments, a transient instrumentation development program to insured the quality of the data, and a companion project to the integral reactor tests having as its purpose the direct measurement of the density of the fuel solution as a function of time during power excursions. Of these various phases of the program, the instrumentation development project has been completed; the integral reactor tests on the first core geometry have been concluded with some 900 transient experiments; the analytical phase has yielded plausible arguments which can explain, in a sense, the behavior of the reactor but which are not yet thoroughly refined nor developed to the point of general application; and the density measurements have commenced with the transient experiments on the second reactor core.

The second core tests and density measurements are a direct outgrowth of the needs of the theorists to have a broader base upon which to build their analytic models. Consequently, since this report concerns results obtained from the tests made upon the first core only, it is of an interim nature. The ultimate aim of our analytical effort is to derive a reliable model basedonfirst principles which will accurately predict the behavior of any of six design variations of the reactor type, and which will assist accurate hazard evaluations of critical experiments and of accidental excursions involving solutions. Until this is accomplished, we must content ourselves with transmitting only those conclusions which may be of value to those evaluating, operating, or designing solution type reactors. A particular effort is made toward that end in this particular report, and such information will be found in Section II. The program activities from 1956 to 1960 are covered in this report and those outlined in the Preface. Periodic reports have been made during this time through the medium of formal technical conferences and society publications. 
The Kinetic Experiments on Water Boiler (KEWB) program was initiated by Atomics International, under contract to the Atomic Energy Commission, in October, 1954. The objective of the program was to establish a firm basis for the evaluation of the safety of aqueous homogeneous reactor designs with regard to an accidental release of large quantities of reactivity. The increasing demand for low power research and training reactors, plus the desire to locate these reactors in highly populated regions, precipitated this detailed consideration of their ultimate safety. This effort has been one of two such experimental programs involving full reactor systems sponsored by the AEC. The other is the Special Power Excursion Reactor Tests (SPERT) being conducted by the Phillips Petroleum Company at the National Reactor Test Station. The latter program is concerned with investigations on heterogeneous water moderated systems.

The intent in the KEWB program is to investigate a sufficient number of parameters to permit the accurate evaluation of radiation hazards. An obvious corollary of this objective is that optimization of core design, from a hazards minimization standpoint, should be possible upon completion of the program. The optimum design may be defined as that which, in the event that all potential reactivity is released, presents no hazard to the reactor operating personnel, the installation, or the environs. These objectives are being carried out by conducting a thorough experimental investigation of two different core geometries to determine the consequences of abnormal reactor operation which results in the release of large amounts of reactivity. To date, the experiments on the first spherical core geometry have been completed and a summary of the results obtained is given in this report. The evolution of the analytic phases of the program, along with the currently proposed theories, is reviewed.

The program has continued with a series of experiments utilizing a cylindrical core geometry, and a companion effort which involves the direct measurement fuel solution density as a function of time during the excursions. Both of these phases of the program are directed toward the obtaining of data on the basic mechanisms which counteract a reactivity injection and the reby determine the course of a power burst. The need for the tests involving a cylindrical core geometry and an independent measure of the dynamic density changes of the reacting solution was brought about by the unique and confounding pressure waves attributable to the geometry of the spherical core and the discovery of a third prominent reactivity compensating mechanism. The latter, due to the 
existence of the reflector, has ruled out the assumption that reactivity not compensated by temperature increase is ascribable to void production alone, and has made an independent measure of the void parameter necessary.

The experimental site selected for the KEWB experiment is in the Santa Susana mountains about 25 miles northwest of Central Los Angeles near the site of the Sodium Reactor Experiment. The reactor is housed in an underground structure and the experiments are conducted remotely at a distance of about $200 \mathrm{ft}$.

Between project initiation in October, 1954, and September, 1955, the experimental facility was designed and construction completed. The reactor system, complete with instrumentation, was brought into operation in July, 1956.

Transient testing of the first core began in the fall of 1956 and was concluded in August, 1959. During this 3-yr interval, more than 900 transient tests were conducted under a variety of initial core conditions and for various reactivity inputs and injection rates. Of these 900 transients, at least 200 had stable periods of less than $2.5 \mathrm{msec}$.

The major parameters which have been investigated include amount and rate of reactivity released, and the following initial reactor conditions: fuel temperature, core pressure, reactor power level, and void volume above the fuel solution in the core.

The reactor system was found to be relatively insensitive to variation of any of the initial system conditions. The response of the assembly, in terms of pressure generated and energy released - the two principle hazards considerations - depended primarily on the amount and rate of reactivity release. 


\section{SUMMARY OF EXPERIMENTAL DATA AND CONCLUSIONS}

The aqueous homogeneous research reactor, known since the existence of the Manhattan District as the "water boiler, "is characterized by a small stainless steel spherical core vessel, about $1 \mathrm{ft}$ in diameter, which is filled with a solution of uranium salt dissolved in dilute acid. The core is imbedded in graphite in most instances, but there have been occasions when other reflector materials have been employed. ${ }^{1}$ Control of the reactor is invariably accomplished by the use of neutron absorbers, located either outside of or penetrating the core vessel. A cutaway view of the reactor tested appears in Figure 1.

The neutron leakage from these reactors is high by virtue of small size and low critical mass; the latter has never exceeded $2 \mathrm{~kg}$ of $\mathrm{U}^{235}$. A low critical mass not only gives rise to high flux per unit power, but also makes the reactor more sensitive to the addition or subtraction of neutron absorbers in the core region. Considerable excess reactivity, of the order of $\$ 4$ or about $3 \% \Delta k$, is frequently installed for experimental purposes; and rather large beam tubes and exposure facilities are normally incorporated in the reactor design to take advantage of the high neutron leakage. Because of these factors, removal of strongly absorbent samples from the vicinity of the core, accidental manual withdrawal or intentional operational withdrawal of the control rods, or activation of some other reactivity injection mechanism could give rise to power excursions with possibly serious consequences.

This class of reactors is identified with large negative reactivity coefficients. For example, it requires approximately $\$ 2$ to raise the higher power models to their nominal operating level of $50 \mathrm{kw}$. About $\$ 1.50$ of this is required to overcome density decrease of the fuel solution caused by the presence of radiolytically produced gases; the remainder is due to the increased temperature of the fuel solution, which again acts to decrease its density. One must add another $\$ 1$ to $\$ 2$ to the total reactivity inventory for experimental purposes if the machine is to be effectively utilized. The safety of this reactor type now becomes a more specific question, since we can speak in terms of the maximum reactivity involved in an accidental transient. This amount-taken as $\$ 4$, or all reactivity which is installed in the machine - represents the most severe excursion the assembly can undergo if we ignore the remote possibility that this reactivity might be augmented by an experiment in process at the time of the excursion. Now, as a result of the KEWB experiments, we are able to state 


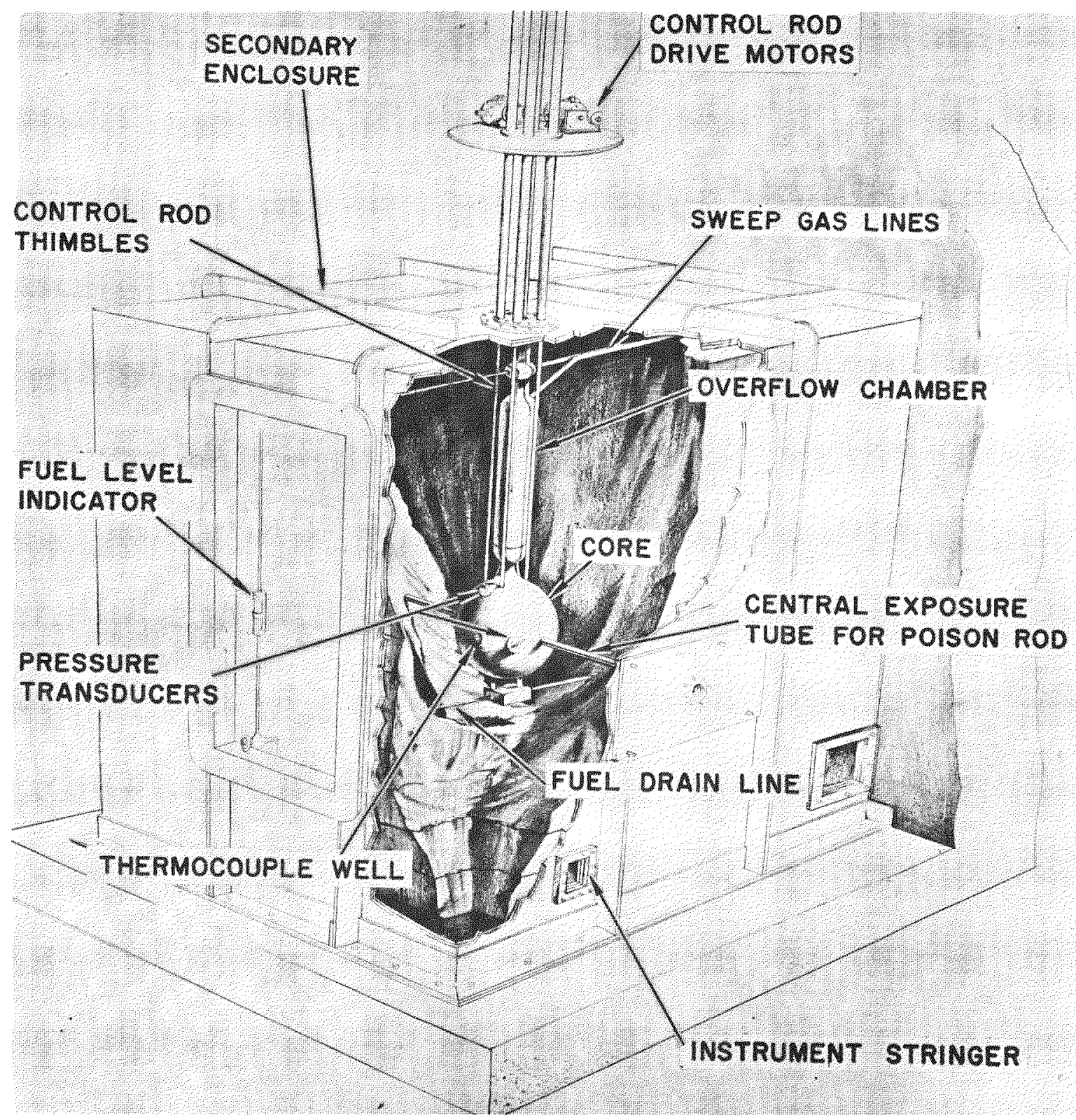

Figure 1. Cutaway View of KEWB Reactor 
In a much more affirmative manner than heretofore possible, the course of events that would occur following such a reactivity introduction in a reactor of this design, and the results

\section{A. COMPLETE AND SUDDEN RELEASE OF ALL INSTALLED REACTIVITY - \$4.00}

The reactivity addition could occur with the initial core pressure anywhere in the operating range for this family of reactors without measurable differences in the results The reactor would have to be at a low power level (a few hundred watts or less) for the full amount of reactivity to be avallable; otherwise, the fuel solution temperature and radiolytic gas inventory would limit the release to something less than $\$ 4$ Thus, we are not concerned with the initial pressure, and since the fuel solution must be near room temperature to have $\$ 4$ reactivity avallable, the existing cooling system requires that the initial power be low in order to maintain the core temperature at near room temperature

Following the reactivity injection, the reactor will rise in power to a few hundred megawatts This rise will be impeded during the last decade by the action of four mechamisms It will be turned sharply within one period ( 2 to $3 \mathrm{msec}$ preceding peak power The inherent devices which counteract the reactivity input are: (1) void production caused by radiolytic gas generation wathin the fuel solution; (2) the retention of neutrons by the reflector. following their thermalization, for periods of time long enough to make them appear as a short-mean-life delayed neutron group, with the attendant loss in reactivity being a function of the reactor period and the abundance and decay constants for these neutrons, (3) the loss of reactivity associated with the conventional delayed neutrons; and (4) the increased neutron leakage from the core vessel and absorption caused by thermal effects All but the latter mechanism account for $\$ 1$ or more of the reactivity compensated The temperature increase in the fuel solution will contribute only about 50 cents to the total reactivity offset

During the last decade of power rise, the core vessel will undergo a strain brought about by the sudden forced expansion of the fuel solution This expansion is manifested by the appearance of an internal pressure wave which rises to its maximum in only 2 or $3 \mathrm{msec}$, the peak pressure occurring as the fuel solution begins to be accelerated into the upper portion of the core vessel, which is normally not occupied by solution The maximum pressure occurs shortly after the power rise has been halted The expansion pressure wave decreases 
In amplitude much more slowly than it rose As it decays, the power drops rapidly without exhibiting any response to the series of impact and reflection pressure waves that occur as the fuel solution-radiolytic gas mixture forces itself from the spherical portion of the core vessel The secondary pressure waves are of the order of 40 to 50 atmos, considerably more than the original expansion wave, which was only about 10 atmos. They impinge on only a portion of the vessel wall, however; and therefore are of less significance, from the standpoint of damage, than the uniform expansion pressure which stresses the vessel on a full diameter. The impact pressures rise to their maximum values in only $300 \mu \mathrm{sec}$, and decay to essentially zero in a like period

Several liters of the fuel solution-gas mixture exit the spherical portion of the vessel. About $2.5 \ell$ is retanned in the overflow reservorr, but some of the spray will be carried to the external plumbing system, including the gas recombination system. Since the energy released in the burst was $4 \mathrm{Mw}-\mathrm{sec}$, and $4 \ell$ of gas is produced per $\mathrm{Mw}-\mathrm{sec}$, the gas recombination system must accomodate $16 \ell$ of hydrogen-oxygen almost instantaneously The data obtained on the reaction of the recombiner system to this sudden evolution of gas indicate that: (1) if the water aspirator pump is on, causing gas to circulate in the intended fashion, an explosion will probably not occur; (2) if the gas pump is not operating, the gas-liquid mixture will reach the catalyst chamber and evidently quench It as an ignition source for up to $3 \mathrm{~min}$, after which time an explosion does occur - presumably because the catalyst has had an opportunity to dry itself by 1ts own heat of recombination; and (3) when an explosion does occur, the maximum pressures transmitted to the walls of the corevessel, the weakest structure in the system, a re limited to about $500 \mathrm{psi}$ The shock wave associated with these explosions rises to its peak value in well under $1 \mathrm{msec}$, and has a decay constant (reduction by a factor of "e") of about $200 \mu \mathrm{sec}$. The inertia characteristics of the core vessel are such that it cannot respond fully to this very high loading rate Hence, the maximum pressure in a hydrogen-oxygen explosion that can be withstood by the vessel is about a factor of two greater than the maximum static pressure the vessel can withstand without rupturing The latter value is about 1500 psi for a 12-1n. diameter, 0.070-1n.-thick stainless steel sphere. It requires over 3000 psi generated in a hydrogen-oxygen explosion to rupture this type of core vessel, even without the external constraints which exist. Pursuing this analysis of the hazard presented by gas explosions 
in the reactor system, we can conclude on the basis of the pressure resistance of the core, and the facts that in such explosions the maximum pressure is 40 times the initial pressure, the vold volume in the core vessel is nominally $7 \ell$ and about $4 l$ of hydrogen and oxygen are produced during a 1 -megajoule energy release, that some 7 megajoules could be generated, and the gas trapped in some unique manner in the core vessel alone and ignited as it became dry. without the integrity of the vessel being compromised This hazard can be put in its proper perspective then, when this large but yet unquestionably safe energy release is compared to the largest obtained in the "A" core experiments involving a nominal fuel loading of 4 megajoules In fact, the only potentially serious situation concerning ignition of the radiolytic gases would be in the case where the reactor operated with a completely inoperative recombination catalyst In this case, the gas pressure in the system could reach very high values If the catalyst then began to recombine the gases and thereby was rapidly heated, an explosion would surely result The experimental data show that it is highly improbable that this would occur An extensive series of explosion tests demonstrated that the catalyst cannot be made inactive for any appreciable length of time, even when the fuel solution foam is injected into the recombiner (see Section VI)

The solution that has been ejected from the spherical portion of the core into the cylindrical overflow chamber returns slowly, over a period of $3 \mathrm{~min}$, to its normal location by gravity drain through a small weep hole at the bottom of the overflow chamber From the time this $25 \ell$ of fuel solution begins its return, the behavior of the reactor is determined solely by the heat removal capacity that is available to it. We are presuming, of course, that the control rods are not yet inserted to terminate the accident If coolant is flowing, the reactor power level plateau following the burst is of the order of the reactor's rated power $-50 \mathrm{kw}$. If coolant is not avallable, the power level decays steadily from this plateau, which is brought about principally by delayed neutrons This decay is caused by heating of the fuel; and without forced cooling the reacting solution will begin to boil within the following 2 to $3 \mathrm{~min}$; and the total reactivity input w1ll be compensated then by steam bubbles, with the reactor subsiding to bolling equilibrium at a few kılowatts of power During the post-burst operation of the reactor, additional radiolytic gas is produced which adds to the inventory 
of combustible mixture that reacts if the recombiner has been inoperative, during the burning recombination once the catalyst ignites the atmosphere

When the gases composing the reactor atmosphere ignite, and the resulting pressure wave impacts on the fuel solution surface, a secondary power excursion occurs, caused by the compression of the gaseous volds within the fuel solution These power pulses are invariably of low amplitude, having a maximum value of a few hundred kılowatts; and are abruptly terminated by the resurgence of the volds as the sharp pressure wave recedes A negligible energy release occurs during such a secondary excursion; and since the fuel solution is, at this time, a composite of both liquid and gas, the shock wave is strongly attenuated as it traverses the fuel medium The maximum pressure sensed underneath the solution, or at the bottom of the core vessel, is about 20 to $30 \%$ of that which appears in the atmosphere above the liquid

If the reactor is permitted to continue under self-controlled conditions, it will seek an equilibrium power determined by the cooling capacity, as mentioned above regarding the platedu power. With the full heat removal capacity available, the reactor will seek a quasıequilibrium power between its rated value of 50 and $100 \mathrm{kw}$. The excess reactivity will be compensated by vapor and radiolytic gas voids generated within the fuel solution If this power levelis in excess of the capability of the recombiner, occasional flashbacks will occur, allowing the recombiner to "catch up" by this rapid recombination means These inflammations will occur much more frequently if the gas circulation pump is not in operation; but the results, aside from frequency, are the same - periodic low-grade power excursions superimposed on the quasiequilibrium power history If there is no forced heat removal. the reactor will retire to a power level of less than $10 \mathrm{kw}$ and the excess reactivity w1ll be compensated in large by bolling with less than $5 \%$ of the reactivity being compensated by radiolytic gas formation

There is only one aspect of this maximum excursion that has been described which deserves attention following the accident, insofar as the operability of the reactor is concerned This is the distribution of uranium and uranium solution. During and immediately following the power burst, uranium solution will be found in unusual locations The solution mist will entrain an abnormally 
high concentration of hydrogen peroxide, which is an intermediate stage in the production of radiolytic hydrogen. This compound is capable of oxidizing the uranium, in solution as $\mathrm{UO}_{2} \mathrm{SO}_{4}$, to the $\mathrm{UO}_{4}$ state, which is insoluble in the original solution. The tolerable amount of hydrogen peroxide is a positive function of temperature; that is, at lower temperatures, precipitation is more likely to occur. As the ejected solution is rapidly cooled by contact with the plumbing external to the core, some uranium peroxide deposition may occur. Also, as the mist encounters the catalyst bed, if it is operating at elevated temperature, vaporization of the solution can occur, with the consequence that a uranium salt residue is deposited on the catalyst elements. To a minor extent this will impair the future efficiency of the catalyst; the reactor will be able to operate successfully after even several excursions, but upon each occasion wherein fuel solution reaches the catalyst bed the recombiner potential will be lessened. The second concern associated with uranium deposition is the localized heating of the salt as a result of relatively high steady-state neutron fluxes which will occur during ensuing operation in proximity to the core vessel. We have indirect proof that some uranium deposition occurred in proximity to the core during the course of the "A" core experiments. Following a series of large transients the reactor solution was allowed to remain quiescent for a few days. Upon resuming the test program, the first large transient was followed almost instantly, with a time delay after the occurrence of peak power of only 30 to $40 \mathrm{msec}$, by ignition of the stoichiometric hydrogen-oxygen atmosphere we maintained above the solution. It is hypothesized that a salt deposit, having been afforded the opportunity to become dehydrated, was heated by fission energy during the transient to the ignition temperature, $550^{\circ} \mathrm{C}$, of the atmosphere. This phenomenon was witnessed on three occasions during the "A" core tests; on each occasion, the circumstances were similar. It is improper to emphasize ignition of the core atmosphere by fission heated uranium however, since most solution reactors provide for dilution of the reactor atmosphere below the ignition concentration of hydrogen. Also, it must be acknowledged that the consequences of ignition under these conditions are no more detrimental to the safety of the installation and personnel than the more delayed explosions reviewed previously; but the abnormally high temperatures that may be associated with prolonged exposure of dry uranium deposits to high neutron fluxes while the reactor is operating at rated power, are of some concern with respect to corrosion damage to the core vessel. As a general recommendation, the 
reactivity inventory should be carefully checked following any excursion which may have displaced uranium into an uncooled region of the metallic surfaces; and if a discrepancy is noted, a thorough rinsing of the system with a solvent should be undertaken. One particular acid combination, sulphuric acid saturated with sulphur dioxide, should be avoided in this process. It has been determined that this reagent vigorously attacks the stainless steels utilized in construction of these reactors.

The preceding review of the events and effects which will follow the sudden introduction of an extreme amount of reactivity into the KEWB type reactor will now be followed by a discussion of the implications of: (a) a lesser reactivity input, appearing in the form of a step increase; (b) reactivity addition which is made linearly with time, such as continuous control rod withdrawal; (c) an.injection of reactivity which might occur after the core is accidently filled, that is, where no initial void volume exists in the spherical part of the core vessel; (d) a general discussion of the effect of the other initial parameters, such as power, pressure and temperature; and (e) the reservations which must be imposed on presently available results insofar as their application to those designs which depart substantially from the model tested.

\section{B. LESSER REACTIVITY INSERTIONS}

\section{Addition of Reactivity Less Than $\$ 1.00$}

Small reactivity injections, say of the order of $\$ 1.00$, represent a much more realistic and probable accident than do such enormous additions as the $\$ 4.00$ excursion reviewed in the preceding paragraphs. The large step addition was of interest mainly in establishing the ultimate safety of the assembly and the mode of operation of the shutdown mechanisms. Reactivity inputs added by the control rods are much more probable than large step additions, since very high accelerations during the withdrawal or addition of a reactivity perturbation device are needed in the latter case to obtain the extremely short reactor periods. The acceleration requirements portend an intentional excursion rather than an accident. However, the smaller reactivity augmentations could occur in a variety of ways. Since continuous rod withdrawal leading to addition of at most $\$ 1.00$ is a more practical case it is especially worthy of review.

The amount of reactivity introduced to the machine is the dominant parameter of those examined in the $\mathrm{KEWB}$ program. This is not unexpected, and undoubtedly is the case in nearly all assemblies. However, the degree of 
dependence of the parameter which causes damage - pressure - on the amount of reactivity is a more subtle question. It is instructive to note that the expansion pressure, the damage criterion for homogeneous reactors, generated during the transients increases, not linearly with increasing reactivity input, but as the $1-1 / 2$ to 2 power of the reactivity. This means, of course, that once sensible inertial pressures appear, they increase rather rapidly as the period is shortened. No inertial pressure is observed until one reaches a 10 -msec period. To reach a $10-\mathrm{msec}$ period requires a reactivity input of $\$ 1.70$, which is outside the range of even simultaneous withdrawal of all control rods from credible starting powers. For considerably smaller reactivities, which can be categorized by the withdrawal of one control rod, or by withdrawal of a sample of moderate absorption without control rod compensation, the reactor will rise into the kilowatt region before the excursion is abated. If the reactivity addition is sufficient to cause a period as short as $0.1 \mathrm{sec}$, the prompt critical regime, the maximum power achieved may be as high as $1 \mathrm{Mw}$. The energy release in the burst will, however, be less than $1 \mathrm{Mw}-\mathrm{sec}$, which accounts for a fuel solution temperature rise of only $15^{\circ} \mathrm{C}$. In this class of transients, reactivity compensation is principally accounted for by the loss of delayed neutrons to the chain reaction. Increases in both the temperature and radiolytic gas inventory each account roughly for 5 to $10 \%$ of the reactivity compensated. These approximations are applicable in the period regime from 5 to $0.1 \mathrm{sec}$.

During the KEWB "A" core tests, a microphone was positioned on the core vessel and the evolution of radiolytic gas was clearly audible during these slower excursions. A transient which reached a peak power of $100 \mathrm{kw}$, for example, was typified by an "Alka Seltzer" type fizzing which reached a maximum intensity in 1 or $2 \mathrm{sec}$ after the power turnaround. This was our first tangible evidence that the gas bubble growth and residence time was of the order of the 1 to $2 \mathrm{sec}$; this had been hypothesized in earlier theoretical studies. 3

For periods in the range of many seconds, the burst itself is ill defined. The power level does not abruptly decrease after the maximum is reached. Instead, the rate of decay is controlled predominantly by the delayed neutron group having the longest mean life. The negative period, therefore, was typically $80 \mathrm{sec}$. As the period becomes shorter, say $5 \mathrm{sec}$, the burst begins to take on a somewhat more symmetrical shape. However, the radiolytic gas associated with the energy release around peak power escapes the fuel solution 
during the initial stages of the sharper power decay and immediately results in a slight resurgence of the power, and a secondary peak results This second peak does not approach the first in magnitude, being limited to about $50 \%$ of its value In some instances as many as three individual maximum were distinguishable in the power traces. These power oscillations were always highly damped It is appropriate to note at this point that at no time during the course of the experimental program did the reactor exhibit uncontrolled divergent oscillatory behavior of the type which has been uncovered in the heterogeneous watex reactor studies 4

Following the long period excursions, the reactor was shut down manually before the solution had the opportunity to cool It has been shown ${ }^{5}$ that otherwise, over an extended time, the reactor would tend to recover and operate eventually at some low power, the level being determined by the reactivity that was installed and the heat removal characteristics of the system Our experiments have shown that in the case of the KEWB reactor, this power level is limited to about $5 \mathrm{kw}$, without forced cooling, for total reactivity inputs as large as $\$ 5$ The post-burstquasiequilibrium power following inputs of less than $\$ 1$ would be substantially lower - probably ranging no higher than a few hundred watts. This will be highly dependent on the quality of the fit a round the core vessel. If there is more or less contunuous contact, the average fuel temperature will be lower for a given steady state power level Thus, for equal reactivity insertions the final reactor power would be higher in the case of a snugly fitted reflector than where there is an insulating air gap surrounding the sphere.

\section{Insertions Between $\$ 1.0$ and $\$ 1.7$.}

As the reactor period lessens to values shorter than prompt critical, $130 \mathrm{msec}$, and approaches $10 \mathrm{msec,}$, which represents the addition of $\$ 170$ of reactivity, the expansion pressures appear These pressures have reached only 15 to 20 psi maximum at the $10-\mathrm{msec}$ period But this low pressure is sufficient to expel fuel solution into the overflow reservoir Another shutdown phenomenon also now makes its appearance, although it is less important than vold formation This compensating mechanism is the decoupling of the reflector from the core, brought about by the substantially longer neutron lifetime in the graphite reflector than in the fuel solution This lifetime difference results in an effectıve loss in reactıvity when the stable period becomes so short that the 
neutrons thermalized in the graphite do not have time to diffuse back into the core and make their normal contribution to the immediately succeeding neutron generation. This phenomenon has been compared to the effect of the six groups of naturally delayed neutrons, both qualitatively and quantitatively. ${ }^{6}$ The treatment of these neutrons as an additional delayed neutron group avoids the difficulties of dealing with a space-dependent problem per se. The modification appears to be acceptable in the theoretical sense, and the information on the behavior of the "7th group" given in the referenced report is based on that model. The analogy to a delayed neutron group can be extended to clarify the reactivity compensation ability of these reflector-moderated neutrons. Several authors 7 have shown that the amount of reactivity that must be compensated in order to turn a burst reaches a minimum a round prompt critical, because the delayed neutrons are being lost to the reactor as the asymptotic period passes through this region. This permits a relaxation of the demands on the shutdown mechanisms for compensation of reactivity around prompt critical, hence less reactivity needs to be counteracted than in the case of reactivity inputs either immediately greater or less than $\$ 1$. The 7 th-group effect is similar; less compensation is required of the temperature and void mechanisms as the reactor period approaches the mean life of the 7th-group neutrons, which has been calculated to be $2 \mathrm{msec}$. At a period of $10 \mathrm{msec}$, the 6 groups of delayed neutrons are holding about $60 \%$ of the injected reactivity at the time of peak power. The remaining three mechanisms, gas voids, temperature, and the 7 th group account in equal proportions for the remaining $40 \%$ of the reactivity offset. The 7 th group, on the basis of what has been said thus far, would be considered as a phenomenon which definitely improves the safety of the concept. This point is considered in more detail in a companion report in this series.

3. Step Inputs Ranging From $\$ 1.7$ to $\$ 3.4$

This range of reactivities and periods ( 10 to $2 \mathrm{msec}$ ) is unique only because it introduces relatively large internal expansion pressures. The 7th group and gas void formation emerge as the dominant control mechanisms, and the six group in-hour equation is conclusively shown not to apply for a graphite reflected system.

The pressures, both expansion and impact, take on the character described previously. All are readily measurable at a reactor period of $10 \mathrm{msec}$. 
The 7th group and void-compensating effects a re of about the same magnitude throughout this period regime. They demonstrate nearly the same dependence on the reactor period. The fact that void formation is increasingly effective as the period is shortened was not firmly established before these experiments had been completed and a resonably acceptable model of the 7 th g roup phenomenon had been factored into the reactivity calculations. As a matter of fact, until it was realized that an effect such as the 7 th group was indeed influencing the in-hour equation, it was believed that the void formation was a very much more potent mechanism than is now thought to be the case, ${ }^{8}$ since all of the reactivity compensation by the 7 th group was originally credited to radiolytic gas evolution. It was during this period that a model of bubble growth in the solution was needed which could explain the exceedingly rapid and efficient collection of gas within bubbles which could decrease the density of the solution, even in the presence of the inertial pressures which were developed. The most promising model which was investigated was based on the interaction of fission fragments, during their flight, with pre-existing voids which began as subcritical-sized bubbles and were forced through the critical-size barrier by the injection of gas from the wake of impinging fragments. There is no overwhelming support for this model as yet and it is entirely possible that a more conventional theory, based on diffusion growth, will prove capable of accounting for the gas compensated reactivity on the varying time scale present.

\section{RAMP INSERTIONS OF REACTIVITY}

If a reactor is started up from source level, usually about $1 \mathrm{mw}$ for these reactors, without the advantage of electronic indicating and safety devices, or if such devices are made inoperative, the worst accident that can occur is the withdrawal of all of the control rods by their electric lift mechanisms. As a facet of the KEWB program, the consequences of this type of situation were examined experimentally. It was in a series of similar experiments that those of the SPERT project uncovered the presence of natural or inherent instability

in swimming pool type cores. ${ }^{4}$ They found that after the insertion of a relatively small amount of reactivity, approximately $\$ 2$, the reactor self-initiates a cyclic excursion phenomenon wherein the power bursts become increasingly intense and, unless terminated by manual action of the operator, are capable of destroying the assembly by melting the fuel elements. The KEWB assembly showed that the homogeneous system is not subject to this inherent instability, 
even when $\$ 5$ of reactivity is inserted and the reactor left to its own devices for nearly one-half hour. The reactor becomes a true "water boiler" under these conditions and, as indicated previously, boils at a quasiequilibrium power of a few kilowatts. This means that in a continuous rod withdrawal accident, where the rods are extracted singly or in any combination, the machine, personnel, or environment will suffer no adverse consequences.

The reactivity addition rates for continuous rod withdrawal tests in the KEWB program were adjusted to the maximum possible; that is, the rods were programed so as to be withdrawn over the region of their maximum differential worth. The addition rates corresponded to $\$ 0.04$ to $\$ 0.16 \mathrm{sec}^{-1}$. Total inputs ranged from $\$ 1.6$ to $\$ 5.0$. The minimum period reached in these transients, which were initiated from a power level of $1.0 \mathrm{mw}$ proved to be the important criterion for prediction of the behavior of the reactor during the significant portion of the burst. If the reactor achieved a minimum period of, say $100 \mathrm{msec}$, the burst was indistinguishable from that resulting from a step insertion of reactivity yielding the same minimum period. The shortest period measured, that induced by the maximum ramp of $\$ 0.16 \mathrm{sec}^{-1}$, was approximately $50 \mathrm{msec}$. As stated previously, this period does not give rise to important expansion pressures. No fuel solution is ejected from the sphere. The reactor simply undergoes a relatively mild transient, reaching a power of about $3 \mathrm{Mw}$, and subsides rapidly to an intermediate power level of 25 to $50 \mathrm{kw}$. The power excursion is completed while reactivity is still being added, even in the minimum total addition tests involving $\$ 1.6$; and during the interim between the burst and ramp termination the reactor power tends to increase slowly, sometimes oscillating mildly. In those experiments where the reactor was afforded no forced cooling, the maximum post-burst power reached was about $50 \mathrm{kw}$. When forced cooling was employed, the post-burst power plateau reached values as high as $200 \mathrm{kw}$. If oscillatory behavior was exhibited, it diminished immediately upon cessation of the ramp injection, and no further power deviations from the gradual decline were witnessed.

In summary, accidental rod withdrawal is of little concern with regard to hazard to the installation, personnel, or environs, in the case of a water boiler reactor of the KEWB type. Reactivity worth $\$ 5$ can be added to the machine, by single or multiple rod withdrawal, without pressures being produced, instability resulting, or manual correction being required. 


\section{EFFECT OF OPERATING PARAMETERS \\ 1. Influence Of Increased Initial Temperature}

The higher power homogeneous research reactors are designed to operate at temperature below saturation at atmospheric pressure. The core vessel atmosphere is normally within $0.5 \mathrm{psi}$ of prevailing atmospheric pressure at rated power, while at shutdown the system is about 1.5 psi below the atmosphere. The temperature of the fuel solution ranges between 25 and $80^{\circ} \mathrm{C}$, depending on the power level and the amount of coolant flowing.

A complete series of excursions has been conducted to examine the effect of increased initial fuel solution temperature on the magnitude of a family of power excursions having the same reactivity driving force. The periods examined ranged from a few seconds to $3 \mathrm{msec}$. Initial temperatures were varied from less than 15 to $95^{\circ} \mathrm{C}$. No important effects were noted. The maximum transient power was decreased only by about a factor of three due to an increase in initial temperature in the most extreme case, and much less than this in the more important tests involving $3-\mathrm{msec}$ periods.

When the starting pressure was reduced to $15 \mathrm{~cm} \mathrm{Hg}$ absolute and the temperature raised to near the boiling point at that pressure, $61^{\circ} \mathrm{C}$, the most marked reductions in the maximum transient power were observed. A decrease of about a factor of three was observed for excursions with periods ranging from 0.6 to $6.5 \mathrm{sec}$.

In tests involving 3-msec periods, the effect of decreasing the initial core pressure was small. The maximum deviation from the excursions made at $70 \mathrm{~cm} \mathrm{Hg}$ initial core pressure, a decrease of $5 \%$, occurred at temperatures near the boiling point at $15 \mathrm{~cm} \mathrm{Hg}$ absolute $\left(61^{\circ} \mathrm{C}\right)$.

These tests show that the kinetic behavior of the reactor system is not sensitive to initial system temperature over the range of temperatures available with system pressures less than one atmosphere absolute. The effects that are observed are such that higher initial core temperatures always give rise to lower maximum transient power.

Decreasing the void volume above the fuel solution in the core vessel did not cause any appreciable change in these tests. 


\section{Influence of Varying The Initial Core Pressure}

The core vessel atmosphere is normally operated at a pressure within 0.5 psi below the prevailing atmospheric pressure while at its rated power. A series of excursions were conducted to examine the effect of decreasing this pressure down to $15 \mathrm{~cm} \mathrm{Hg}$ absolute. A few excursions have also been conducted at initial pressures up to 2 atmos absolute. These tests were made for both the $85 \%$ and full core cases.

No effects due to initial system pressure were observed for excursions with stable periods less than $100 \mathrm{msec}$ for either core loading. For excursions with stable periods longer than $100 \mathrm{msec}$ there is a decrease in the maximum power with decreasing initial pressure when the core vessel is $85 \%$ full of fuel solution. Transients with stable periods of from 5 to $10 \mathrm{sec}$ showed a decrease of about $30 \%$ in the maximum power achieved as the pressure was varied from 70 to $15 \mathrm{~cm} \mathrm{Hg}$ absolute. No pressure effects were observed with the full core.

\section{Influence of Increased Initial Reactor Power}

The majority of the excursions run with this system were initiated from an initial reactor power less than $1 \mathrm{mw}$. This represents the most likely condition under which unintentional excursions might occur, since they are most probable during reactor startup. To investigate the effect of higher initial power on the response of the system, a series of excursions were conducted at initial power levels up to $20 \mathrm{kw}$.

These tests showed that the kinetic response of the system was also insensitive to the initial reactor power. No measurable difference was observed for transients with stable periods of less than $50 \mathrm{msec}$. For longer period transients with stable periods up to one second, there is a decrease in the maximum excursion power as the initial stable power is increased. A decrease of almost a factor of two was observed for excursions with stable periods of $100 \mathrm{msec}$ as the initial power was increased from $1 \mathrm{Mw}$ to $20 \mathrm{kw}$.

These results demonstrate that the shutdown of the reactor during short period transients initiated by step inputs of reactivity is not affected by the presence of large low pressure gas bubbles which are in the fuel solution during high level stable power operation. 


\section{E. RESERVATIONS ON APPLICATION OF DATA AVAILABLE}

Prediction of the maximum excursion possible and of its consequences with a particular reactor configuration is a problem involving many subtleties. For example, if we consider a water boiler with appreciably larger core volume than the KEWB "A" reactor (the reasoning which follows will hold in reverse for smaller core volume), we can expect an increase in the $\mathrm{H} / \mathrm{U}$ ratio and therefore an increase in the core neutron lifetime. An increase in lifetime dictates that the period produced by the assembly will be longer than the " $A$ " core installation for equal reactivity release. This difference is trivial in the period range dominated by the delayed neutron summation term in the in-hour equation, but approaches direct proportionality to the lifetime ratio for very short periods. Since release of a fixed amount of excess reactivity is the ultimate criterion for the evaluation of the safety of any reactor, those systems yielding longer periods are generally considered to be more safe.

However, even though a longer period for a given reactivity release appears to be a step in the direction of greater safety, there is a complicating factor. The larger reactor will be less sensitive to small changes in size and density, so that its void and temperature coefficients of reactivity will be smaller. This will tend to increase the burst size. The expectation is that this tendency to increase the burst magnitude and energy release at the resultant longer period will not be as great as the advantage gained from lengthening the period, but there is not sufficient data available at this time to make this contention conclusive and quantitative. Also, the effect on the inertial pressure, which is the limiting factor in maintaining integrity of the reactor core at extremely short periods, is not predictable with certainty at present. It is, however, believed that the longer period would be preferable in terms of magnitude of the pressure pulse.

More positive predictions can be made about alteration of the graphite reflector in a water boiler, if, again, the ultimate safety is governed by the release of a fixed amount of reactivity. Since the reflector-delayed neutrons have the property of lengthening the apparent core lifetime, * and store reactivity at the time of peak power, they effectively provide the reactor with a longer

* See Part II of this report series. An exception is if the reactor period were much shorter than the apparent delay time of the reflector-delayed neutrons. Such short periods do not appear possible for graphite-reflected water boilers. 
period without demanding a correspondingly large increase in reactivity-compensating capability for a given reactivity release. This is clearly a step in the direction of safety. Alteration of the reflector material or configuration in the direction of reduction of the thermal neutron lifetime in the reflector and/or its thermal neutron savings will reduce the safety of the assembly; and conversely for alterations which increase these quantities.

To summarize, from the standpoint of ability of the reactor to withstand release of a fixed amount of reactivity:

1. It appears that changes in water boiler configuration from the KEWB "A" core such that the core neutron lifetime increases will probably result in no loss of or increase in safety; and conversely for decrease in lifetime. There are compensating factors, however, which cannot be evaluated from available data, that can modify this conclusion in the specific terms of pressure generation.

2. Reduction of the reflector delayed neutron abundance or mean delay time will reduce the safety of the reactor. Conversely, for increase in these quantities. 


\section{DESCRIPTION OF KEWB FACILITY AND INSTRUMENTATION}

\section{A. REACTOR TEST BUILDING}

The reactor test building, a plan of which is shown in Figure 2, is an underground concrete structure 15 by 26 by $10 \mathrm{ft}$ high. The outside walls and floor are reinforced concrete $8 \mathrm{in.} \mathrm{thick,} \mathrm{and} \mathrm{the} \mathrm{roof} \mathrm{is} \mathrm{a} \mathrm{reinforced} \mathrm{concrete} \mathrm{slab} 1 \mathrm{ft}$ thick. The entire structure is covered with $6 \mathrm{ft}$ of earth for shielding purposes.

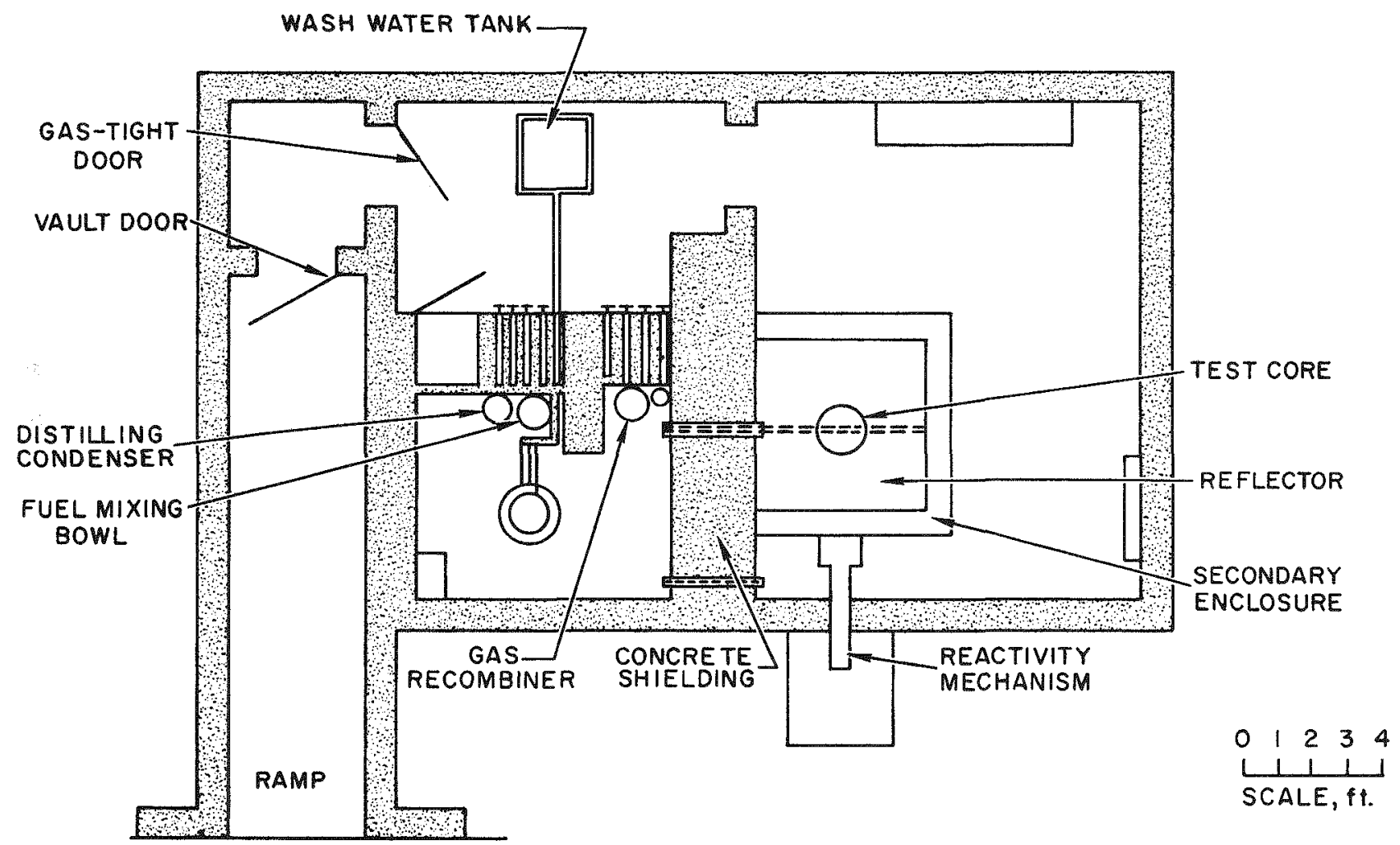

Figure 2. Reactor Building Layout 
The interior of this building is divided into three rooms: (1) the reactor room ( 12 by $15 \mathrm{ft}$ ), which contains the reactor core, graphite reflector, control rod system and the necessary detection equipment for stable and transient operation; (2) the gas and fuel-handling room, which contains the radiolytic gas recombiner, fuel storage tank and associated plumbing system; (3) the valve gallery which contains the control handles for the valves in the gas and fuel handling system. Concrete shielding walls two feet thick separate the three rooms.

Ventilation of the building is provided by a 2000-cfm blower which draws air from the building through a bank of absolute filters and discharges it up a disposal stack. Fresh air is admitted into each room by a duct which passes from the room up through the earth covering. Each of these ducts contains a Keystone butterfly valve at its upper end which is closed during operation to seal the building. A similar Keystone valve is located in the exhaust line just ahead of the absolute filter bank.

An exclusion area around the reactor test building is established by a 6 -ft chain link fence. This area is unoccupied whenever the reactor is operated. The gates in this fence have microswitches attached so that an indicator light on the operating console goes out if any gate is opened. Figure 3 shows the layout of the exclusion area. The area inside the exclusion fence is asphalt-covered to prevent erosion of the earth covering over the reactor test building.

\section{B. CONTROL AND ELECTRICAL BUILDINGS}

The control building is a 12 by $20 \mathrm{ft}$ sheet steel building located $200 \mathrm{ft}$ from the reactor test building. All recording and control instrumentation necessary to operate the reactor in a normal fashion plus the special instrumentation needed for recording transient operation are located in this building.

A small sheet steel building, called the "electrical building," is located near the reactor test building. All preamplifiers and power supplies that need to be near the detectors in the reactor room to reduce cable loss and noise are located in this building.

\section{WASTE STORAGE BUILDING}

A concrete block building (6 by $8 \mathrm{ft}$ ) inside the exclusion fence around the reactor test building is used for temporary storage of radioactive waste material. 


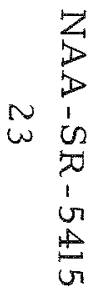

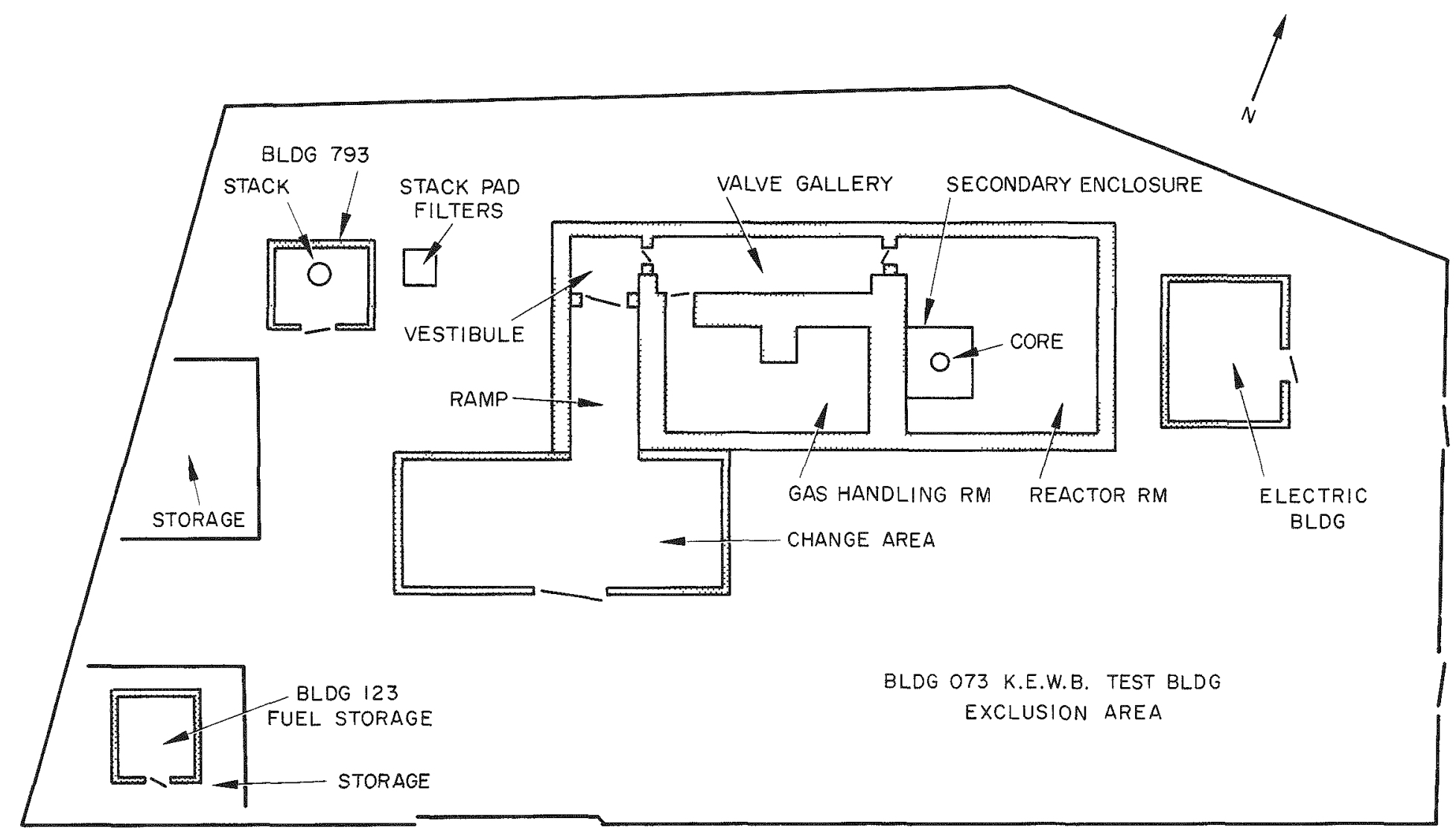

Figure 3. Exclusion Area Layout 
Two steel-lined wells $6 \mathrm{ft}$ deep and $2 \mathrm{ft}$ in diameter are located in the concrete floor of this building to provide storage for any material for which the 8 -in. concrete block walls of the building do not provide adequate shielding.

D. DESCRIPTION OF KEWB REACTOR SYSTEM

1. "A" Core

A layout drawing and photograph of the KEWB "A" core vessel are shown in Figure 4. The sphere is $12.3 \mathrm{in.}$ ID and has a minimum wall thickness of 0.22 in. The overflow chamber attached to the top of the sphere consists of a central 2 -in. tube $18 \mathrm{in.}$ long enclosed in a 4-1/2-in. outer tube. The deflection dome at the top of the central tube aids in the separation of the gas and liquid during an excursion which expels fuel solution from the sphere into this overflow chamber. The fuel solution is deflected into the annular region between the tubes and retained there. The hydrogen-oxygen gases are allowed to pass through a stainless steel entrainment eliminator and then to the recombiner or ballast tank. The fuel solution slowly drains back to the core through a 3/16-in. hole at the bottom of the $2.5 \ell$ reservoir formed by the two concentric tubes.

A 2-1/4-in. OD tube is re-entrant in the sphere along a horizontal diameter. This tube accomodates the poison rod which was used to introduce reactivity steps to initiate power transients. Four additional re-entrant tubes which pass through the sphere parallel to the vertical diameter provide passages for the control rods. A fuel drain line connects the bottom of the core to the fuel handling system in an adjacent room. Two sweep gas lines connect to the top of the overflow chamber above the entrainment eliminator. Sweep gas enters through the lower line and mixes with the hydrogen-oxygen gases from the core. The mixture is then swept out the top line and carried to the gas recombiner.

Pipes from the top of the overflow chamber and the bottom of the core connect to a standpipe located at the edge of the graphite reflector. This standpipe is used to determine the liquid level in the core. A removable plug at the top of the standpipe is also used to introduce small aliquots of fuel and water directly to the core.

The spherical part of the vessel contains three bosses for pressure transducers and two bosses for thermocouples. The overflow chamber can accommodate two pressure transducers. 


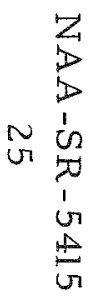
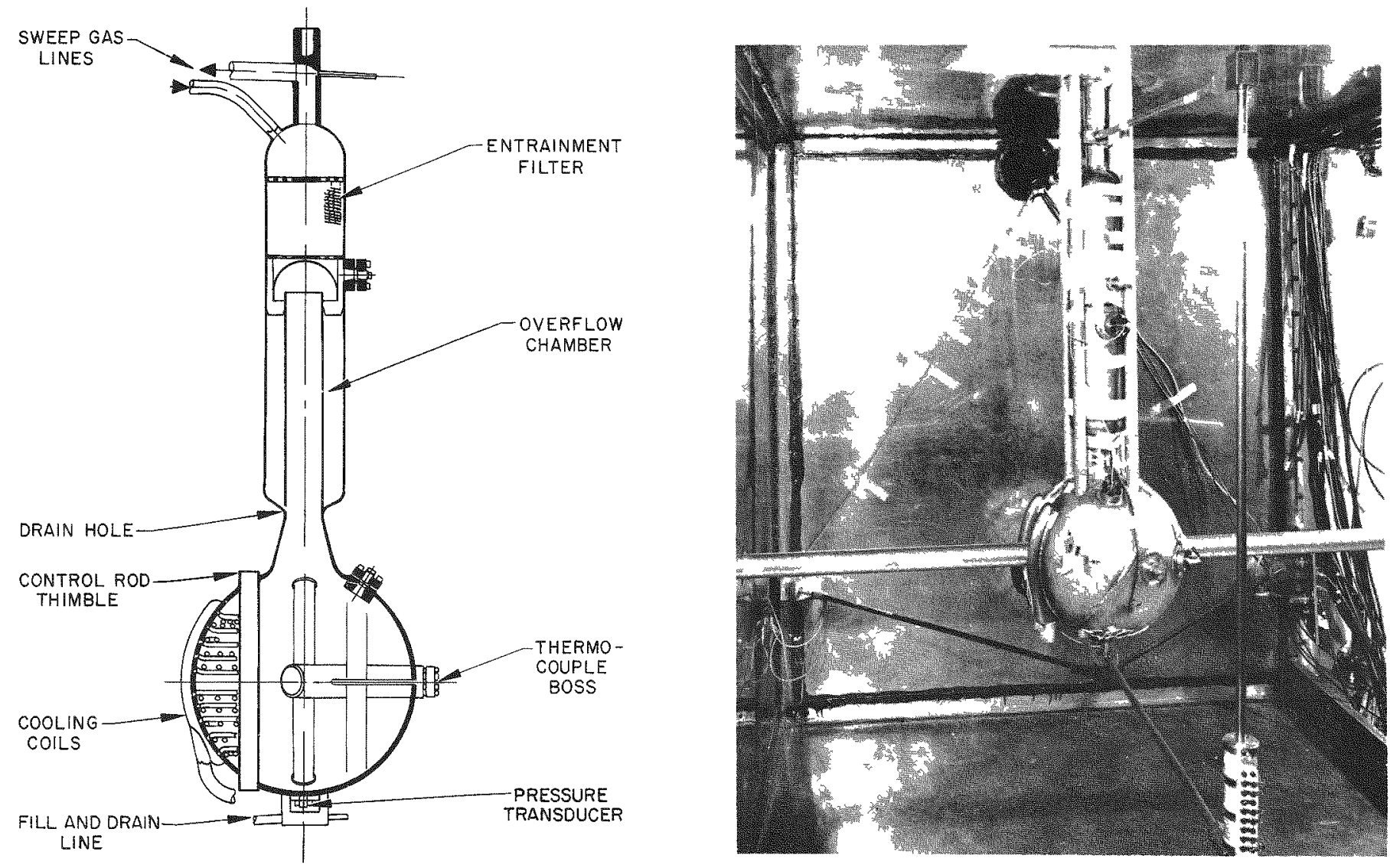

Figure 4. Layout Drawing and Photograph of Core Vessel 
Cooling of the fuel solution is provided by cooling colls of stainless steel tubing 1/4-in ODwith 0 028-in wall Ten colls, each $9 \mathrm{ft}$ long, are connected to external inlet and outlet manifolds along one side of the core. Figure 5 shows a photograph of the cooling colls assembled in one half of the core vessel before final assembly This provides cooling adequate to maintain the fuel solution at less than $80^{\circ} \mathrm{C}$ when the reactor was operating at $50 \mathrm{kw}$.

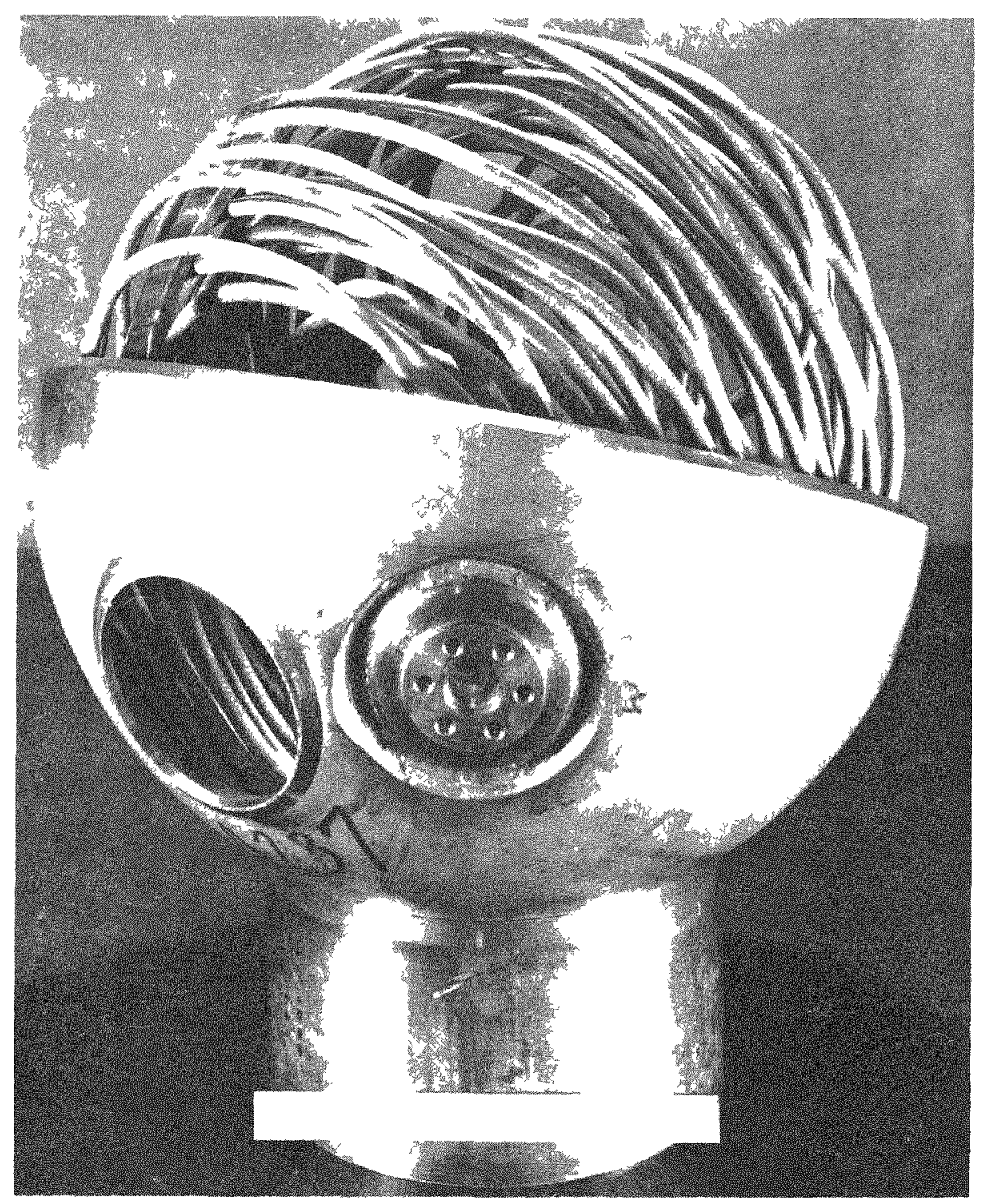

Figure 5. Cooling Coils Mounted in One-half of Core Vessel before Assembly 


\section{Control Rod System}

The control rod system consisted of four normal sintered $\mathrm{B}_{4} \mathrm{C}$ rods contained in stainless steel thimbles. The poison section of the rods was 16 in. long and of 3/4-in. diameter. At the "all-in" position the lower end of the poison section was slightly above the lower surface of the sphere. The rods were positioned by conventional rack and pinion drives and fell freely when released by electromagnets which attached them to their individual racks.

The rods controlled about $\$ 2.10$ reactivity each, and a total of $\$ 9.0$. Some interaction of the rods was observed and will be discussed later in the section dealing with control rod calibrations. The withdrawal rate for the rods was $6 \mathrm{in.} / \mathrm{min}$, which corresponds to $\$ 0.04 \Delta \rho / \mathrm{sec}$ for the linear portion of the control rod calibration curve.

\section{Reflector}

The reflector consisted of unmachined AGOT-grade graphite bars stacked to form a 56-in cube. The bars are normally $4-3 / 8 \mathrm{in}$. square and have somewhat rounded edges. Since these rounded edges leave small voids when the bars are stacked, the gross density of the reflector is less than the normal $1.6 \mathrm{gm} / \mathrm{cm}^{3}$ by a few percent. The graphite bars that are adjacent to the core are machined to fit the shape of the vessel. The reflector rests on a concrete pedestal and is enclosed by a reinforced sheet aluminum secondary enclosure.

\section{Cooling system}

For the first 1.5 yr of operation the reactor was cooled by a "once through" tap-water cooling system. A 1000-gal. holdup tank was used to retain the cooling water until it could be checked for activity and released to ground drainage. The induced activity observed in the cooling water was always much less than tolerance, but the possibility of migration of fuel solution into the coolant in case of a breach of the cooling coils required the holdup and monitoring precaution.

This "once-through" system proved unsatisfactory and was replaced with a closed-loop distilled water system which contains an air-blast heat exchanger that dissipates the heat to the atmosphere. The main reasons for this change were: (1) the 1000-gal. capacity of the holdup tank limited the length of time in which the cooling system could be continuously operated and caused delay of the experimental program while the coolant was checked for activity and discharged; 
(2) the inlet coolant temperature was uncontrolled and depended on the length of time the coolant was run, and on the ambient air temperature; (3) the presence of chloride salts in the coolant water caused concern for corrosion of the cooling coils by the water.

5. Gas and Fuel Handling System

All operations involving equipment contained in the "gas handling room" adjacent to the reactor room, such as transporting fuel to and from the core vessel, measuring and adjusting the pressure in the core, connecting the gas recombiner or ballast tank to the system, were conducted remotely from the valve gallery which is separated from this room by a 2 -ft concrete shielding wall

The gas-handling systems sweeps 7 cfm of gas through the core vessel. The sweep gas dilutes the hydrogen and oxygen produced in the core and carries the mixture through a platinized alumina catalyst bed where recombination takes place. The water formed by the recombination of the hydrogen and oxygen is then returned to the core vessel by the returning sweep gas.

An aspirator provided the driving pressure for sweep gas flow; and phase separation took place in a $20-\ell$ reservoix which also served as the housing for an entrainment filter and the catalyst bed. A heat exchanger at the inlet to the canned rotor aspirator pump removed the heat of recombination from the system. The working liquid for the aspirator was distilled water and was maintained at constant level in the reservoir by the action of an overflow wire.

The gas recombiner is paralleled in the system by a $20-\ell$ ballast tank. The recombiner can be valved-off from the system and the evacuated ballast tank substituted for it. With an initial pressure of $15 \mathrm{~cm} \mathrm{Hg}$ absolute in the core vessel and ballast tank, the reactor could be operated for $120 \mathrm{kw}-\mathrm{min}$ before the system atmosphere achieved positive pressure.

The fuel handling system consisted primarily of three vessels with their interconnecting piping. A $3-\ell$ filling bowl is used to introduce uranium into the system and to hold fuel solution during concentration by vacuum distillation. The contents of this vessel can be gravity drained to a $20-\ell$ cylindrical tank, 6 in. in diameter, which served as the main fuel solution storage tank for the system. The fuel solution could also be drained by gravity from the core to this vessel. Solution was transferred from this vessel to either the core or filling bowl by pressurizing the storage tank and opening the proper valves in the system. 
A distillation condenser was mounted above the filling bowl and was used to trap wate $r$ vapor during concentration of the fuel solution in the filling bowl

An elevation view of the piping and vessels for the reactor system is shown in Figure 6.

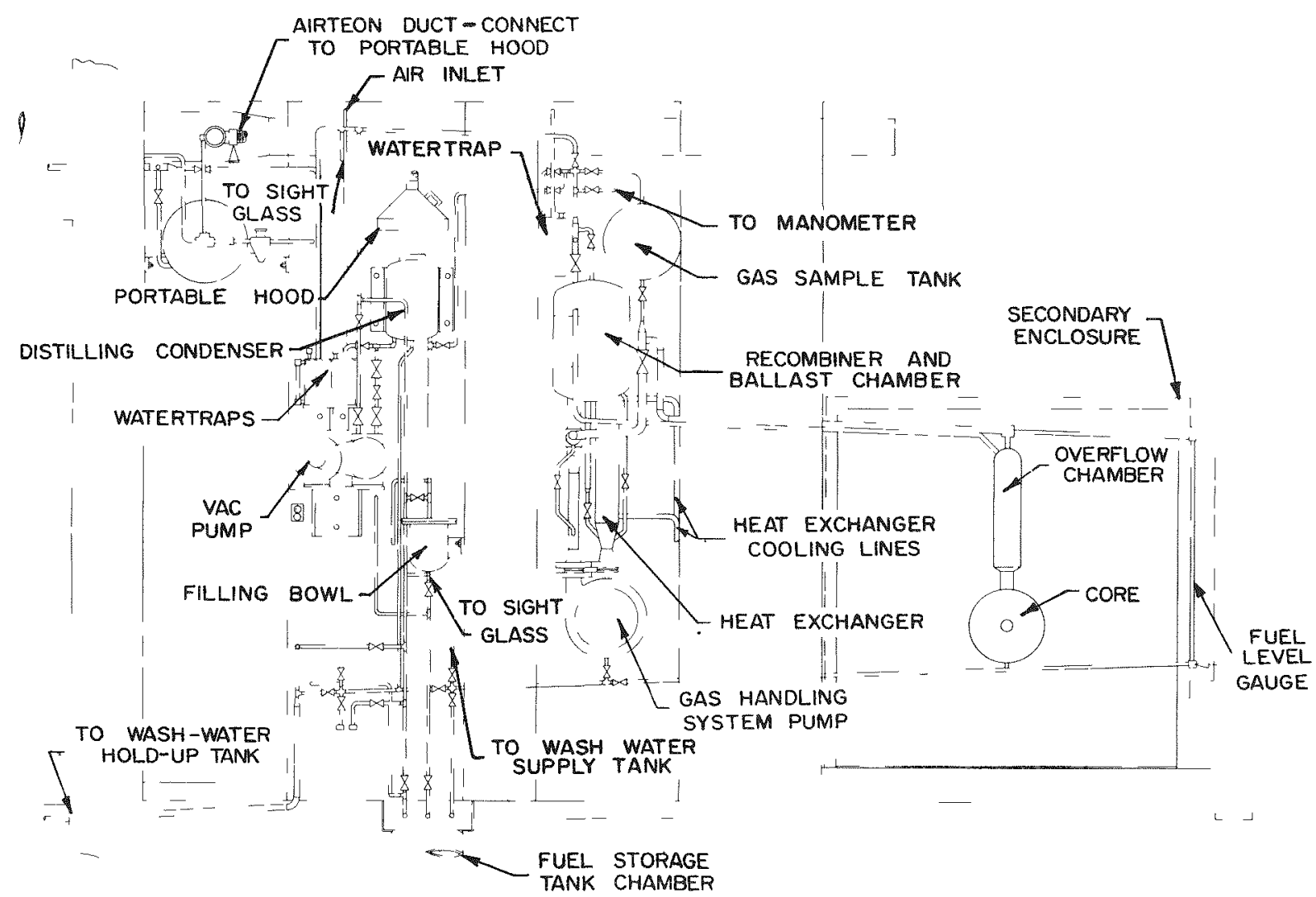

Figure 6. Elevation View of Piping and Vessels for Reactor System

Disposal of the radioactive gases from the reactor was provided by a 300-gal. storage tank buried near the building and connected directly to the gas handling system. This tank was used to collect and temporarily store (under slight vacuum) these radioactive gases. Where required, the tank was evacuated and the vacuum pump exhaust was fed to the stack blower intake. The activity in the stack was continuously monitored, and interlocks were connected such that excessive activity or fallure of the blower motor would automatically stop the active gas flow. A 1000-gal. tank buried beneath the floor level of the building and connected to the fuel and gas handling system was used to store waste liquid from the facility. This tank is equipped with pumpout connections that can be used if and when the tank is filled.

$$
\text { NAA -SR - } 5415
$$




\section{Conventional Reactor Control Instrumentation}

A block diagram of the conventional (non-transient) reactor control instrumentation is shown in Figure 7. Low level power indication for startup was provided by two pulse-counting channels, one a linear and the other a logarithmic system. Each channel consisted of a Radiation Counter Lab Mark II BF 3 chamber, an Atomics Instrument Model $216 \mathrm{C}$ preamplifier, an Atomics Instruments Model 204B linear amplifier, and a count rate meter. Power for the $\mathrm{BF}_{3} \mathrm{cham-}$ ber and the preamplifier was provided by an Atomics Model 316 power supply. Each channel had a remote operated cadmium sleeve which reduced the channel count rate by a factor of 15 when drawn over the $\mathrm{BF}_{3}$ chamber.

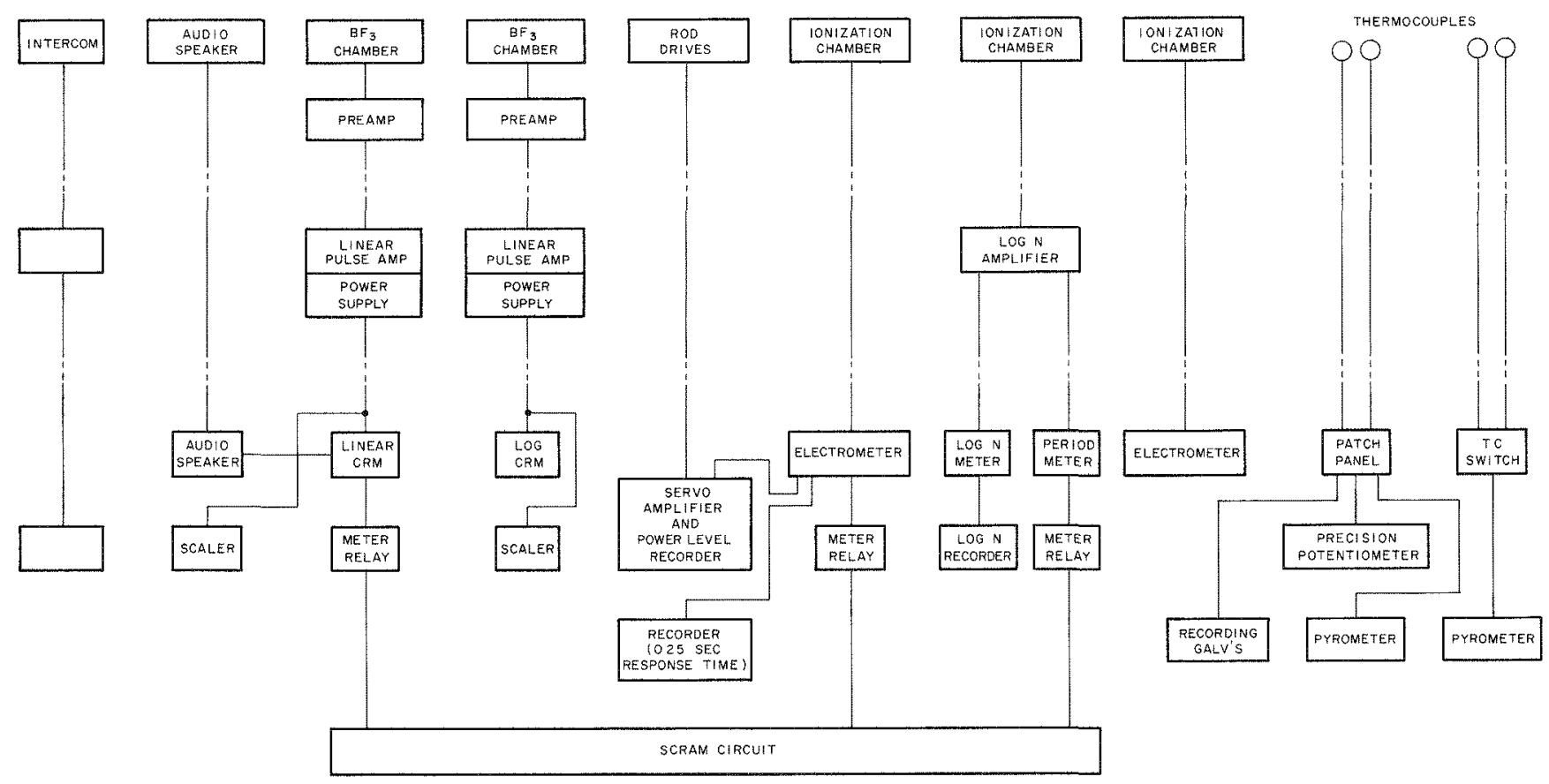

Figure 7. KEWB Conventional Reactor Control Instrumentation Block Diagram 
For the first two years of the KEWB program, an Electronics Linear Count rate meter was used in the linear system. For the balance of the "A" core program, a Hewlitt-Packard Model 500B linear count rate meter was used. A Radiation Counter Lab Model 2404 log count rate meter provided 4 decades indication between 1 and $10^{4}$ counts per sec. Both systems were used during startup until they showed count rate of 1000 per sec. This represented a power level of about $0.4 \mathrm{w}$. At this power both linear and log current instruments were on scale and the pulse counting circuits were switched off. The high voltage was removed from the $\mathrm{BF}_{3}$ chamber by remote switching to conserve their life. Typical tube life was several years under these conditions.

The linear count rate meter pulse output was connected to loud speakers located in the control room and reactor building to provide an audio indication of the neutron field intensity. The current output of the linear CRM operated a meter relay in the scram circuit.

During the critical assembly two scalers were used in parallel with the linear and log count rate meter. The scalers used were Berkeley Model 2000.

Currents proportional to power were obtained from lead-covered boronactivated ionization chambers designed and manufactured by Atomics Internationa1. The average sensitivity of these chambers was 8.5 by $10^{-15}$ amperes/neutron/sec/ $\mathrm{cm}^{2}$.

Linear power was indicated by a model $\mathrm{V}$ Beckman micro-microamperemeter. This meter read currents through 7 decades from $10^{-10}$ amps to $10^{-4}$, amps which were analogous to reactor powers from $0.8 \mathrm{w}$ full scale on the lowest range to $800 \mathrm{kw}$ full scale on the highest range. The output of the Beckman amplifier actuated a high power level scram circuit relay. The circuit of the amplifier was modified to prevent spurious up and down scale transients during range switch. The reactor power indicated by this circuit was recorded on a Leeds and Northrup self-balancing potentiometer recorder model Series 60 . The L \& N recorder contained a three-action servo amplifier which could be used for automatic reactor control at any set power when an extended period of constant power level operation was desired.

A Brown Electronic recorder Type 153 with one-quarter second full-scale pen response time was also used to record the power level signal from the Beckman micro-microammeter. This system could reliably record reactor powe $x$ 
transients with reactor periods as short as 1 sec, and peak powers as high as $140 \mathrm{kw}$. Chart speeds were adjustable to $4 \mathrm{in} . / \mathrm{sec}$.

To help the reactor operator detect very small power changes during steady power operation, a Tullamore Electronics Laboratory vacuum tube Electrometer, Model VTE-1, was used. This instrument contains a bucking current supply which enabled the operator to measure extremely small variations in input current. The input current for this meter was supplied from an Atomics International boron activated ionization chamber.

Log power and period indication of the ionization chamber current was obtained from a Radiation Count Lab Model 2407 (ORNL-Q-915) Log N power and period meter. The log power output of this meter was recorded by a Brown Electronic Model 53 recorder. The period output operated a meter relay in the scram circuit.

The temperature of the core and inlet and outlet temperature of the core cooling water was measured by thermocouples made from stainless-steelsheathed, $\mathrm{MgO}$-insulated iron-constantan thermocouple stock. Iron-constantan lead wire was used to carry the signal from the reactor room to the control room where a patch panel made each pair available to a melting ice reference junction and a Rubicon precision potentiometer.

Otheriron-constantan couples attached to the sphere overflow chamber, gas lines, and graphite were terminated in the patch panel and were read by means of a West Instrument Corp. pyrometer, Model IS.

The temperatures of the recombiner gas phase, water phase, and catalyst bed were measured by iron-constantan thermocouples terminating in a Leeds and Northrup thermocouple switch and a Honeywell Type J pyrometer. Gamma field intensities in the reactor building was monitored by a remote area monitor, Jordan Electric Manufacturing Co., Model R-3R.

The airborne activity in the reactor building were monitored using a Nuclear-Chicago Model $1620 \mathrm{~A}$ count rate meter. The air in the reactor room, secondary enclosure, valve handling room, and the gas handling room could be remotely sampled with a custom made solenoid valve air routing system operated in conjunction with a gas pump. Air was pumped from one of the four locations through a counting chamber and back to its source in a closed loop. The sampling station could be selected remotely from either the valve handling room 
or the electrical building. The activity measured by the count rate meter was continuously recorded by an Esterline-Argus recording ammeter.

7. Transient Instrumentation

A block diagram of the Transient Instrumentation is shown in Figure 8.

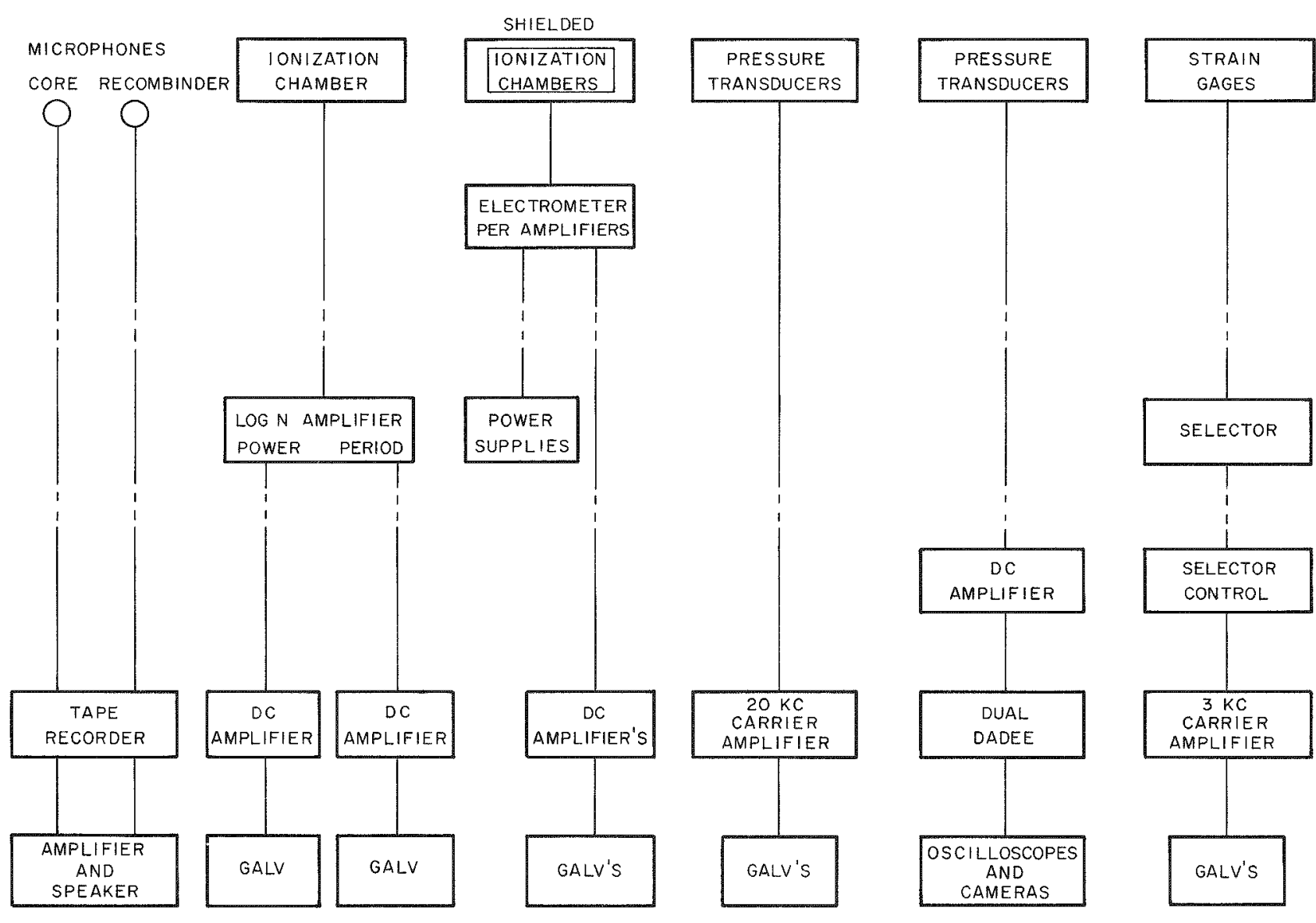

Figure 8. KEWB Transient Instrumentation Block Diagram

a. Power Detecting and Recording Systems

\section{(1) Log N Systems:}

The kinetic study of water boiler reactors entails the measurement of reactor periods at least as short as $2 \mathrm{msec}$ and reactor power peaks of $500 \mathrm{Mw}$ or more. The ionization chambers serving a $\log \mathrm{N}$ amplifier of the ORNL $Q-915$ type can be located remotely enough from the reactor to obtain a neutron field attenuation so that the system will record peak powers of the order of $10^{9} \mathrm{w}$ in the last decade of the log $\mathrm{N}$ amplifier range. However, the minimum usable 
capacitance in the input circuit of the log $\mathrm{N}$ amplifier coupled with the high values of resistance of the log diode in the same circuit during the passage of the reactor power through the first decades of the $\log N$ amplifier range produces a response time constant so long that the system cannot follow the power transient until the last few decades. Figure 9 shows a typical oscillogram of the log power signal from a $\log \mathrm{N}$ amplifier during an $8.4 \mathrm{msec}$ run. This effect limited the use of the $\log \mathrm{N}$ amplifier to transients with periods longer than $8 \mathrm{msec}$.

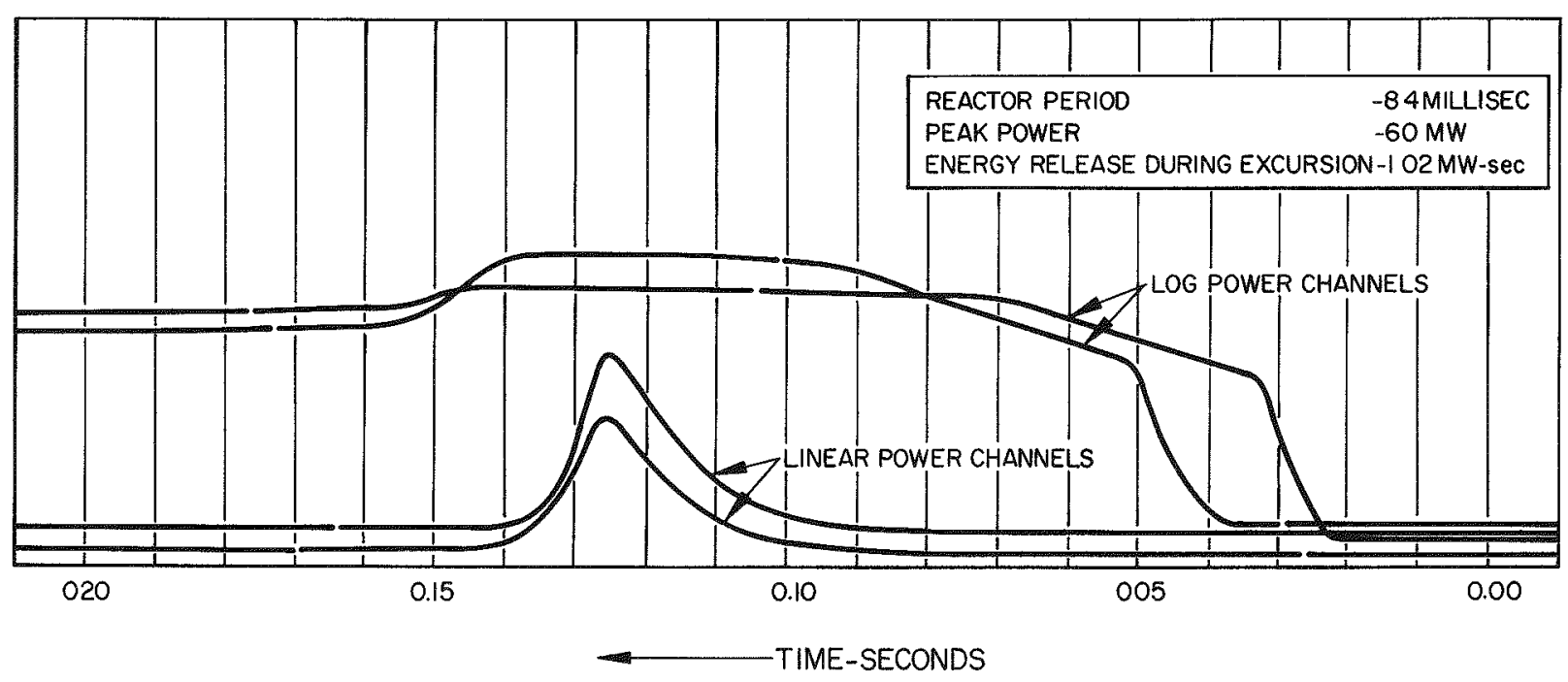

Figure 9. Power Traces for Transient 88B

The period circuit of the $\log \mathrm{N}$ amplifier was modified in various ways to facilitate the direct recording of the reactor period, but proved in practice to be noisy and unreliable. The period information obtained from these instruments was obtained from the slope of the log power trace which lies between the initial sharp rise and the saturated portion. The portion of trace of interest is pointed to by the $\log$ power channel arrows in Figure 9 Reactor periods only as short as $10 \mathrm{msec}$ could be measured with this instrumentation.

When reactor periods shorter than $10 \mathrm{msec}$ were induced in the reactor, the period data had to be computed from the linear power instrumentation. oscillogram traces.

(2) Linear Power Measuring Systems

The first linear power system used in the KEWB program consisted of an Atomics International boron-activatedionization chamber, and a modified 
Southwestern Electric Co. Model "B" direct coupled amplifier located in the electrical building which served as both electrometer and galvanometer driver amplifier and a Consolidated Electrodynamics Co. Model 5-119 recording oscillograph. The input circuit of the Model "B" amplifier was modified by removing the gain control potentiometer and replacing the $6 \mathrm{~J} 6$ input tube with a 6C5. A range resistor switch mounted in another chassis was connected between the ionization chamber and the input grid of the 6C5. The drift rate of this system made it difficult to use. The grid current of the $6 \mathrm{C} 5$ was large enough to make power calibration inaccurate. The power requirement of the Model " $B$ " was $500 \mathrm{w}$, while its useful output in this system was $520 \mathrm{Mw}$.

A linear power system was designed and built by KEWB personnel to replace this system. The new system used an electrometer preamplifier located as near as practical to the ionization chamber in the reactor building. The power supply for the electrometer preamplifier was located in the electrical building. The output of the preamplifier was connected to a chopper stabilized direct coupled amplifier (Kintel Model $11 \mathrm{lAF}$ ) which was used as the galvanometer driver amplifier.

The Kintel amplifiers were satisfactory from the beginning of their use. However, the electrometer preamplifier ultimately required several modifications. By selecting as the electrometer tube a 9002 hard vacuum medium size triode, grid current problems were eliminated. Zero drift was made insignificant by using Zener diode voltage regulation of the filament supply for the electrometer preamplifier. Only radiation-resistant circuit components were used in the electrometer preamplifiers. Tests which were made to determine the magnitude of the spurious signals caused by reactor radiation showed them to be negligible in comparison to the ionization chamber signals. The electrometer preamplifier had 15 range resistors with values starting at $10^{8}$ and descending to $10^{3}$ ohms. Each decade was split at $5 x, 2 x$, and $1 x$. The radiationsensitive components used in the regulated positive and negative high voltage supply for the electrometer were protected by locating the supply in the electrical building. Circuit diagrams of the electrometer preamplifier and its power supply are shown in Figures 10 and 11 . Linear power recording systems were used to record the three highest decades of the reactor power excursions. The magnitude of the excursion peak powers has been about four decades higher than the power available for calibration. The usabledynamic ranges of the electrometer 
were required to cover five decades for convenient operation. The band pass of the system had to be wide enough to record 2 -msec reactor period excursions with less than $5 \%$ amplitude error.

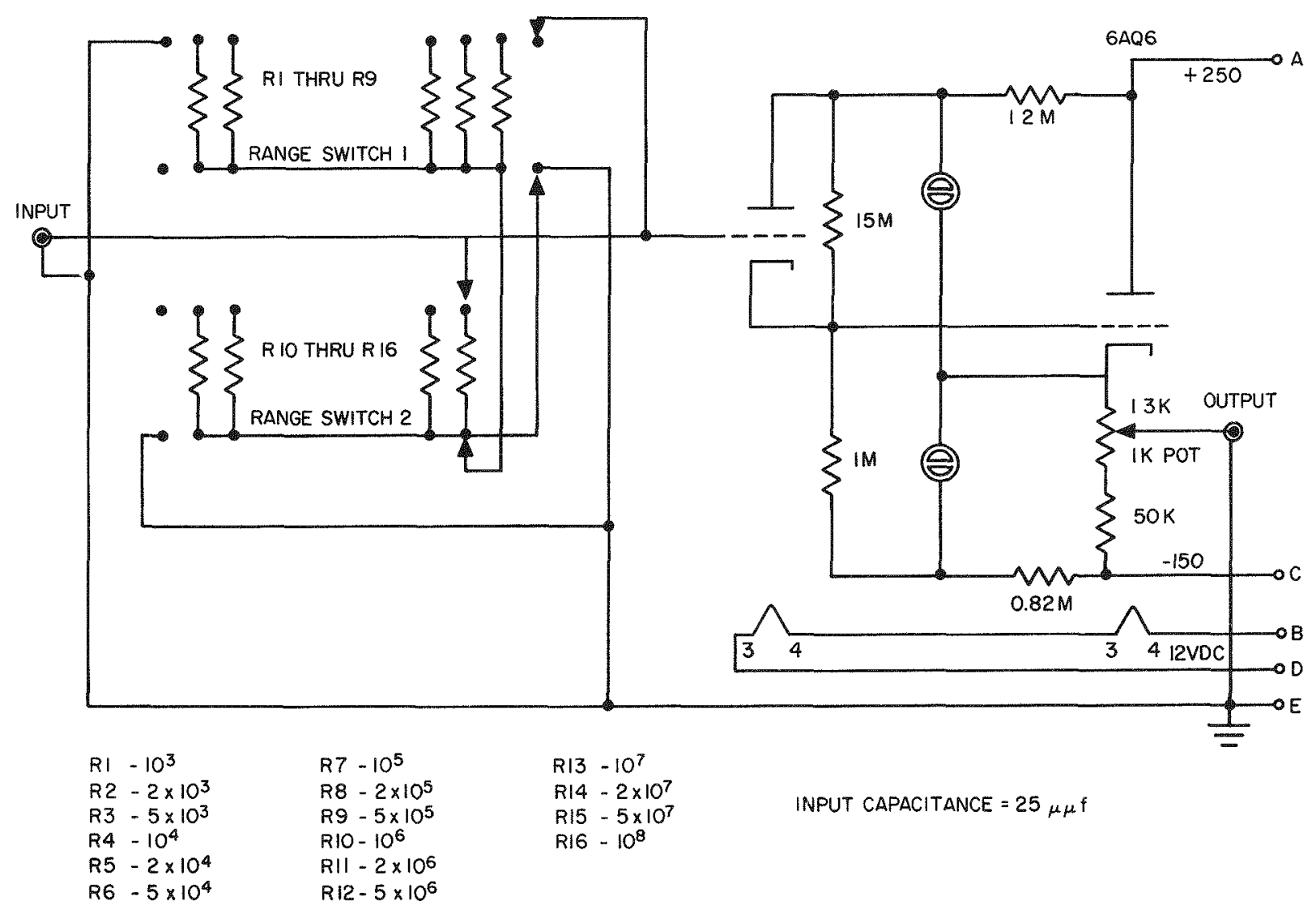

Figure 10. Circuit Diagram for Electrometer Head

Boron-coated ionization chambers were used to measure the neutron flux which is assumed proportional to instantaneous power. The sensitivity of these chambers is 8.5 by $10^{-15}$ ampere/neutron $/ \mathrm{sec} / \mathrm{cm}^{2}$. With $600 \mathrm{v}$ applied to these chambers, $150 \mu$ a can be drawn without saturation effects. Such a current would flow when the flux at the surface of the chamber was 2 by $10^{10}$ $\mathrm{n} / \mathrm{sec} / \mathrm{cm}^{2}$. Since the flux in the reactor room at the peak of the highest power excursions was two or three decades greater than 2 by $10^{10} \mathrm{n} / \mathrm{sec} / \mathrm{cm}^{2}$ the ionization chambers were shielded by cadmium and water-cadmium attenuators. 


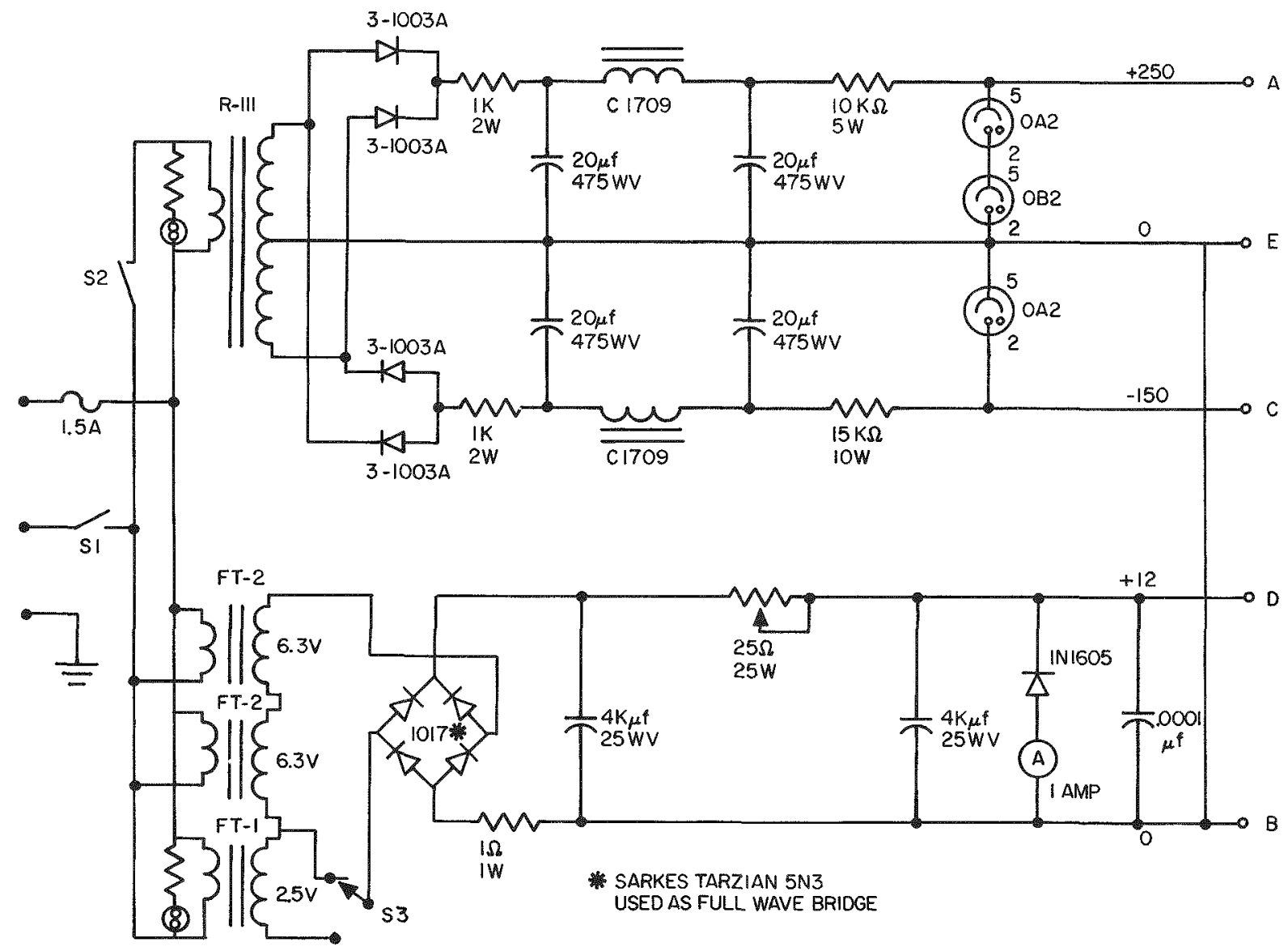

Figure 11. Circuit Diagram for Electrometer Head Power Supply

The band pass of the electrometer preamplifier when driven by a voltage generator was flat from 0 to $35 \mathrm{kc}$.

During reactor power transients with a $2-m s e c$ period, the ionization current created a voltage drop across a $10^{4}$ ohm resistor. This voltage was applied to the input grid of the preamplifier. The cathode follower output fed a $250-\mathrm{ft}$ length of RG $62 / \mathrm{U}$ coaxial cable which terminated in the input of a stabilized dc amplifier. These dc amplifiers, which have a bandpass flat to $\pm 0.3 \mathrm{db}$ from 0 to $5 \mathrm{kc}$, were used as driver amplifiers. The galvanometers used have a flat frequency response from 0 to $1200 \mathrm{cps}$.

Four linear recording systems were utilized to measure the reactor power during transient operation. They were grouped in pairs to provide selfmonitoring. One channel in each pair drove two galvanometers so that one of the galvanometers covered the power decade in which the transient peak occurred, 


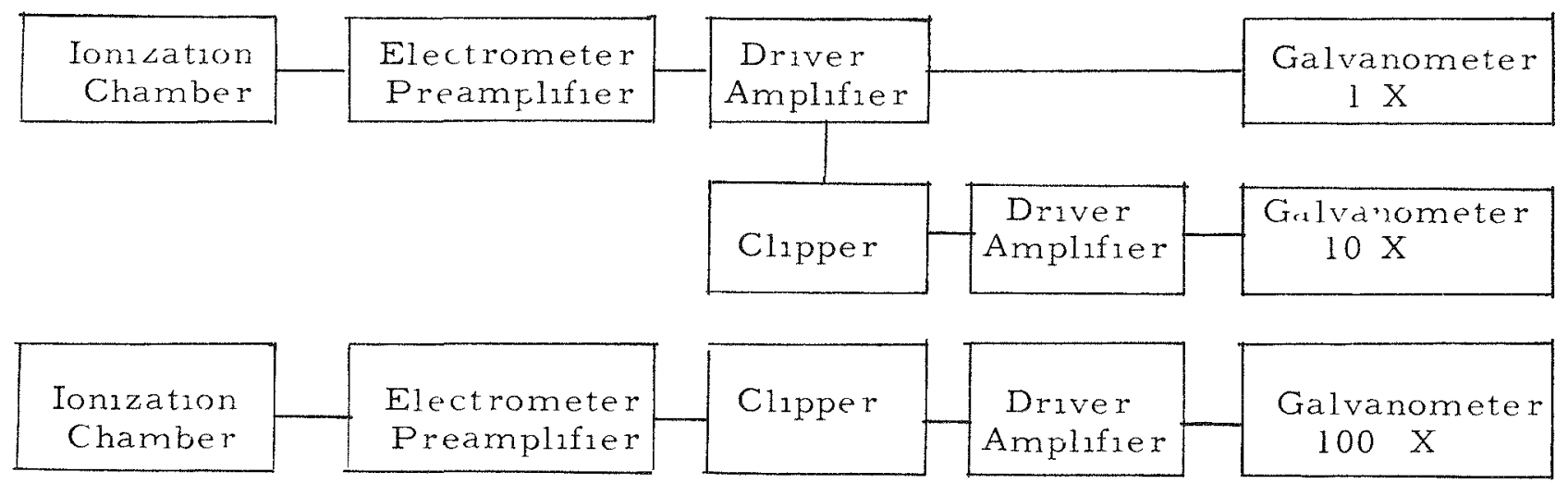

Figure 12. Revised Linear Power Recording System

and the other covered the next lower power decade. The second channel of each pair covered the second lower power decade.

Block diagrams of the circuits are shown in Figure 12 In this manner the three upper decades of the power excursion were linearly recorded It will be noted in Figure 19 that the two more sensitive linear power signals were clipped to prevent overloading the galvanometer driver amplifiers and to limit the galvanometer currents to safe values

\section{b. Pressure Detecting and Recording System}

The dynamic pressure detecting and recording system installed in the KEWB reactor consisted of four pressure channels, each with a Statham model PA 217TC-1, 217TC-1.5M-350 unbonded strain w1re transducer, a Kintel dc amplifier, a Dual DADEE (Dynamic Analog Differential Equation Equalızer) and an oscilloscope channel for recording A block diagram of a single channel is presented in Figure 13. The oscilloscope traces were photographed with Polarold cameras. Three Tektronix oscilloscopes were used

The pressure transducers were obtained from Statham Instruments Inc., to meet the required specifications as to case size and material, absence of organic insulators, natural frequency of ringing, ability to withstand hydrogenoxygen explosions pressure limits, zero unbalance, compensated temperature 


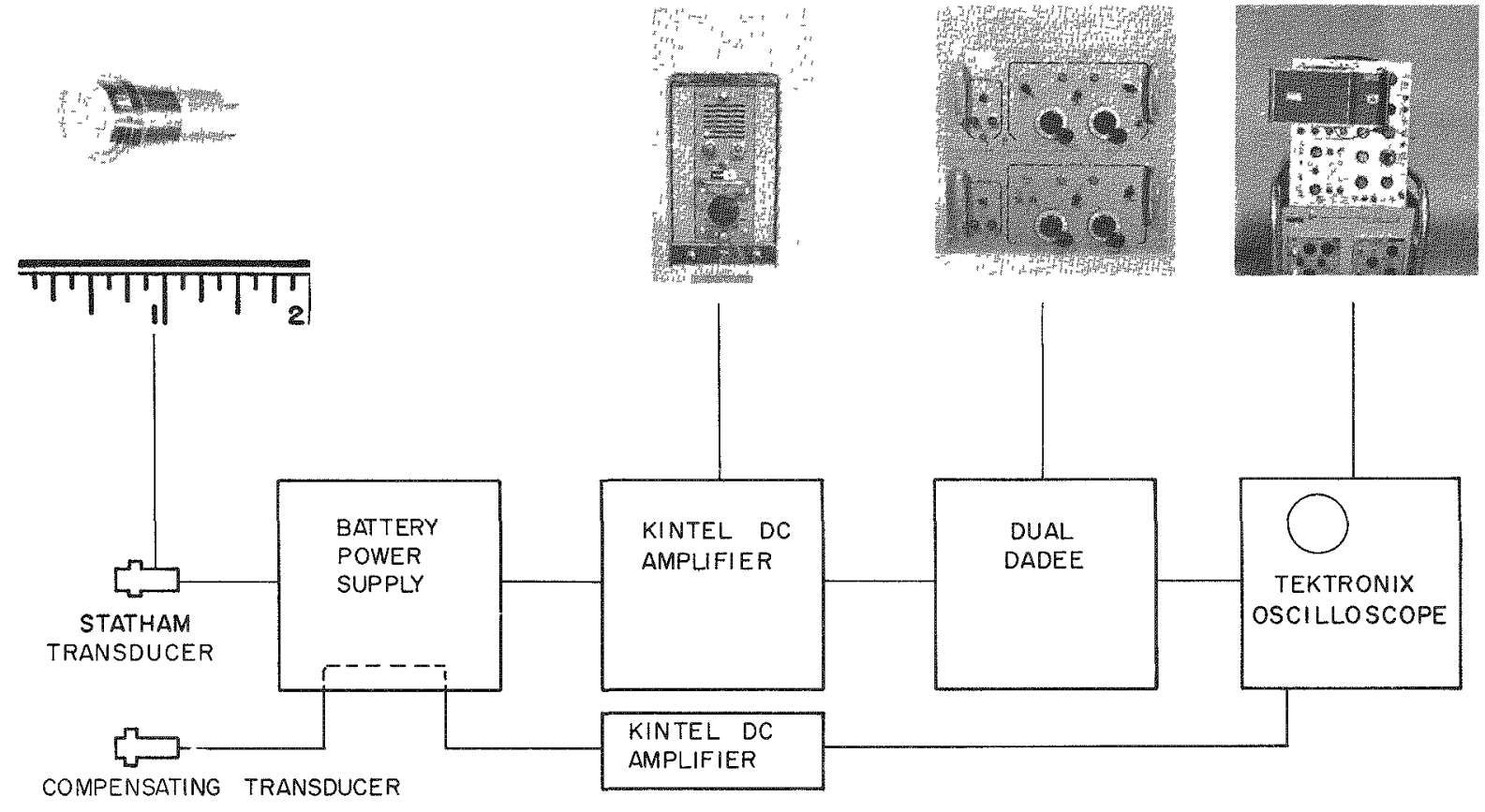

Figure 13. Block Diagram of Fast Pressure Recording Channel

range and linearity. This model has a range of 0 to $1500 \mathrm{psia}$. It contains a 4-arm strain wire bridge, which is excited with 6v dc from batteries. The transducer cases were machined from Type 347 stainless steel in order to resist corrosion by the reactor fuel solution. The compensated temperature range is 0 to $230^{\circ} \mathrm{F}$, and the natural frequency is about $35 \mathrm{kc}$ with a small component of about $100 \mathrm{kc}$ also present.

By means of a shock tube, each of these transducers was calibrated before installation with static pressures, and also dynamically with shock waves in nitrogen and with stoichiometric hydrogen-oxygen explosions. These included explosions at initial gas pressures up to 2 atmos absolute, which pressure leads to a step change of about 1100 psi at the transducer. A Dual DADEE circuit was in use for the calibrations. Sensitivities were in the range $20.6 \pm 3 \mu_{\mathrm{V}}$ per psi for all the transducers by all three methods.

The Dual DADEE mentioned above is designed to compensate for ringing and time lag in a transducer and is described in detail in a paper by Ford and 
Newton. ${ }^{9}$ Briefly its function is to solve electronically the differential equation of motion of a transducer,

$$
A_{1} \ddot{x}_{1}+A_{2} \ddot{x}_{2}+B_{1} \ddot{x}_{1}+B_{2} \ddot{x}_{2}+\ddot{x}_{1}+\ddot{x}_{2}=D F(t)
$$

where $D$ is a proportionality constant, $X$ is the signal entering the Dual DADEE, $A_{1}$ and $A_{2}$ are inertia constants, $B_{1}$ and $B_{2}$ are damping constants and $F(t)$ is the forcing function. The signal $X$ enters the Dual DADEE where two similar sets of operations are performed on it. One set of operations consisis of differentiating. $X$ twice with respect to one of the system's resonant frequencies forming $A_{1} X_{1}$ and $B_{1} X_{1}$. Similarly differentiating twice with respect to the system's second frequency forms $\mathrm{A}_{2} \mathrm{X}_{2}$ and $\mathrm{B}_{2} \mathrm{X}_{2}$. These four quantities are mixed with the original signal by means of adding circuits to form the left side of the above equation. The inertia and damping constants are introduced by potentiometers. The proper settings for these are determined experimentally by using a shock tube to excite the transducer. With proper settings, the ringing frequencies of the transducer are attenuated and the response time is improved. The settings remain the same as long as the transducer remains unaltered.

The pressure transducers were located at the top of the core, at the bottom of the core, on the overflow chamber and on the recombiner (see Figure 4). After initial installation of the the transducers, the reactor system was pressurized to low pressures (below $250 \mathrm{psig}$ ) to check the pressure system operation. It was noticed that the transducers at the top and bottom of the core gave static pressure readings about $25 \%$ higher than they did when calibrated in the shock tube before mounting them in the core. The other two gave about the same readings as before. When removed from the mounting flanges in the core and remounted in the shock tube, the two transducers which read high produced the same readings as in the original calibration. The conclusion was that the mounting bosses at the top and bottom of the core had warped surfaces which distorted the transducer case, producing the increase in static sensitivity. The stressed mounting was reproduced on the shock tube by using a washer with radial ridges under the transducer. The dynamic sensitivity showed no significant change even though the static sensitivity had increased.

The pressure transducers mounted on the core responded to radiation and vibration as well as to pressure. To compensate for this effect, each trans ducer mounted on the core has another transducer mounted adjacent to it, but 
not communicating with the inside of the core vessel. The compensation is accomplished by subtracting the signals by means of a differential preamplifier in the oscilloscope. Operating experience has shown that the radiation signals usually occur before most pressure signals in a fast transient; and these as well as the signals caused by vibration of the core vessel are not large.

Sweep speeds on the oscilloscopes in the neighborhood of $2 \mathrm{msec} / \mathrm{cm}$ have been required to observe the shapes of expansion pressure pulses occurring during transients of periods down to $2 \mathrm{msec}$. Triggering is accomplished with a thyratron circuit fired by the signal from a $\log \mathrm{N}$ power channel on the rising portion of the power curve. This pressure system gives a direct peak pressure readout and is capable of full response to pressure changes within 2 or $3 \mu$ sec. Data are available for inspection immediately after the transient. A typical pair of pressure traces for the top of the core and the bottom of the core during a 2 -msec transient is shown in Figure 14. Peak pressures are 400 psi at the top of the core and 260 psi at the bottom in this figure.

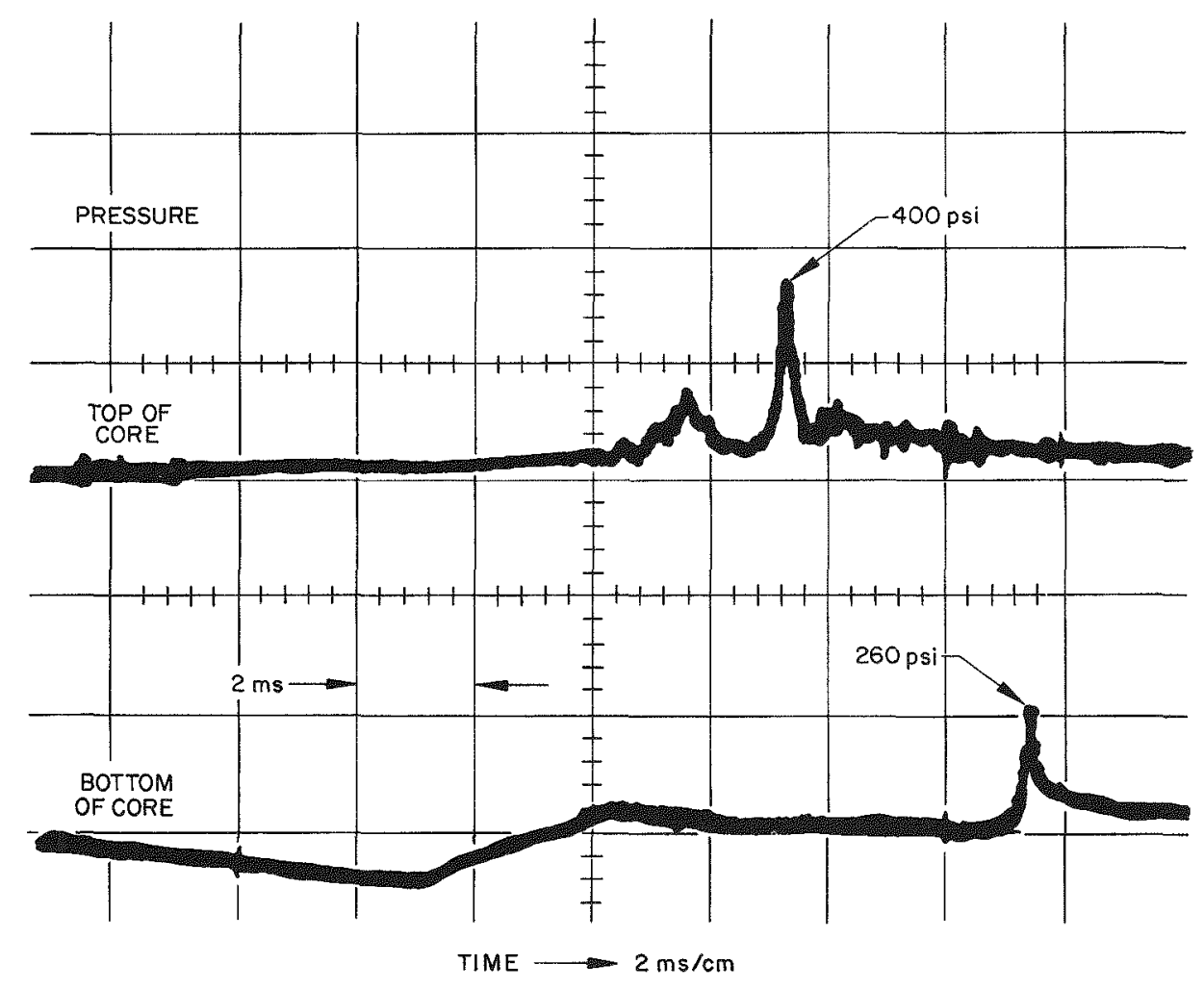

Figure 14. Pressure Record for 2-msec Transient 
When hydrogen-oxygen explosions are to be observed, a different mode of triggering is used because the time at which any explosion occurs is more or less random. Internal triggering is used on one oscilloscope, from the signal given by the transducer on the overflow chamber, as the explosion wave passes that location. The oscilloscope for the top of the core and the bottom of the core is triggered simultaneously with the triggering of that for the overflow chamber. It operates on a slow sweep since the time required is several milliseconds for the detonation shock front to reach the bottom of the core through the solution. Generally, ignition occurs in the recombiner and the reaction travels into the overflow chamber and then into the core. Ignition has been found to follow a power pulse only after a substantial time increment, usually ranging from $15 \mathrm{sec}$ to two min.

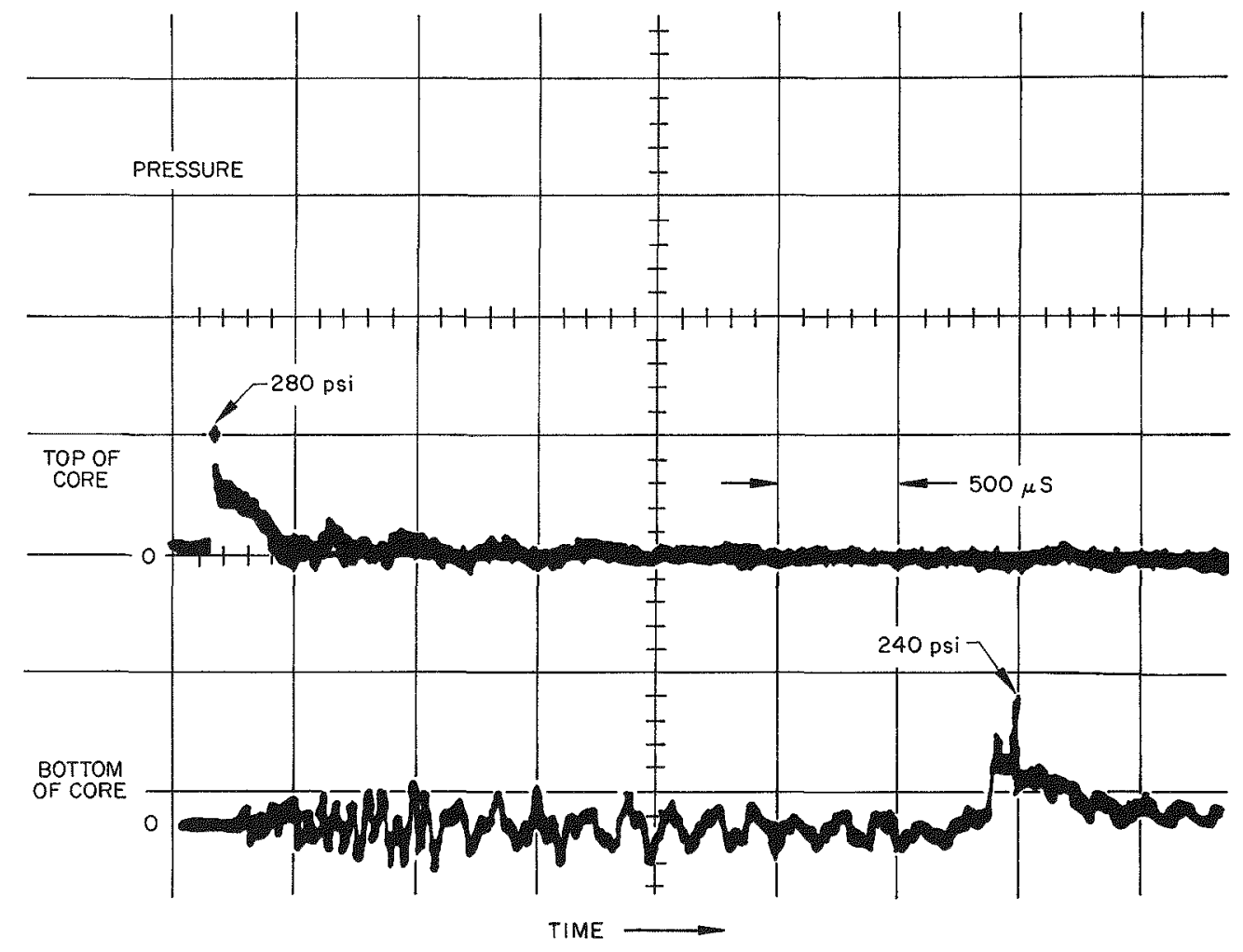

Figure 15. Pressure Record for a Hydrogen-Oxygen Explosion in the Core Vessel Following a Power Transient

Figure 15 shows the oscilloscope pressure traces for the top of the core (upper trace) and the bottom of the core (lower trace) in a hydrogen-oxygen explosion occurring during transient 33I. The sweep is $500 \mu \mathrm{sec} / \mathrm{cm}$. The pressure step 
is detected at the top of the core a little more than $3 \mathrm{msec}$ before it is detected at the bottom of the core. The peak pressure at the top of the core in this case is 280 psi and at the bottom of the core, 240 psi. The pressure rise is much less sharp at the bortom of the core because here the transducer is under fuel solution, which attenuates the shock front.

A summary report describing the details of the research work done in the process of the development of this pressure system has been published. ${ }^{10}$

\section{c. Reactivity Devices \\ 1) Mechanical Device}

The KEWB "A" core had a horizontal tube 1.6 in. in diameter through the center of the core. $\mathrm{A} \mathrm{B}_{4} \mathrm{C}$ poison rod for inducing ramp input of excess reactivity was mounted in this tube. The poison rod could be inserted in the core and withdrawn at several different rates; the assembly is shown in Figure 16.

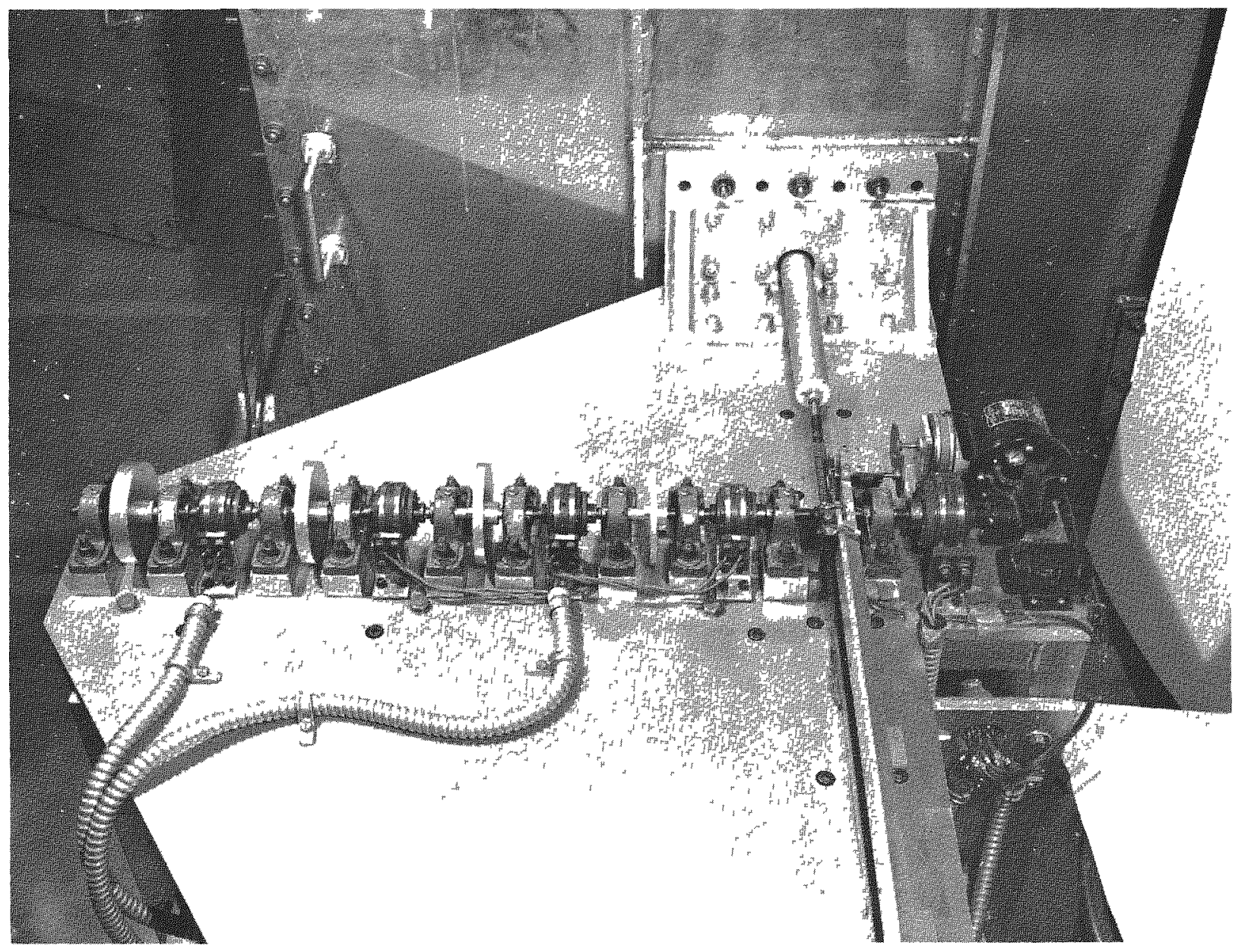

Figure 16. Mechanical Reactivity Device 
The poison rod is coupled by a universal joint to a rack gear 48 in long A 15-1b weight is attached to the rack gear by means of a 1/8-in-diameter steel cable The cable passes over a pulley so that the vertically falling weight imparts a horizontal motion to the rack gear and the poison rod

The spur gear that engaged the rack was pinned to a shaft on which were mounted two electromagnetic clutches One clutch engaged the first in a series of flywheels, and the other engaged a drive motor for repositioning the poison rod The speed with which the poison rod was removed from the core was controlled by the number of flywheels engaged at the time the motor clutch was de-energized The fosition of the poison rod was remotely indicated by a potentiometer mechanically connected to the rack gear by a gear train The position signal was recorded on an oscillogram by a light beam galvanometer

\section{2) Pneumatic Reactivity Device}

Reactivity releases of the order of $\$ 5.0$, such as those examined in the course of the KEWB experiments, produce reactor periods down to $2 \mathrm{msec}$ Thus it is necessary to insert reactivity as nearly approaching a step input as possible if the reactor power is to rise unperturbed for several periods before shutdown begins To achieve this rapid reactivity insertion in the KEWB, a pneumatic accelerator was used to eject a $\mathrm{B}_{4} \mathrm{C}$ poison rod from the core This device could insert $\$ 5.0$ reactivity in $20 \mathrm{msec}$. This near-step reactivity release placed the reactor on a stable period of $2 \mathrm{msec}$ and could be satisfactorily used to produce even shorter periods

The pneumatic accelerator (Figure 17) was comprised of a poison rod $(P)$ attached to an air driven piston $(p)$, a compressed air reservoir (R) provided with a solenold (S) operated valve $\left(V_{0}\right)$, and a cylinder (C) fitted with various valves The poison rod and its piston were contained in the reactor through-tube (T) and the accelerator cylinder respectively The through-tube and therefore the poison rod passed through the core on a horizontal diameter

The piston was driven by compressed air released into the cylinder from the reservoir It drew the poison rod completely out of the reactor reflector $(G)$ and then stopped the rod on an air buffer.

As the piston was driven outward by the compressed air from the reservoir. it compressed the air in the cylinder ahead of it. This air compression acted as a buffer to slow down and stop the piston The compressed buffer 


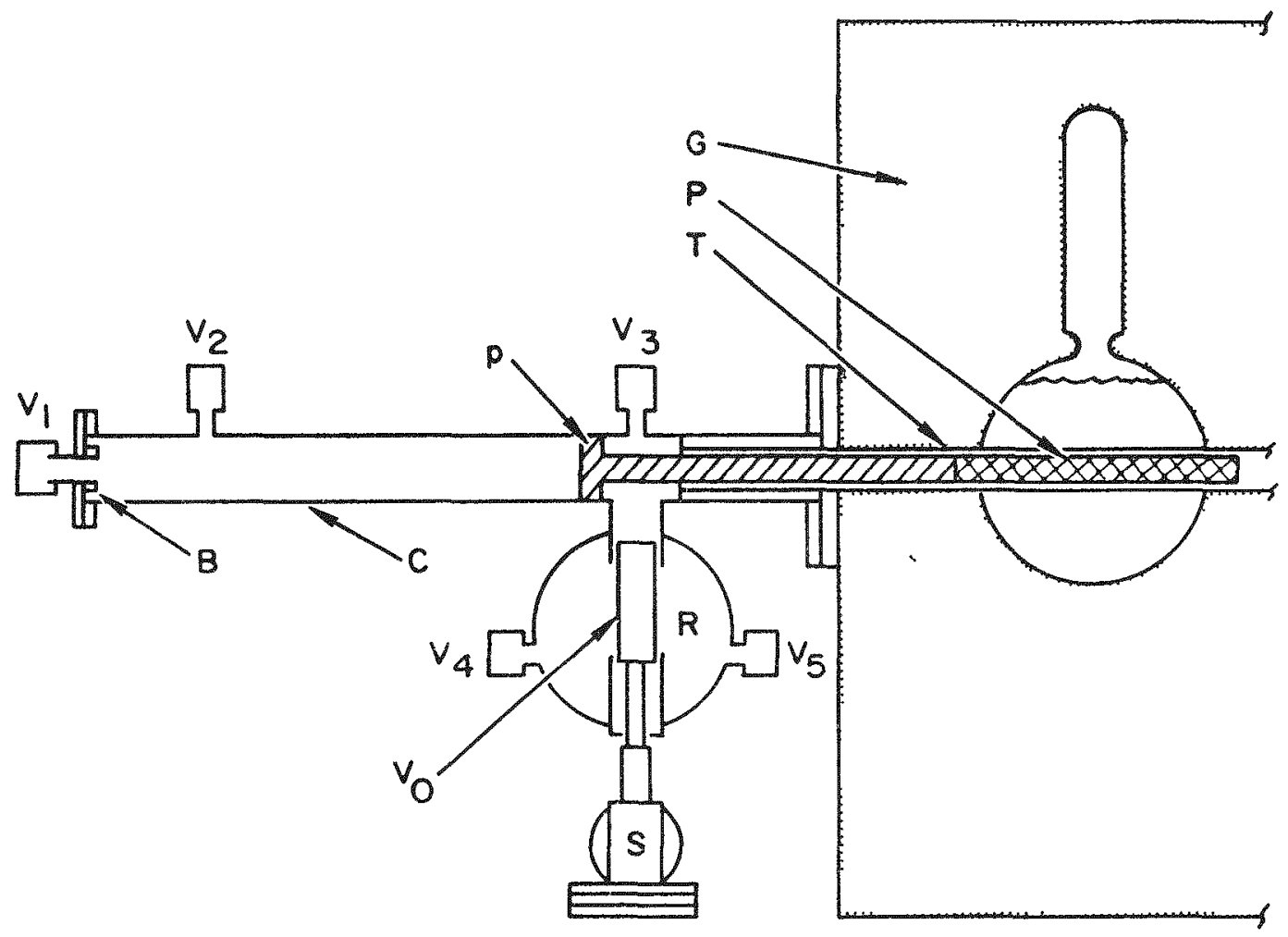

Figure 17. Pneumatic Reactivity Device 
air would also drive the piston and the attached poison rod back into the reactor in such a manner that the piston and rod would oscillate on an air spring if some means had not been used to prevent it. The spring-loaded valve $\left(\mathrm{V}_{2}\right) \mathrm{bled}$ off the buffer air, allowing the piston to travel outward with the least possible deceleration while the poison rod was inside the reflector. The size of the valve orifice determined in large measure the rod travel characteristics. If the orifice was too large the piston would strike the end of the cylinder. On the other hand, too small an orifice would cause the rod to rebound into the reactor. The appropriate orifice size was determined with the aid of Fastex camera films of trial ejections and was selected to give the least ejection time compatible with a rebound limited to six inches which did not allow the poison rod to re-enter the reflector. The pressure of the drive air, although reduced, overcame the rebound and again drove the piston outward and held it against a rubber bumper (B) which prevented the piston from striking the metal end of the cylinder.

The poison rod was reinserted into the reactor by introducing compressed air at 8 psi into the cylinder on the buffer side of the piston by means of a valve $\left(V_{1}\right)$. The spring-loaded dump valve remains closed against this pressure and the piston drives the poison rod gently into the reactor until it reaches a remotely adjustable mechanical stop. The air trapped between the piston and valve $V_{0}$ during the reinsertion operation is released through valve $V_{3}$, which opens simultaneously with $\mathrm{V}_{1}$ and the tube housing the poison rod. The position history of the piston rod during an ejection was provided by a magnet carried by the piston. The magnet generated a voltage as it passed under a series of pickup coils located at 2 -in. intervals along the cylinder.

A panel located in the control room console provides for the complete remote control and supervision of the reactivity mechanism. The piston can withdraw the poison rod from its farthest inserted position to where the rod clears the reflector (30 in.) in $60 \mathrm{msec}$. The rod withdrawal time and maximum velocity are varied by adjusting the pressure of the air in the reservoir. The rod position traces in Figures 18 and 19 show the maximum rod velocities to be 800 and $600 \mathrm{in.} / \mathrm{sec}$ respectively, which were produced by reservoir air pressures of 80 and 60 psi respectively.

The reactivity value of the poison rod, when centered in the core, has been measured to be $\$ 6.50$. Figure 18, which is a plot of the poison rod position and the reactivity released by the rod as a function of time, shows that 


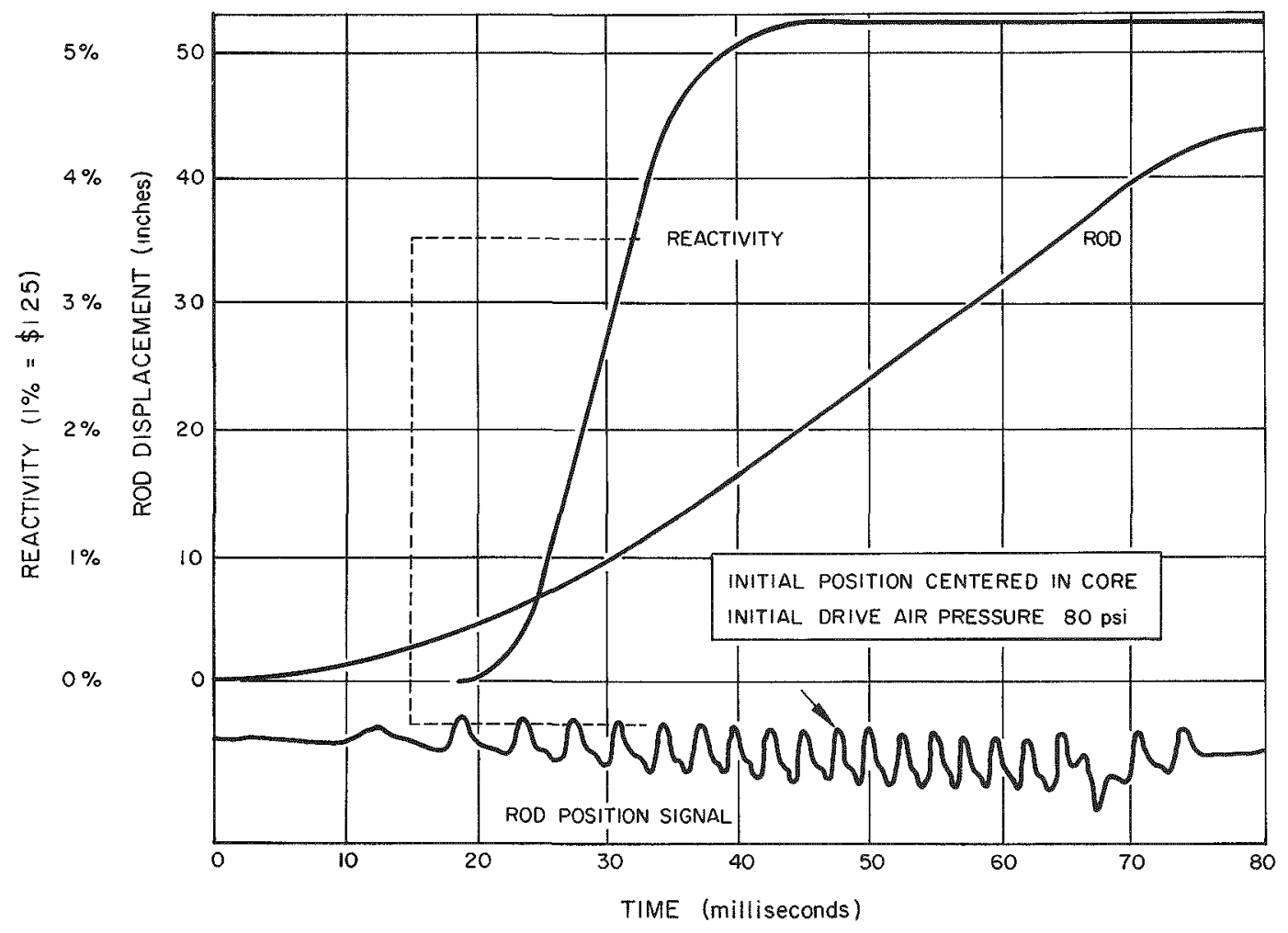

Figure 18. Poison Rod Position and Resulting Reactivity Change vs Time

the rod travelled $4 \mathrm{in.}$ before appreciable reactivity release began. Essentially, all of the reactivity held by the rod was released when it had travelled 22 in.

This 22 -in. displacement corresponds to the 11 th rod position pulse which is indicated by an arrow in Figures 18 and 19.

Since the KEWB core was loaded to $\$ 5.0$ reactivity, the reactor was not critical until the rod had moved out $8 \mathrm{in.}$ During this 8 -in. travel, the rod was accelerated to nearly maximum velocity. This permitted the mechanism to insert the $\$ 5.0$ reactivity in $20 \mathrm{msec}$.

Figure 19 is an oscillogram of a typical reactor power excursion with a $2-\mathrm{msec}$ reactor period. It may be noted that the 11 th pulse, which indicates full reactivity insertion, occurs $43 \mathrm{msec}$ before peak power. An inspection of the more sensitive linear power traces shows that the reactor power was rising with a constant period until $10 \mathrm{msec}$ prior to the power peak. The time increment between these two events, that is, reactivity fully inserted and onset of shutdown, is $33 \mathrm{msec}$. The reactor power increased a little over seven decades 


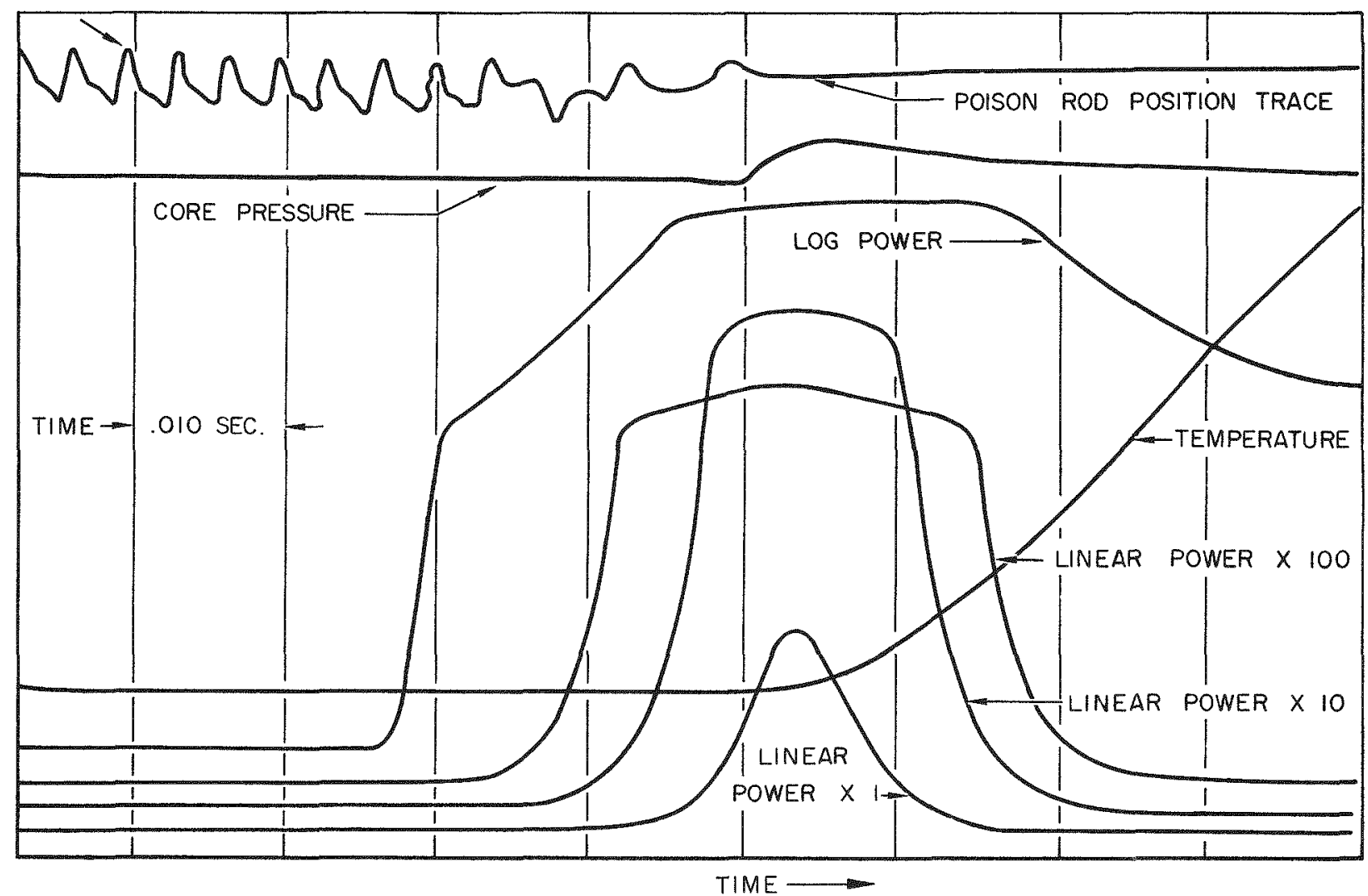

Figure 19. Typical Power Transient Oscillogram

on a stable period during this time interval. This excursion involved an initial power level of approximately $10^{-4} \mathrm{w}$. Other experiments included an investigation of the effects of starting powers up to about $25 \mathrm{kw}$. These experiments sharply reduce the time available for the reactivity addition, and thereby place the greatest demand upon the accelerator mechanism.

\section{d. Fast Thermocouple Development}

As fission energy is released in the water solution of uranyl sulfate, the temperature of the core rises. If the reactor period is short enough, the heat distribution is adiabatic; and until bubble formation caused movement of the solution this temperature distribution in the core was a good indication of the flux distribution. The temperature history during a transient provides data on that part of the intrinsic reactor shutdown due to temperature reactivity compensation. Dynamic measurement of the temperature presented several problems. 
The rapid temperature changes of the $\mathrm{KEWB}$ reactor core during short period power transients were too fast to be recorded by the rmocouples available at the beginning of the KEWB program. The development of suitable thermocouples was undertaken by the KEWB personnel.

The temperature sensing elements must withstand immersion in the core solution, which is highly corrosive. It was composed of 0.75 molar $\mathrm{UO}_{2} \mathrm{SO}_{4}$ and 0.5 molar $\mathrm{H}_{2} \mathrm{SO}_{4}$ in distilled light water. The $\mathrm{pH}$ of this solution is 0.7. If the thermocouples were to survive in the core, they must be made of corrosion-resistant metals or be protected from direct contact with the fuel solution. The first used in the KEWB program were fashioned from $0.005-i n$. iron and constantan wire insulated with $\mathrm{MgO}$ enclosed in a Type 347 stainless steel sheath. The outside diameter of the sheath was 0.040 in. A suitable length of flawless stock was cut and polished to remove any tool marks. The $\mathrm{MgO}$ insulation was sandblasted out to a depth of $0.020 \mathrm{in}$. or more (Figure 20 , View A). The wires were twisted around each other and pressed down 0.005 to $0.010 \mathrm{in}$. below the end of the sheath, which was closed over the wires by using a dull diagonal cutting plier (View C) and sealed by heliarc welding without the use of extraneous metal (View D). The welded tip was polished and inspected for $\mathrm{MgO}$-filled pits or other flaws. The good tips were flattened by introducing about $0.060 \mathrm{in}$. of the sheath between the specially shaped and polished jaws of a vise. This flattening enclosed the thermocouple junction in a blade 0.007-in. thick, 0.1-in. wide and 0.1-in. long (View E). After a final polish and inspection the thermocouples were given electrical tests. View $F$ is a section of a completed the rmocouple.

Satisfactory thermocouples were then connected to a cold junction and a recording oscillograph. The thermocouple was plunged into a beaker of hot water and the time for the couple to respond to $63 \%$ of the final temperature change was measured. This method of obtaining response time is acceptable when dealing with time constants longer than about $5 \mathrm{msec}$. Time constants of $20 \mathrm{msec}$ were obtained with the best thermocouples produced in this manner.

From the temperature trace of the oscillogram (Figure 19), it can be seen that the temperature rise in a 2 -msec period power excursion was virtually a step function for these thermocouples. While the usefulness of these thermocouples was limited for short period power transients, they were adequate if the period was longer than $90 \mathrm{msec}$; and they proved very effective in other 


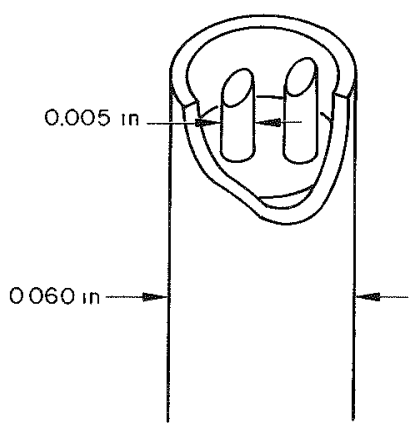

$A$

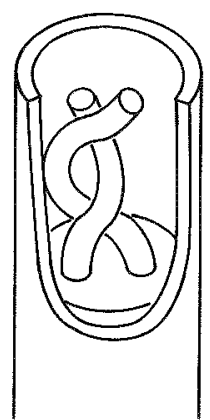

B

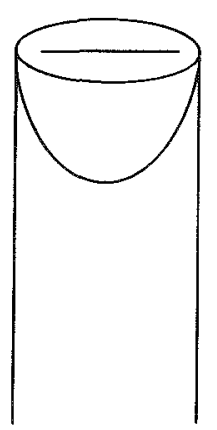

$\mathrm{C}$
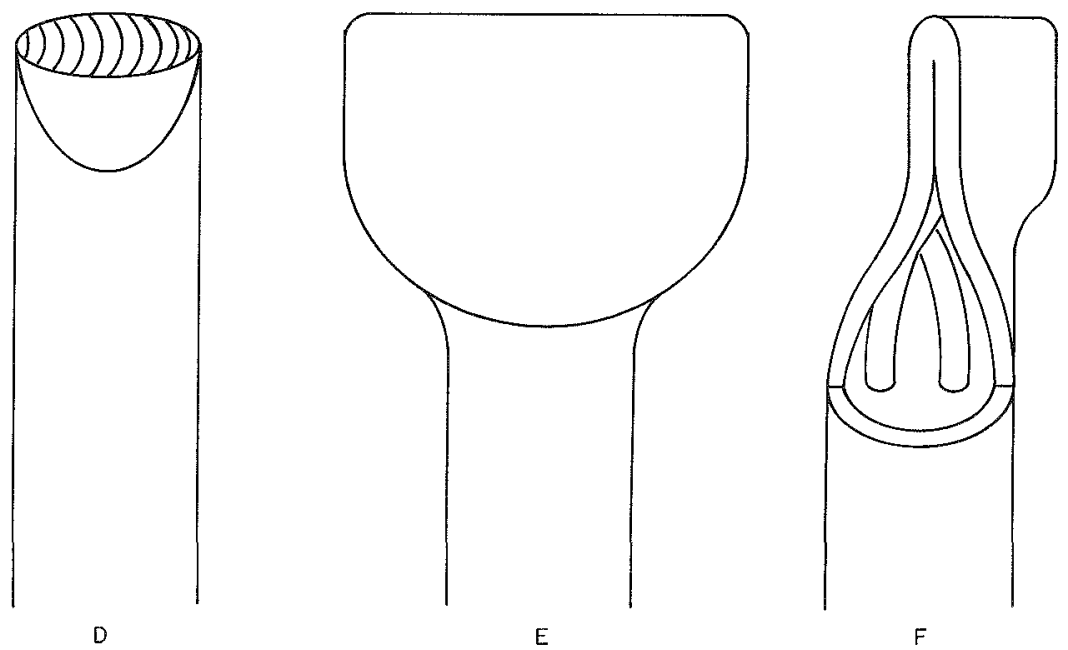

Figure 20. Thermocouple Fabrication Sequence

phases of the program. They resisted the adverse environment of the KEWB core for more than a year. They can be used under conditions of high temperature and pressure as well as in a corrosive medium. Their response is faster than any commercially available thermocouple which was offered for use in the KEWB.

A $2-\mathrm{msec}$ period reactor excursion requires that the thermocouples have a time constant of $0.3 \mathrm{msec}$ if the reported temperatures are to be within $10 \%$ of the true value at all times. A continuing development program has demonstrated that bare wire thermocouples can be fabricated which have time constants at least as short as $0.5 \mathrm{msec}$. The useful lifetime of these thermocouples is being investigated. 


\section{e Data Reduciion System}

To expedite the detalled reduction of occasional oscillograms under circumstanres which are not appropriate for routinely employed digital computer techniques, an oscillogram trace displacement readout aevice was developed There are 10 to 15 traces, depending on the experiment, which are recorded on a KEWB oscillogram These include linear power. log power, temperature and pressure traces Ease of operation, accuracy and digital readout in terms of parameter units were the important design requirements

The readout device consists of a linear potentiometer, a voltage supply scaling network, and a digital voltmeter (Figure 21) The precision linear motion potentiometer has a 5-in travel Its repeatability error is less than $1 \%$ full scale, hysteresis does not exceed one percent full scale, and error due to nonlinearity does not exceed plus or minus $05 \%$ independent of position The potent1ometer was mounted on a lucite plate which was machined to accept a movable magnifying cursor (Figure 22) To eliminate backlash, the cursor was attached directly to the slider of the potentiometer

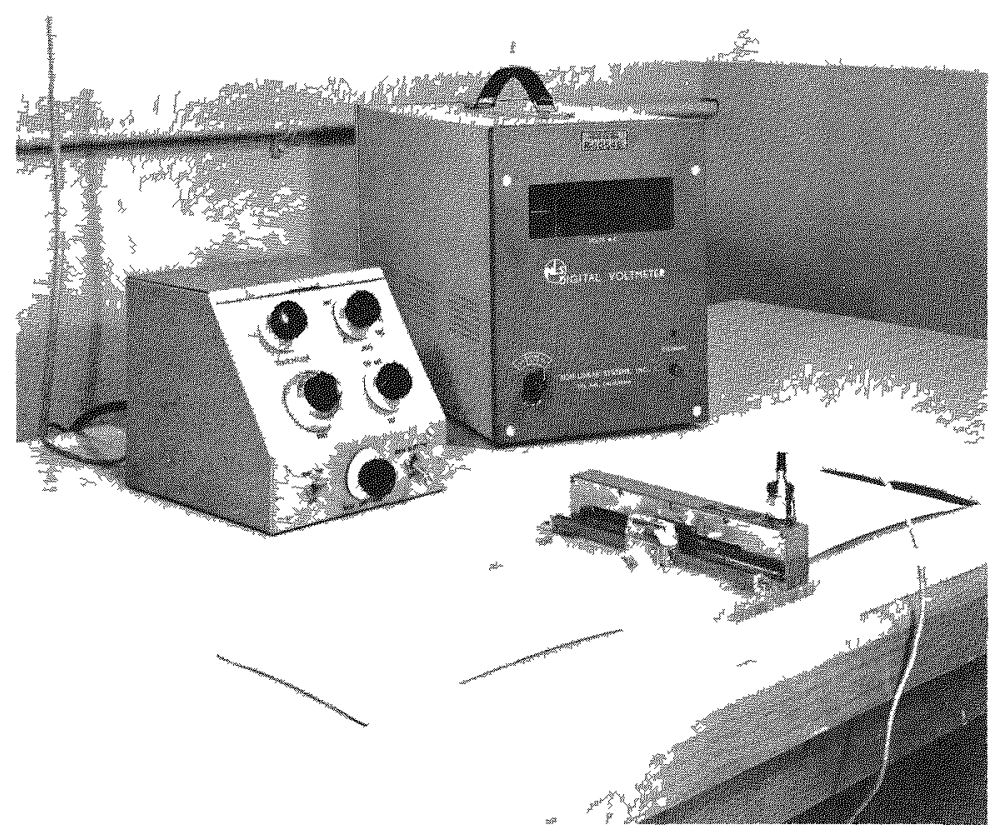

Figure 21. Digital Oscillogram Readout System 


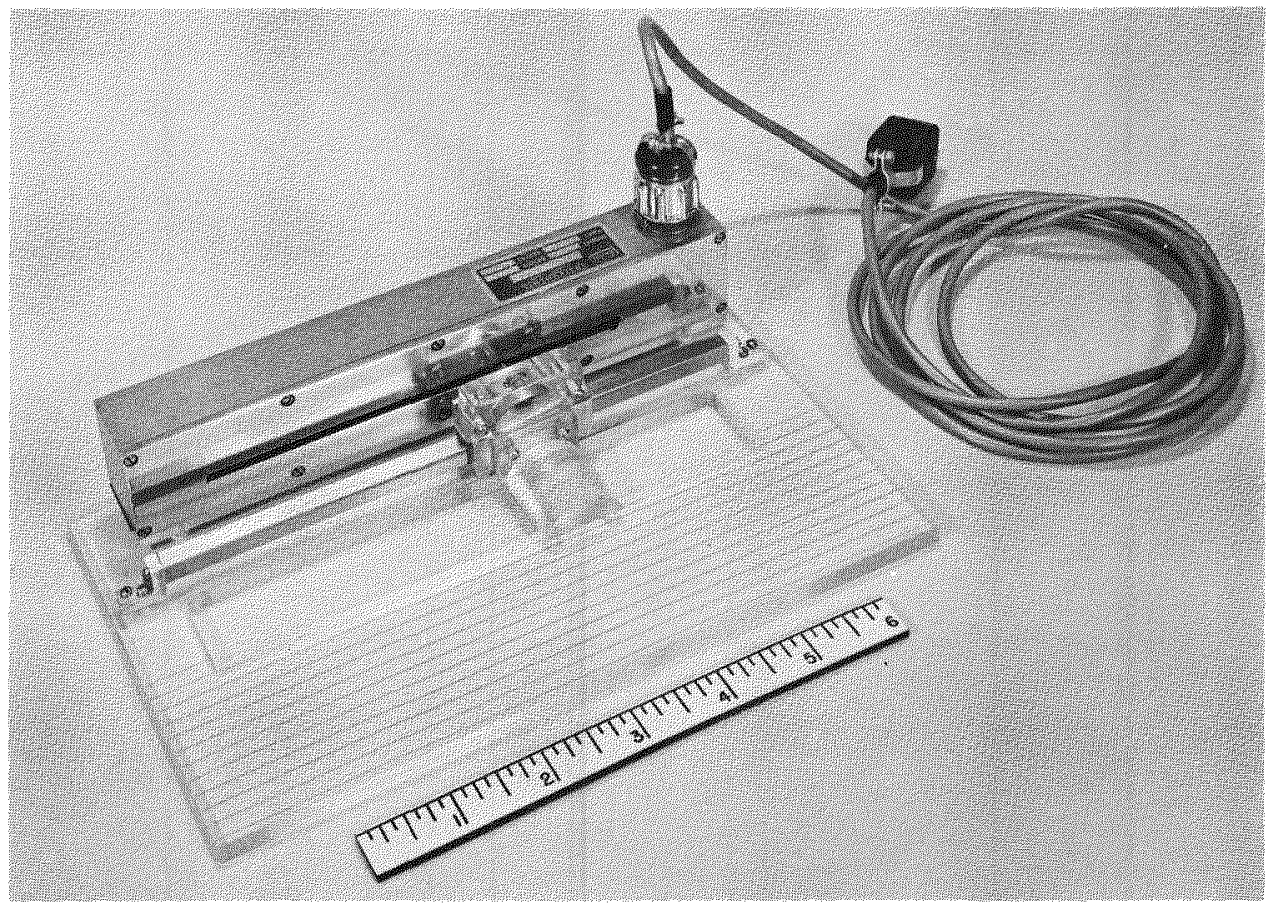

Figure 22. Readout Head Showing Linear Potentiometer and Cursor

The digital voltmeter used in this system has linearity error of less than $0.3 \%$. Its resolution is $0.2 \%$. This provides an overall system precision which is limited primarily by the accuracy with which the cursor is located on the oscillogram trace.

The output potential may be adjusted to be proportional to power, pressure, temperature, or strain by properly scaling the voltage supplied to the ends of the potentiometer element. The voltage source, which has course and fine adjustments, is contained in a compact control unit. The calibration data pertinent to the trace under inspection are used to determine this voltage. The voltage controls have arbitrary scales and they are adjusted until the desired scale factor, in parameter units per inch, appears on the digital voltmeter. During calibrations exactly one-fifth of the potentiometer supply voltage, which corresponds to precisely one inch trace deflection, is delivered to the voltmeter. The value of any point on the trace is thereafter displayed directly by the voltmeter when the cursor is positioned.

The control unit also provides a bias source which permits the reader to adjust the voltage at any arbitrary displacement of the cursor to zero. This 
allows the deflection of the trace to be read relative to its own base line without having to adjust the relative position of the readout potentiometer and the oscillogram.

The readout circuit of this device is controlled by a three-position foot switch. In its first, or normal position, the calibration factor appears on the voltmeter. Repetitive reading of the scale factor insures against error resulting from instrument drift. In the second position, the value of the trace deflection appears in parameter unit values. In the third position, the net deflection potential is made available to auxiliary devices such as a Clary printer or an IBM card punching machine. 


\section{MEASUREMENT OF REACTOR PARAMETERS}

\section{A. VOID COEFFICIENT}

The introduction of voids into the core region causes a decrease in reactivity. The magnitude of this effect depends on the size and position of the void. Such voids, caused by radiolytic gasses and steam, occur during reactor operation.

Since direct access to the fuel solution was impractical, the void reactivity determination was performed in the through tube. A series of lucite cylinders containing calibrated voids, were inserted into the core region, and graphite plugs into the reflector regions of the through tube. The lucite plug for the core region was chosen mainly because it represented approximately the same reactivity worth as fuel solution.

Progressively larger sections of the lucite were removed, leaving a right circular cylindrical void at the center of the core. The loss of reactivity for each step was determined by noting the control rod positions when the reactor was critical at 4 watts. A plot of reactivity los $\mathrm{vs}$ void volume is given in Figure 23. Graphical differentiation of Figure 23 yields a "Void Coefficient of Reactivity", Figure 24, which is void-volume dependent.

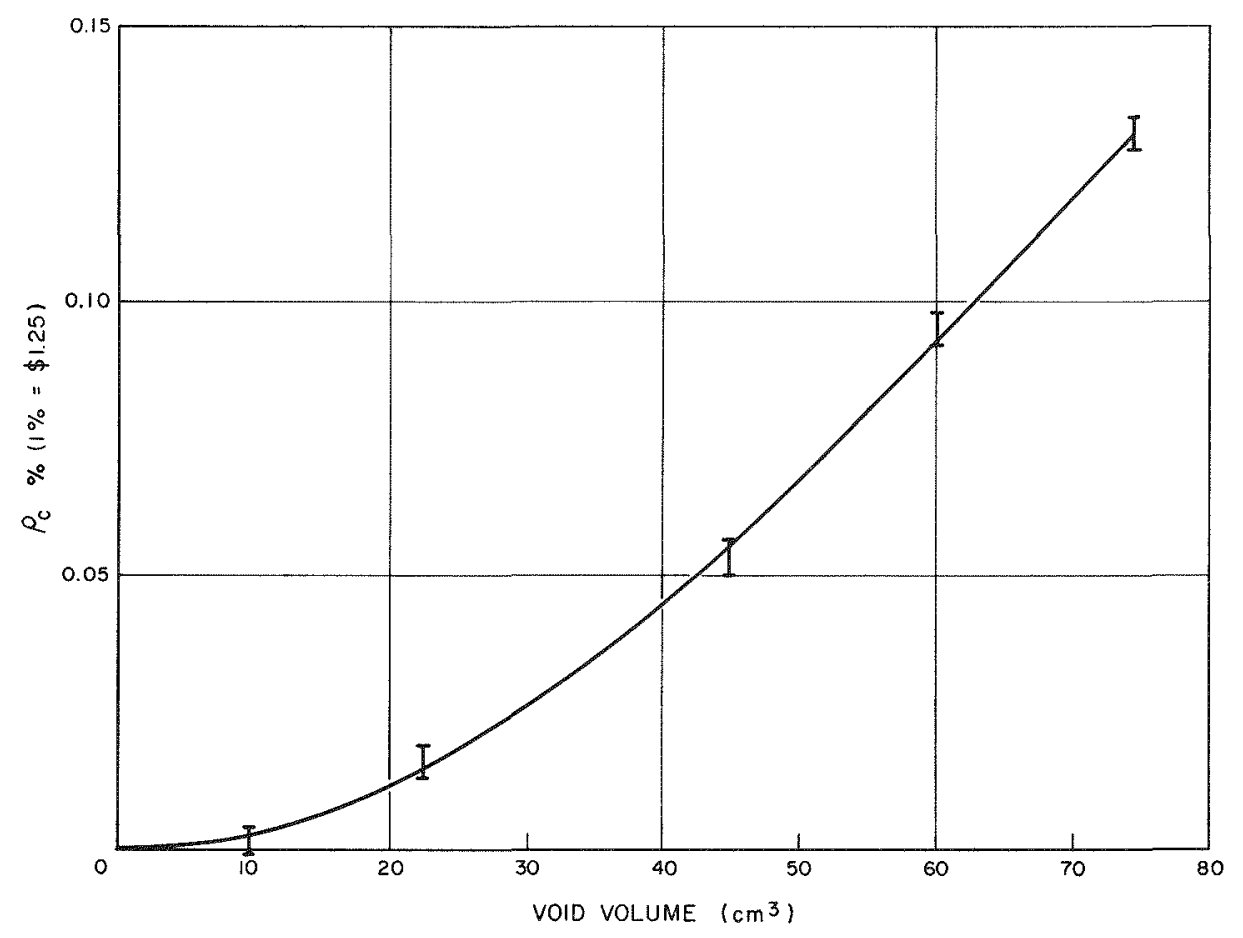

Figure 23. Reactivity Consumed in Calibrated Voids 


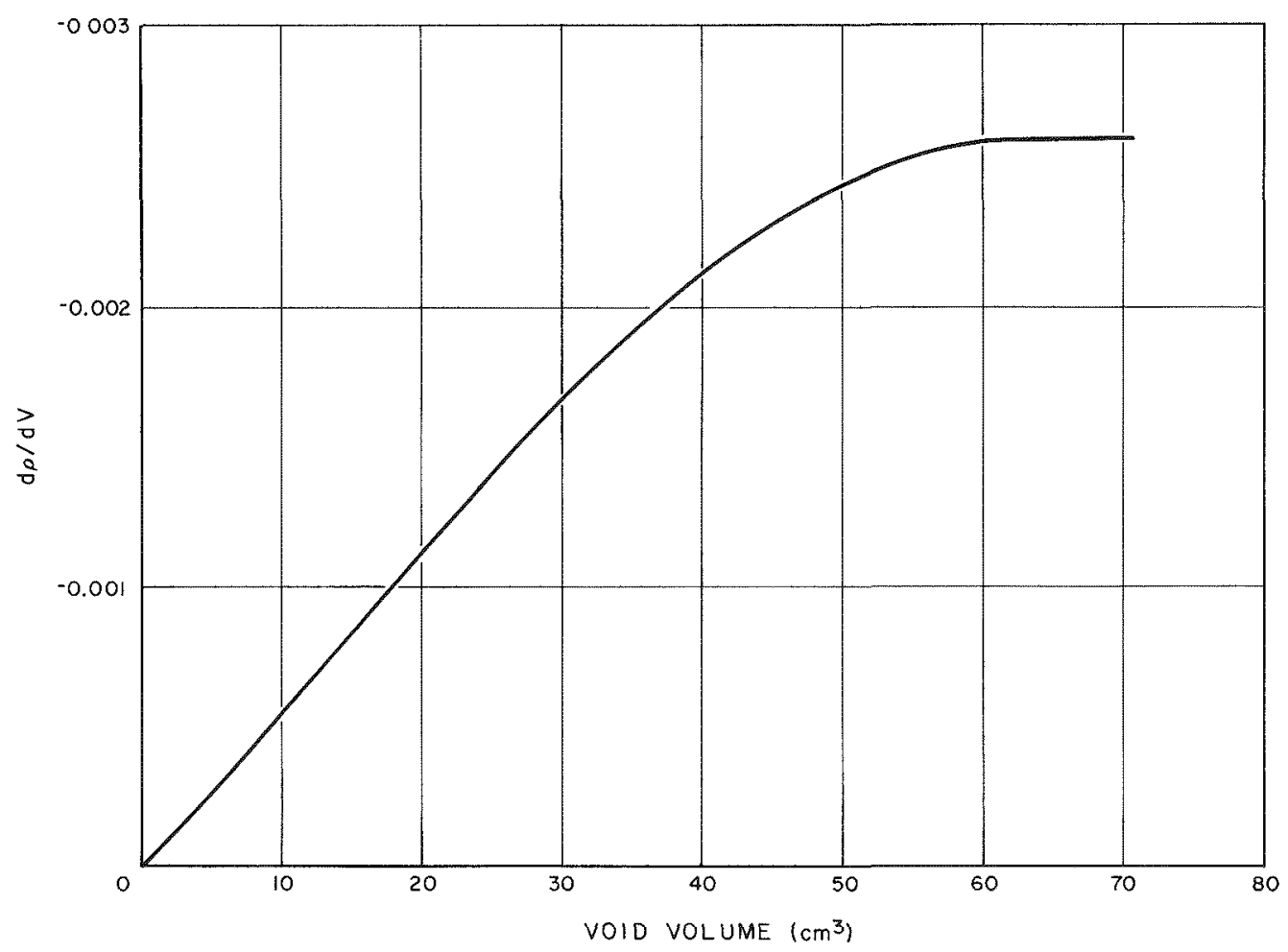

Figure 24. Void Coefficient of Reactivity vs Void Volume

The results of this void coefficient measurement must be applied in the analysis of dynamic bubble-void growth with caution because of the idealized representation of decreased moderator density.

A traverse of the core region with one void volume was also made. The reactivity worth of the void vs position is plotted in Figure 25.
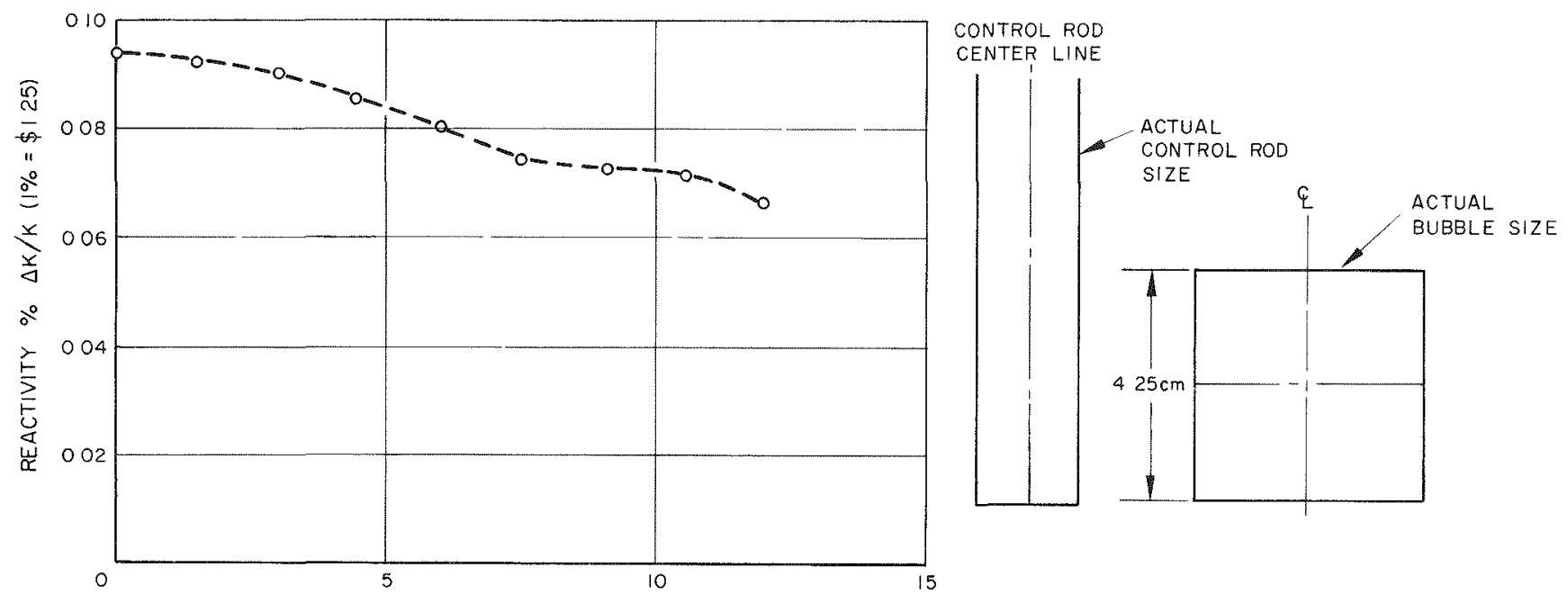

DISTANCE OF BUBBLE CENTERLINE FROM CENTER OF CORE

Figure 25. Traverse of $60.0 \mathrm{~cm}^{3}$ Void

$$
\text { NAA-SR }-5415
$$




\section{B. TEMPERATURE COEFFICIENT OF REACTIVITY}

Inasmuch as the KEWB spherical core differed in wall thickness from other reactors of this type (with consequently higher critical mass), it was considered desirable to determine the temperature coefficient of reactivity of this core for comparison with that of similar reactors.

Two techniques were used to measure the temperature coefficient. First, critical rod positions at various temperatures were noted and reactivity changes with temperature were then obtained from the control rod calibration curves. This method was used in both the full and underfull cores, and the results are shown in Figure 26. A second method was used to check the results for the

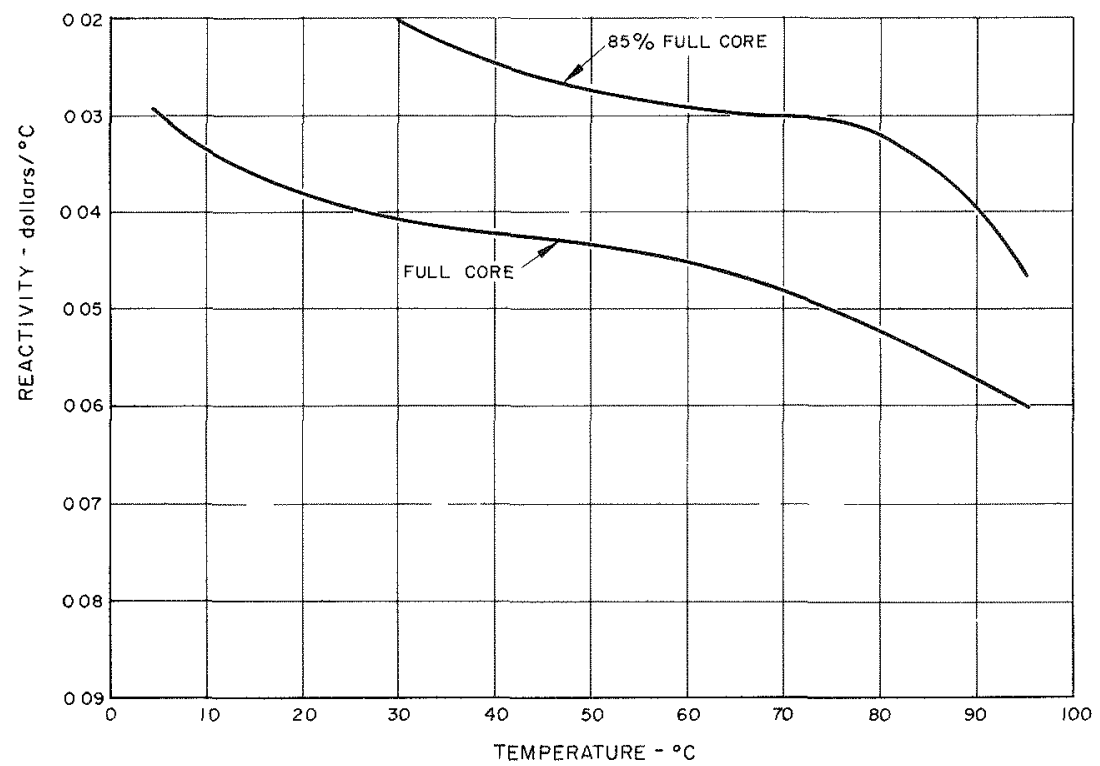

Figure 26. Temperature Coefficient vs Temperature for $85 \%$ Full and Full Core Cases

underfull core only. The results obtained by the two methods were in good agreement. For the second method, control-rod-induced transients were used to determine directly the reactivity consumed between pairs of temperatures. The procedure for the transient technique was as follows: A critical rod position at temperature $\mathrm{T}_{1}$ was determined. The reactor was then shutdown and the core cooled to a lower temperature $\mathrm{T}_{2}$. The control rods were thereafter quickly and simultaneously withdrawn to the position corresponding to criticality at temperature $T_{1}$. Reactivity consumed between $T_{1}$ and $T_{2}$ was computed from the observed stable period using the in-hour equation, which is insensitive to the neutron lifetime in the period region utilized. This technique was followed for a series of temperature steps. 
The general shape of the curve is as would be expected, the temperature coefficient becoming negatively larger near the boiling point. The more negative full-core temperature coefficient was probably caused by the removal of fuel from the spherical geometry due to thermal expansion of the fuel solution. The magnitude of the underfull temperature coefficient is smaller than has been observed in other similar reactors with a comparable core volume, (e.g., SUPO, Armour Foundation reactor). Therefore, our estimate of the ability of the assembly to self-terminate a power rise was pessimistic to the extent of the differences in the coefficient and the coefficients influence on the course of an excursion.

\section{GAS PRODUCTION COEFFICIENT}

Considerable difficulty was experienced obtaining reproducible results in the initial measurements of the gas production coefficient. After this difficulty was observed, a detailed procedure was devised to control the core solution history. This consisted of making a "dummy" run immediately preceding each "G" value determination. In each case the "dummy" run had parameters duplicating those of the data run and was terminated in a manner that insured the fuel solution being saturated with hydrogen and oxygen. The pressure was adjusted after each "dummy" run to the desired pressure for the "G" value determination. At no time was air bled into the system to adjust the pressure; thus, the reactor atmosphere always consisted of a stoichiometric proportion of hydrogen and oxygen. Pressure increases were accomplished by reactor operation to insure a hydrogenoxygen saturated solution. A time schedule prescribing the time of startup and shutdown, and of each measurement and a specific valve procedure was also developed to insure reproducible results.

The experimental method for determining the energy coefficient of gas production consisted of observing the pressure change in a known volume at a known temperature. If it is assumed that the gases evolved were ideal and solely occupy the volume, then the STP volume of gas produced is

$$
V_{c}=\frac{273^{\circ} \mathrm{K} \times \mathrm{V} \times \Delta p}{76 \mathrm{~cm} \mathrm{Hg} \times \mathrm{T}}
$$

$\mathrm{V}=$ system void volume in liters

$\Delta \mathrm{p}=$ system pressure change in $\mathrm{cm} \mathrm{Hg}$ abs.

$\mathrm{T}$ = system temperature in ${ }^{\circ} \mathrm{K}$. 
This value is divided by the integrated power of the run, in units of kwh to give " $G$ " as the number of STP liters of hydrogen-oxygen produced per kwh of reactor operation. The experimental results for both core loadings are plotted in Figure 27. It should be noted that two curves are given for the underfull core; one being pressure dependent and the other pressure independent. The data

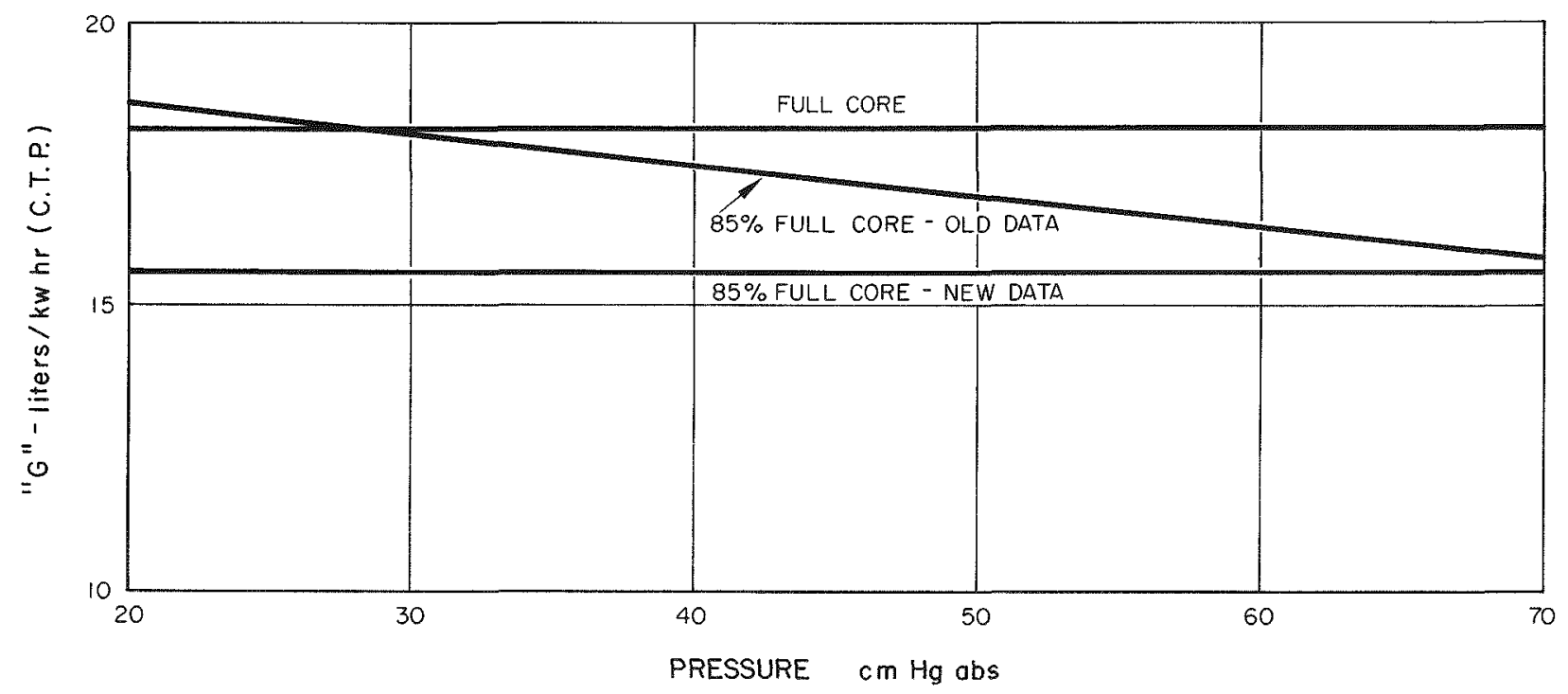

Figure 27. "G" Value vs Final Core Pressure

indicating a pressure dependency were obtained early in the KEWB program before catalytic agents ( $\mathrm{Fe} \& \mathrm{Cu}$ ) which accelerate hydrogen pe roxide decomposition were added to the fuel solution. The increase in " $G$ " for the full core is as would be expected for the higher water concentration.

\section{POWER COEFFICIENT OF REACTIVITY}

A set of experiments were conducted to evaluate the power coefficient of reactivity caused by the increase in the equilibrium inventory of gas voids in the fuel solution.

The reactor was operated at various stable power levels with the core temperature constant. Control rod positions for each power were noted, and reactivity worths obtained from the control rod calibration curves. The reactivity values were then referenced to a $4-w$ critical condition and the reactivity consumed $v s$ the reactor power level, plotted as shown in Figure 28. The greater reactivity consumption in the full core indicates that the expansion due to the increasing inventory of gas bubbles displaces fuel from the spherical portion of the core. 


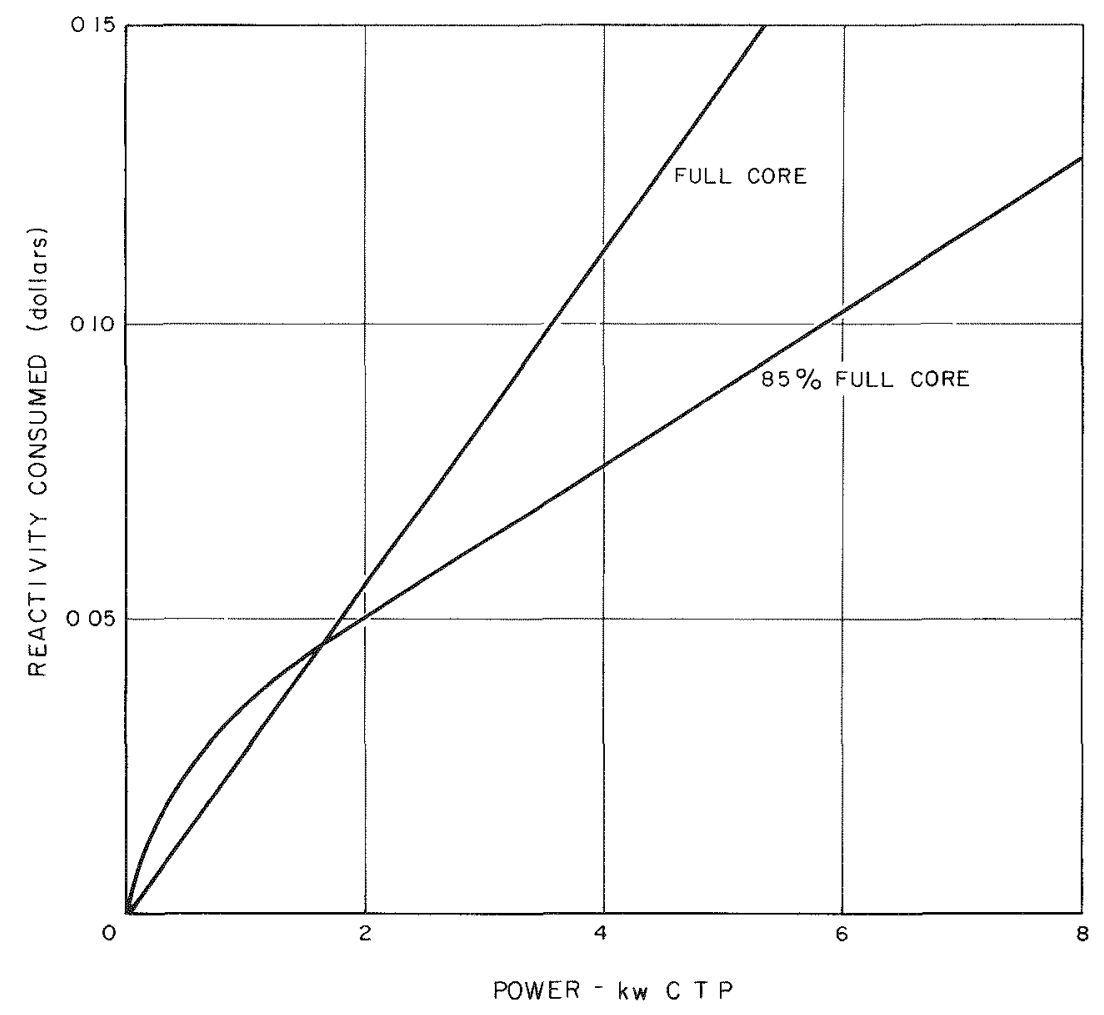

Figure 28. Reactivity Consumed vs Reactor Power Level

\section{E. CONTROL ROD CALIBRATION}

Three distinct methods were used to calibrate the control rods of the KEWB spherical core. One of these was a subcritical method and the other two were variations of the conventional period method.

\section{Subcritical method}

To calibrate a rod with this method it was necessary to relate $\rho$, the activity, to the subcritical multiplication $M$. Using

$$
\rho=\frac{k_{\text {eff }}-1}{k_{\text {eff }}}
$$

and

$$
M=\frac{1}{1-k_{\text {eff }}}
$$

we obtain the relation

$$
P=\frac{1}{1-M}
$$


However, $M$ was large compared to 1 , therefore we had as a good approximation for the reactivity

$$
\rho \simeq \frac{1}{M}
$$

Now defining

$\mathrm{M}=\mathrm{cm}$

where $m$ is the counting rate and $c$ a constant of proportionality, we could relate the reactivity to the subcritical counting rate.

A separate constant had to be determined for each rod to be calibrated. This was accomplished by bringing the reactor to criticality with all four control rods at the same level, noting the critical rod positions, and then withdrawing the rod to be calibrated to a predetermined supercritical position. The positive reactor period obtained was measured and converted to a reactivity worth by means of the KEWB inhour equation. The three rods not being calibrated were then inserted until the reactor was just subcritical, with the fourth rod at the all-out position. Counting rates were then taken at the previously determined critical and supercritical positions of the rod to be calibrated. Applying Equation 4 at each of these positions and subtracting one from the other, we obtain

$$
\Delta \rho=\rho_{\mathrm{SC}}-\rho_{\mathrm{C}}=\frac{1}{\mathrm{C}}\left(\frac{1}{\mathrm{M}_{\mathrm{C}}}-\frac{1}{\mathrm{M}_{\mathrm{SC}}}\right)
$$

where

$$
\begin{aligned}
\Delta_{p} & =\text { reactivity obtained from reactor period } \\
\rho_{s c} & =\text { reactivity worth of supercritical rod position } \\
\rho_{c} & =\text { reactivity worth of critical rod position } \\
M_{S C} & =\text { counting rate at } s c \text { rod position } \\
M_{C} & =\text { counting rate at c rod position }
\end{aligned}
$$

We then calculated the proportionality constant from

$$
C=\frac{1}{\Delta \rho}-\frac{1}{M_{c}}-\frac{1}{M_{s c}}
$$


A rod could now be callbrated by taking counting rates at its various positions and converting them to reactivity worths by using Equation 4 . The reactivity worths were then normalized to zero reactivity for the all-out position. A plot of a typical subcritical rod calibrati-n is shown in Figure 29.

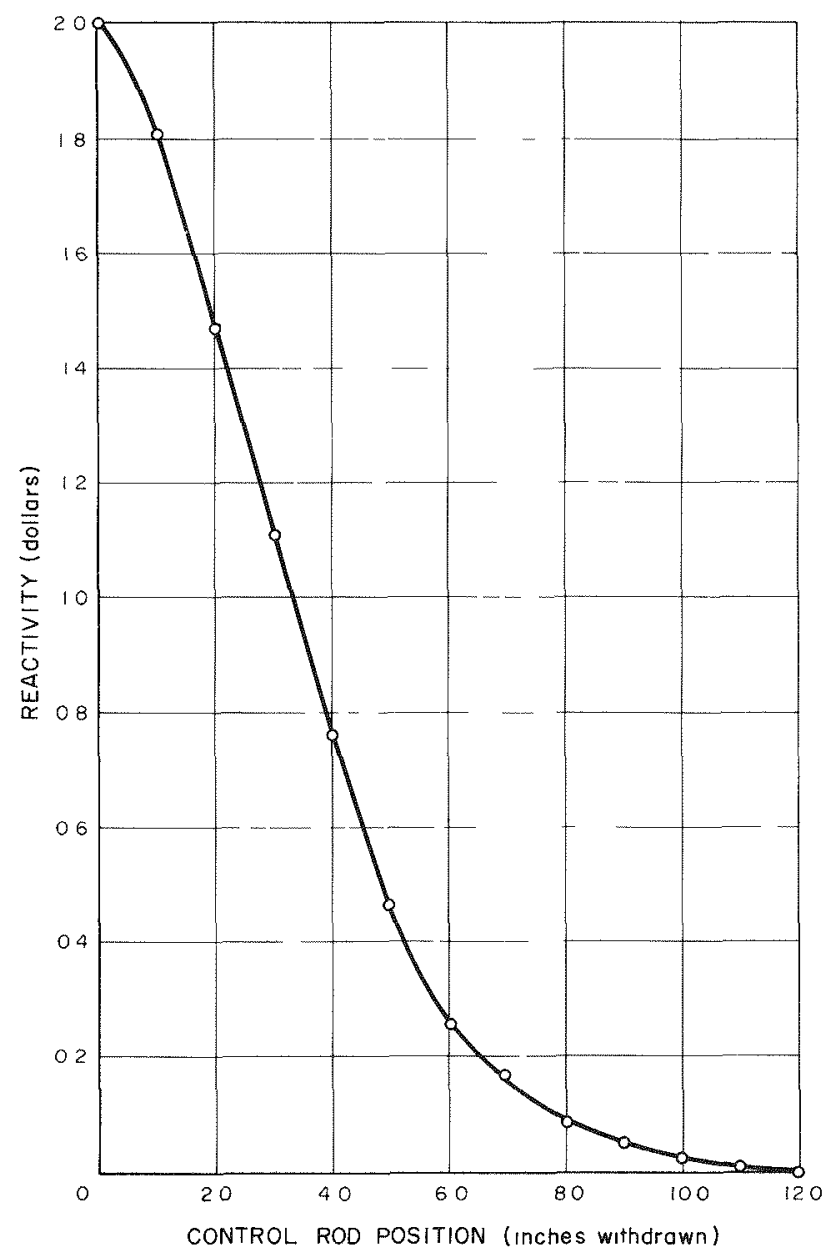

Figure 29. Subcritical Control Rod Calibration Curve, Rod 4

\section{Period Method-single rod calibration}

Using this method it was possible to calibrate two of the control rods simultaneously. One of the rods to be calibrated was left at the all-in position (position of maximum rod worth) and the other rod was extracted to the all-out position (position of minimum rod worth). The other two rods were pulled to a position such that the reactor was just critical. These two rods were left in this position for each step of the calibration. The all-in rod was then withdrawn to a position such that the reactor was supercritical on a reactor period of the order of 20 sec. 
The reactor period was again converted by the KEWB in-hour equation. This gave the reactivity worth of this rod between its critical and supercritical positions.

Next the all-in rod was lifted to the supercritical position used in the previous step. The two rods not being calibrated were adjusted to their critical position as found in the first step. The all-out rod was then adjusted to attain criticality. The interval between this new critical position for the all-out rod and the position used during the previous critical determination has the same reactivity worth as found in the first step. Again the all-in rod was pulled a step further and the reactivity worth determined for that portion of the rod travel.

This step-by-step procedure was repeated until both rods had been completely calibrated. The procedure was then repeated for the other two rods. Control rod calibration curves obtained with this method for both the full and underfull sphere conditions are given in Figures 30 and 31 respectively.

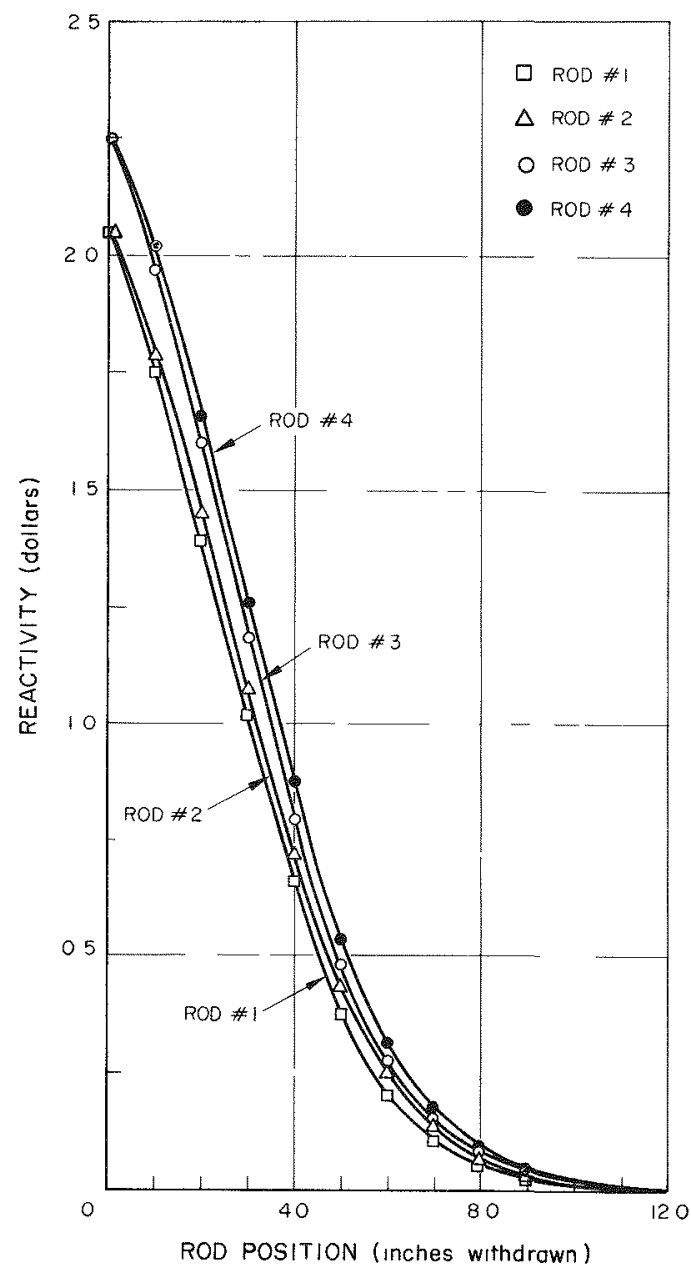

Figure 30. Control Rod Calibration Curves, $85 \%$ Full Core

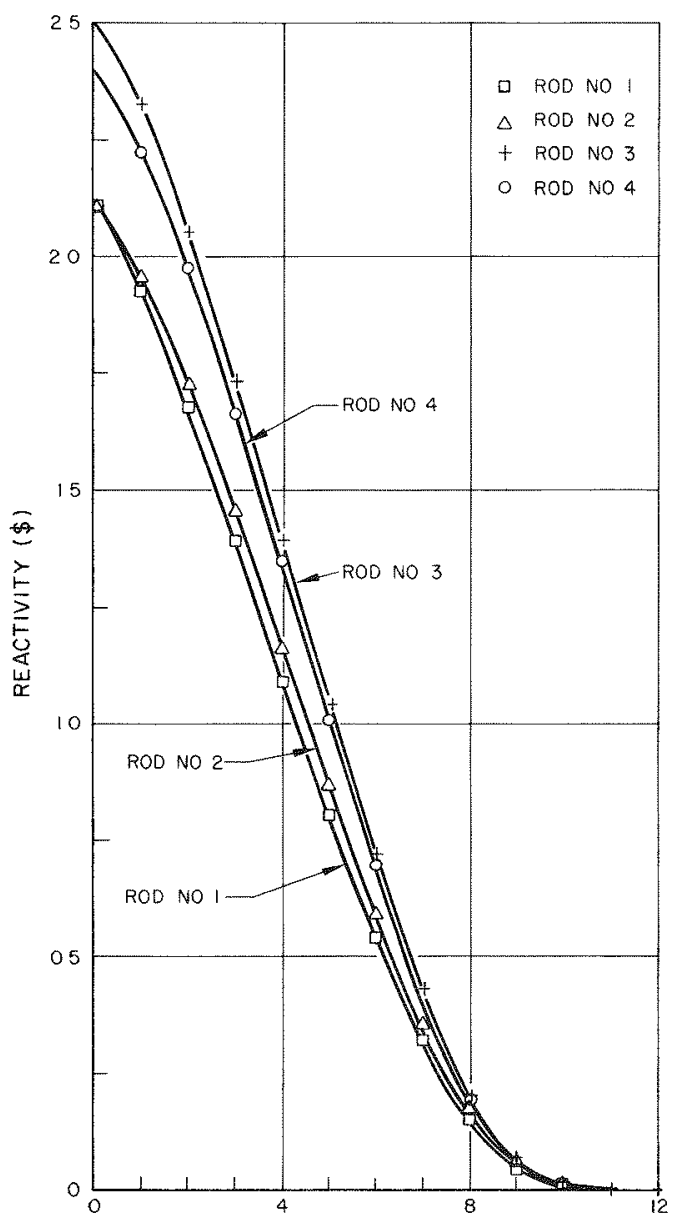

ROD POSITION (INCHES WITHDRAWN)

Figure 31 . Control Rod Calibration Curves, Full Core 


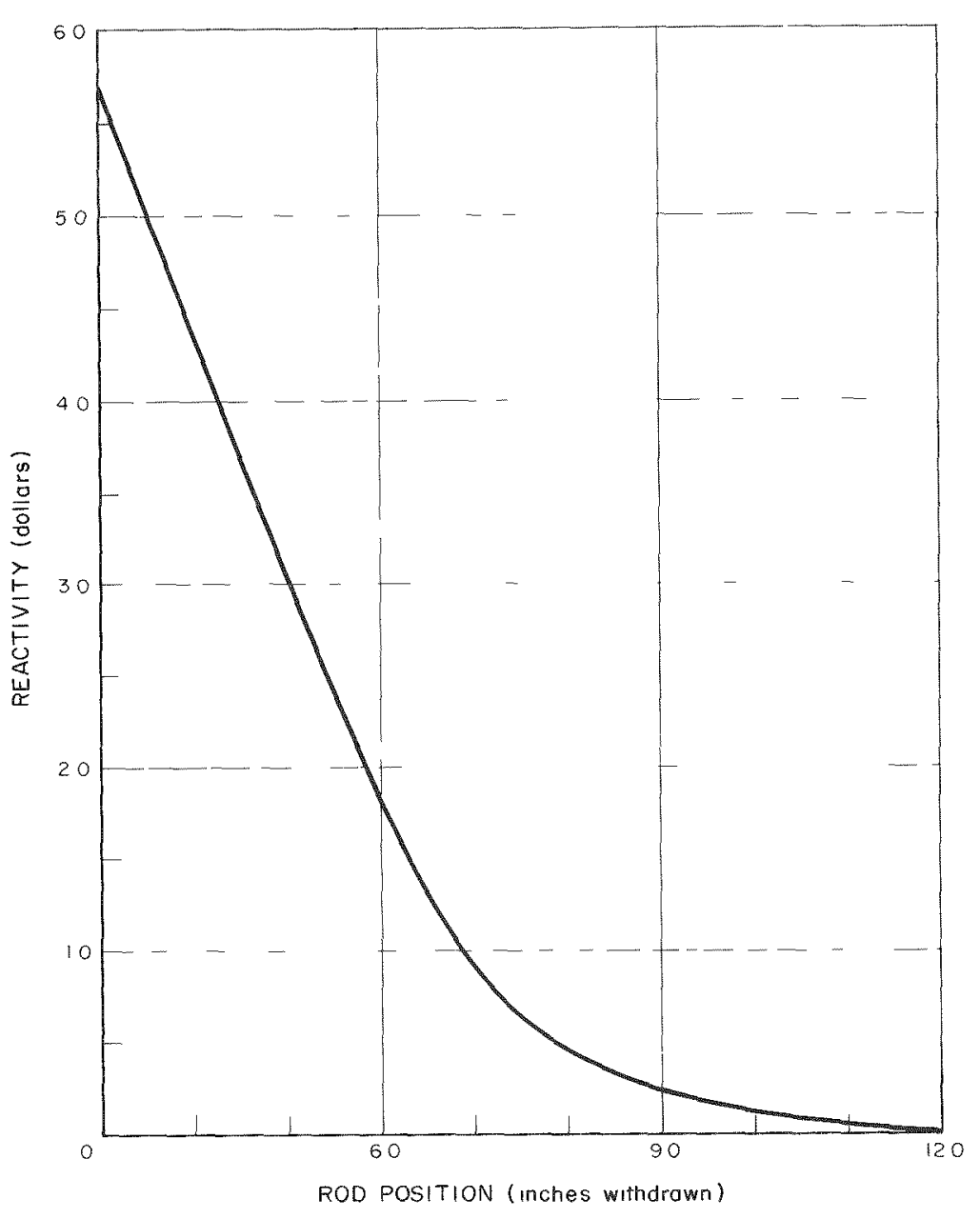

Figure 32. Ganged Four-Rod Calibration Curve, Full Core

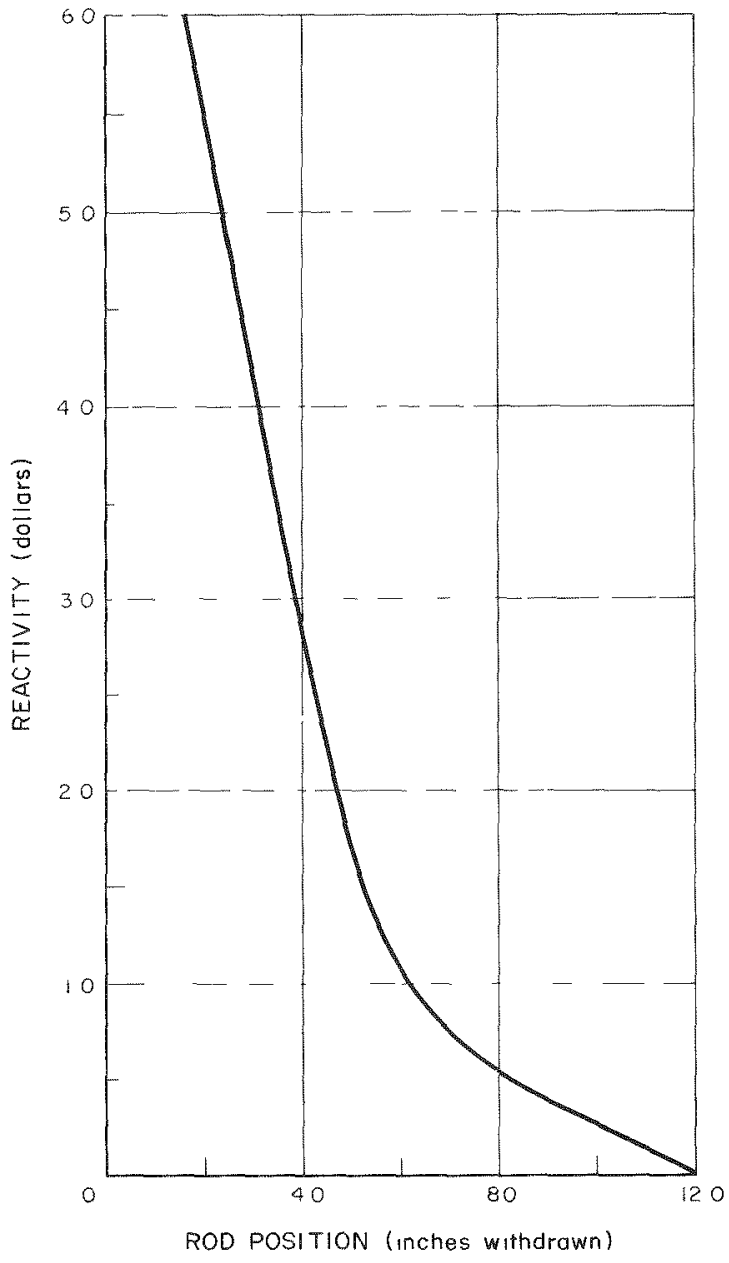

Figure 33. Ganged Four-Rod Calibration Curve, $85 \%$ Full Core

\section{Period Method - Composite Rod Calibration}

During the experiments, it was desirable to have a control rod calibration curve giving the reactivity worth when all four rods are at the same position. To obtain this curve, the four control rods were pulled together to a supercritical position. The resulting reactor period was measured, and then the temperature of the fuel solution was changed. The temperature change for successive measurements permitted limiting the reactor periods to the range of 30 to $1 \mathrm{sec}$, well below the prompt critical regime, where the neutron lifetime affect on the inhour equation becomes measurable. For the full core case, the rods were calibrated over a major portion of their rod travel by changing the critical position with temperature. A plot of this curve is found in Figure 32. A calibration curve of this type was obtained for the $85 \%$ full core by analysis of all available transient data in the desired period range. This curve is found in Figure 33. 
The calibration curve for the first few inches of travel and the total worth of the rods cannot be obtained by the method, since critical position for all four rods at $25^{\circ} \mathrm{C}$ was between 2 and 3 in.

\section{F. TRANSIENT POWER RECORDER CALIBRATION}

The transient linear power recording channels consisted of a boron-lined ionization chamber, an electrometer-amplifiex system, and a recording galvanometer. A more complete description of the system is given in Section III of the report.

The calibration was performed in two parts. First, the voltage sensitivity for each channel was measured. This was done by replacing the ion chamber with a calibrated constant voltage source and recording the resultant galvanometer deflection for several input voltages. Next the current sensitivity per kilowatt for each ion chamber was found by direct measurement of the ion current with a micro-microammeter for stable power operation up to $8 \mathrm{kw}$. Combining the two measurements, a calibration factor $(k)$ for the entire system in terms of power per inch deflection of the galvanometer could be calculated from

$$
\mathrm{K}=\frac{1}{\mathrm{G} \times \mathrm{R} \times \mathrm{C} \times \mathrm{V}}
$$

where

$$
\begin{aligned}
& G=\text { the amplifier gain used during the voltage calibration } \\
& R=\text { the electrometer range resistor } \\
& C=\text { the current sensitivity in terms of amps/kw } \\
& V=\text { the voltage sensiivity in terms of inches/volt. }
\end{aligned}
$$

\section{G. PRESSURE TRANSDUCER CALIBRATION}

A description of pressure recording systems used during the KEWB program can be found in Section III of this report.

With both systems, a static calibration was performed after the transducers were installed in the spherical core. This was accomplished by varying the core pressure in steps and recording the system response for the various pressures. For the galvanometer recording CEC carrier system, the response was recorded directly on the oscillograph as inches of galvanometer deflection per psi of pressure. The fast response DADEE system calibration was recorded as millivolts of transducer signal per psi of pressure. 
The Statham transducers used with the DADEE system were calibrated both statically and dynamically outside of the core system. The dynamic calibration required measuring hydrogen-oxygen explosions pressures which could not be performed with known pressure pulses when the transducers were mounted on the core. Instead, it was necessary to do this calibration in a shock tube where the dynamic pressures generated could be reliably calculated. A comparison of the static calibrations obtained for the Stathum transducers gave a reliability check on the transducer after it was mounted in the core. Any change in the static calibration indicated that the dynamic calibration could also be changed and an investigation was required.

\section{H. FLUX TRAVERSES IN CORE AND REFLECTOR}

Thermal neutron flux distributions were determined by using the foil and wire activation methods. Indium wire flux traverses were made in the horizontal through tube for two conditions, the tube air-filled and moderator-filled. A thin wall stainless steel tube was used to support the wire in the empty through tube. The wire was irradiated at $5 \mathrm{w}$ for $2 \mathrm{~min}$, and then cut into 1 - $\mathrm{cm}$ lengths for counting purposes. The count rates obtained for each segment were corrected to an arbitrary zero time and normalized to a $0.050-\mathrm{gm}$ sample mass. Figure 34 is a plot of the count rates normalized to the peak count rate.

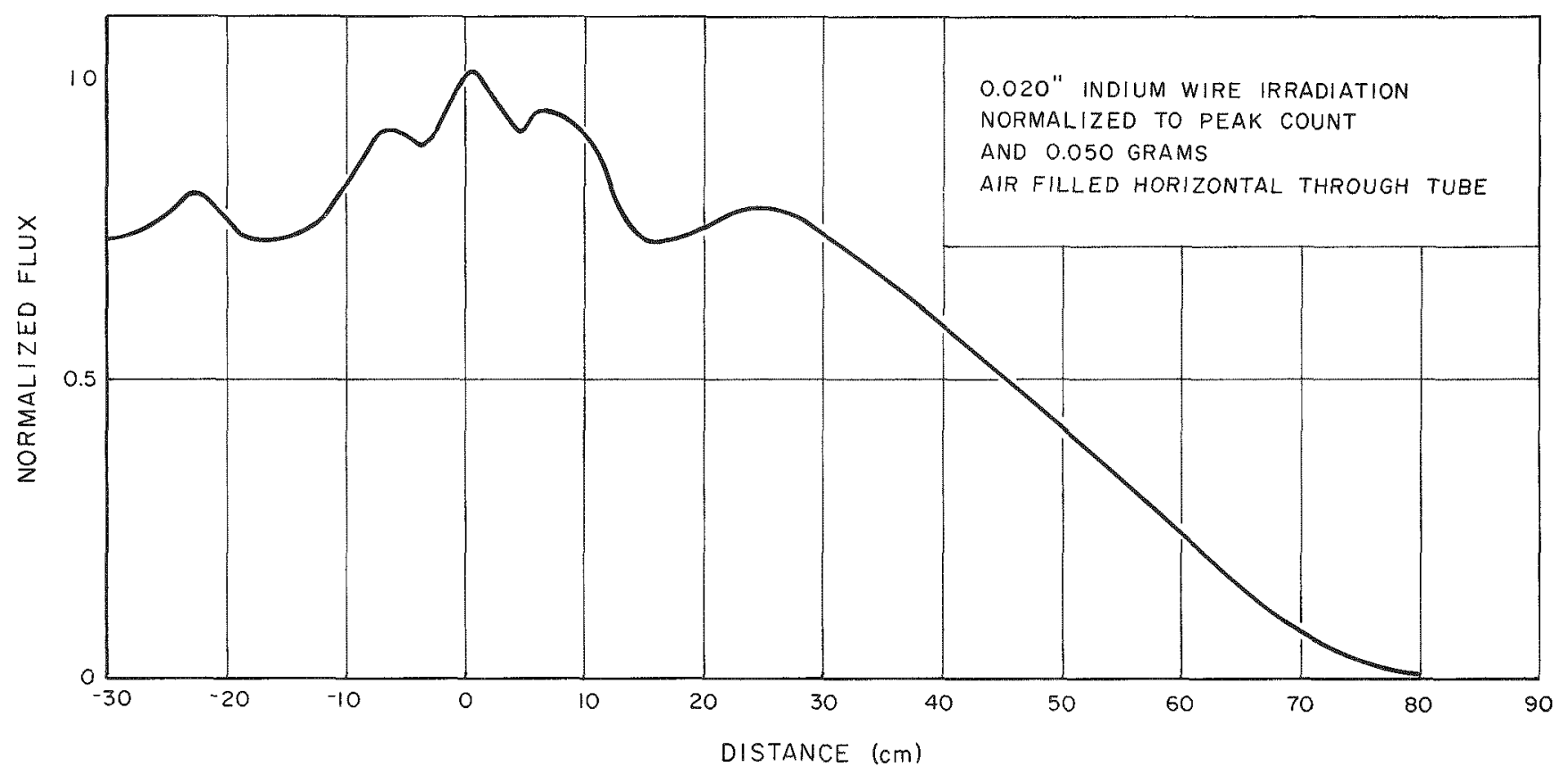

Figure 34. Steady-State Flux Distribution in Air-Filled Horizontal Through-Tube using Indium Wire 
The moderator-filled through-tube experiment was conducted in the same manner as the air-filled, with the exception that a lucite insert was located in the core section and the reflector sections of the tube were filled with graphite. The wire was cut and counted as in the empty through tube traverse. The normalized flux distribution is plotted in Figure 35. No absolute flux determinations were made for either of the in-wire experiments.

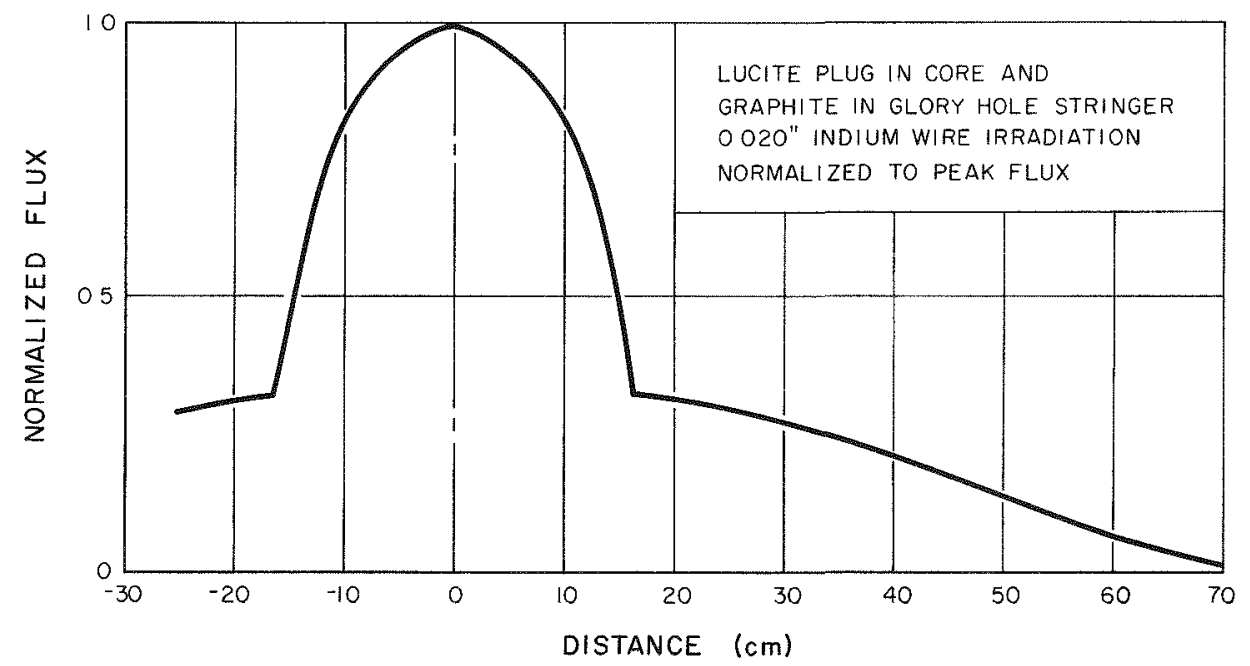

Figure 35. Steady-State Flux Distribution in Moderator-Filled Horizontal Through-Tube using Indium Wire

Gold foils $1 \mathrm{~cm}^{2}$ were irradiated in an empty through-tube for both steadystate and transient exposures. The foils were placed in either Al or Cd foil covers held $2 \mathrm{in.}$ apart in an Al holder. Every third foil was Cd-covered. This gave a $\mathrm{Cd}$ ratio plot and permitted an absolute thermal neutron flux determination. The steady-state exposure was at $3.6 \mathrm{kw}$ for 5 min while the transient exposure was a 3-ms step reactivity input resulting in an energy release of $2.95 \mathrm{Mw}-\mathrm{sec}$. The foils were counted, after a suitable cooling period, with a calibrated gas flow, $2 \pi$ proportional counter. Plots of the steady-state thermal neutron flux distribution and the transient thermal nvt are shown in Figure 36. Ninety percent of the transient neutron dose is delivered in a $20-\mathrm{ms}$ interval.

A gold foil traverse, as described in the preceding paragraph, was also performed in the reflector. A 2-in. cylinder was bored out of a graphite stringer to receive the foil holder. This stringer was located parallel to the through tube. The center line of the stringer was at the same level as the through-tube center 


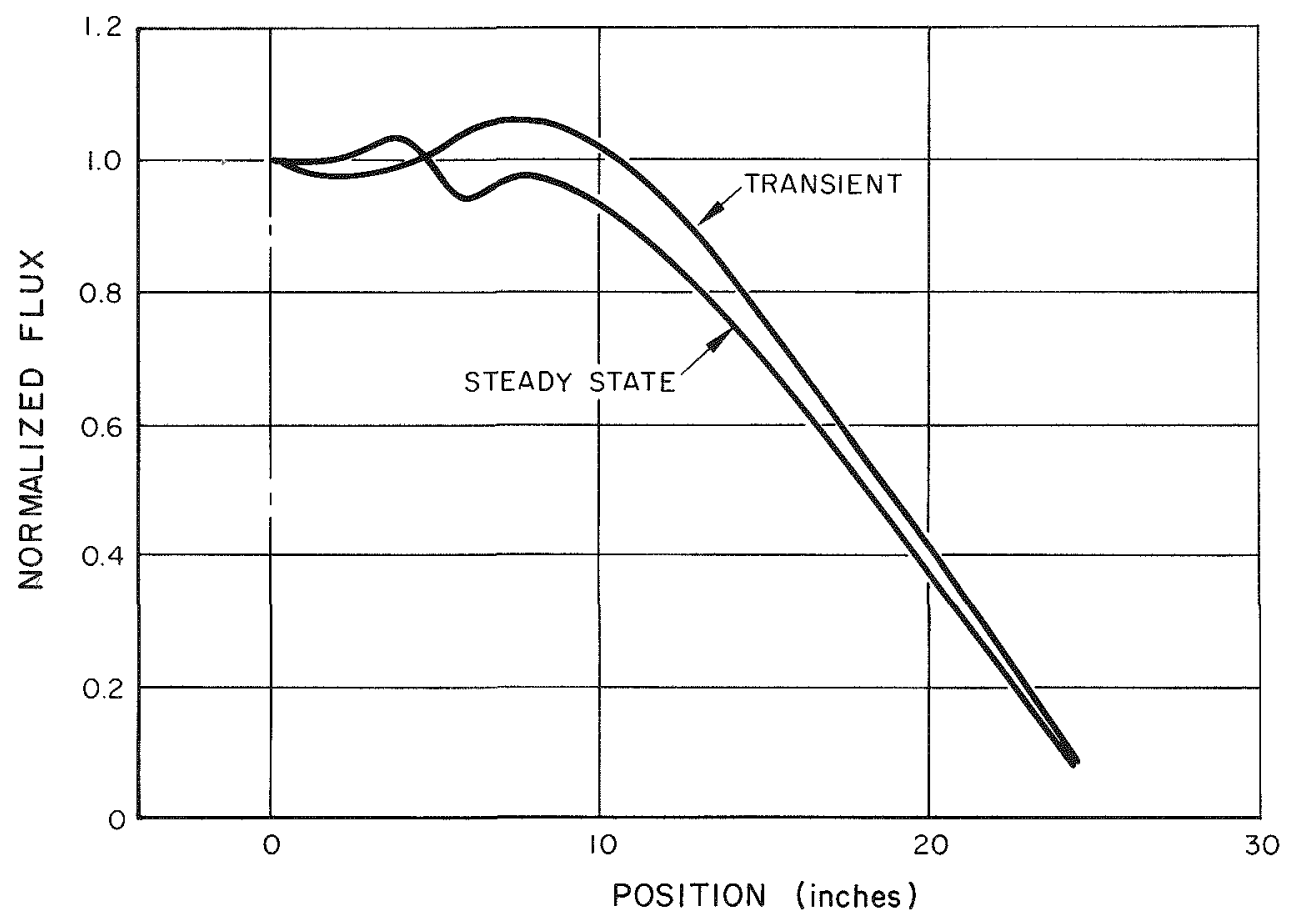

Figure 36. Transient and Steady-State Thermal Flux Distribution in Air-Filled Horizontal Through-Tube Using $1 \mathrm{~cm}^{2}$ Au Foils.

line, and $2 \mathrm{in.}$ from the outer edge of core. The exposure conditions were the same as those described for the through tube. Figure 37 show s the steady-state thermal flux distribution.

Plots of the Cd ratios obtained from the $\mathrm{Au}$ foil experiments are given in Figures 38 and 39. These ratios were obtained by plotting curves of the bare and cadmium-covered activities.

\section{THERMAL POWER CALIBRATION}

The reactor power level for the KEWB system was normally determined by a Beckman micro-microammeter measuring the output current of a boron coated, lead-shielded ionization chamber. Since the micro-microammeter and chamber sensitivity was not stable over long periods of time, it was necessary to calibrate this power detecting system periodically. This was accomplished by using a fixed procedure.

The term "coolant thermal power" (CTP) is defined to mean the rate of heat removal from the fuel solution by the coolant at steady state operation. This value is given by the expression 


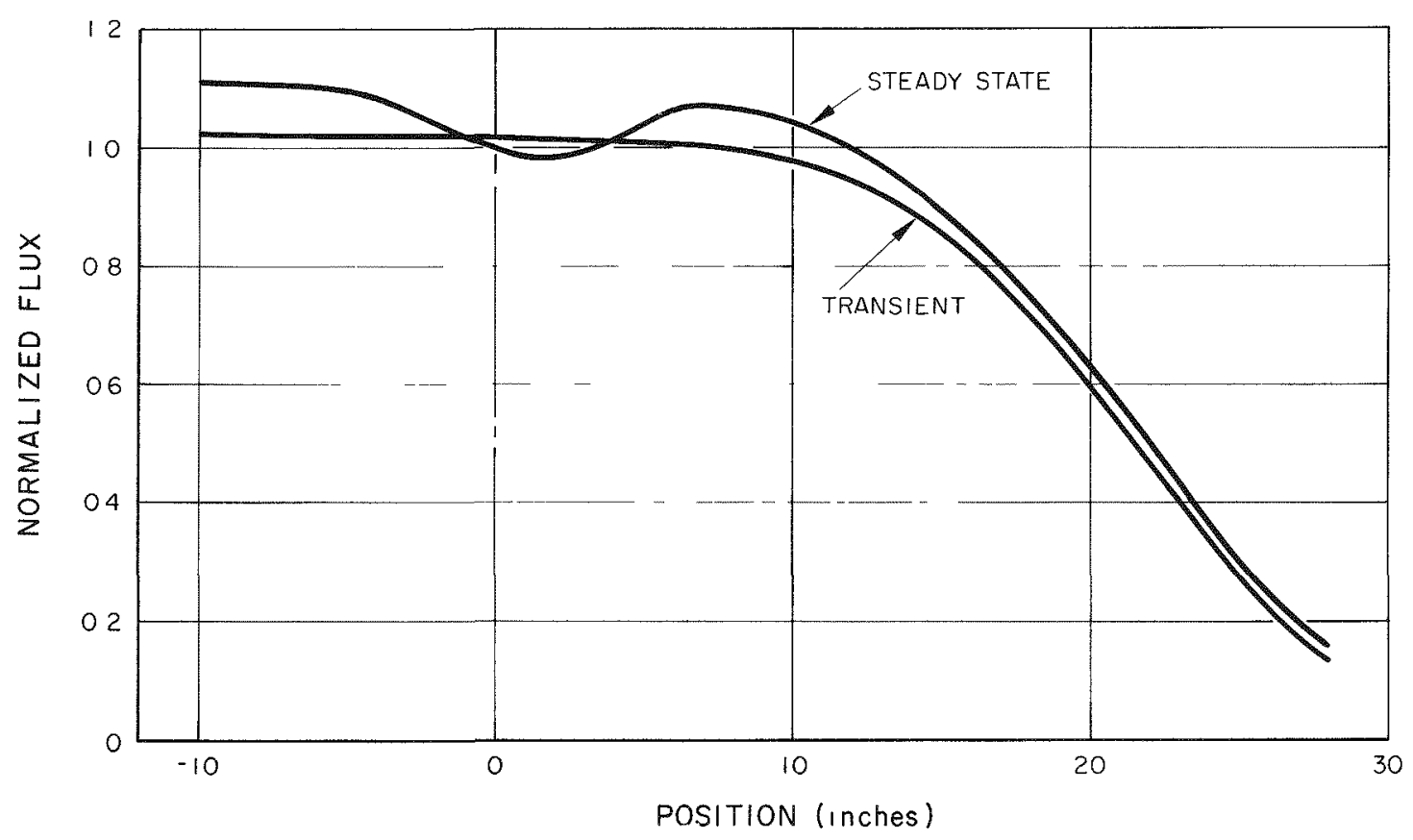

Figure 37. Transient and Steady-State Thermal Flux Distribution in Horizontal Exposure Facility Using $1 \mathrm{~cm}^{2}$ Au Foils.

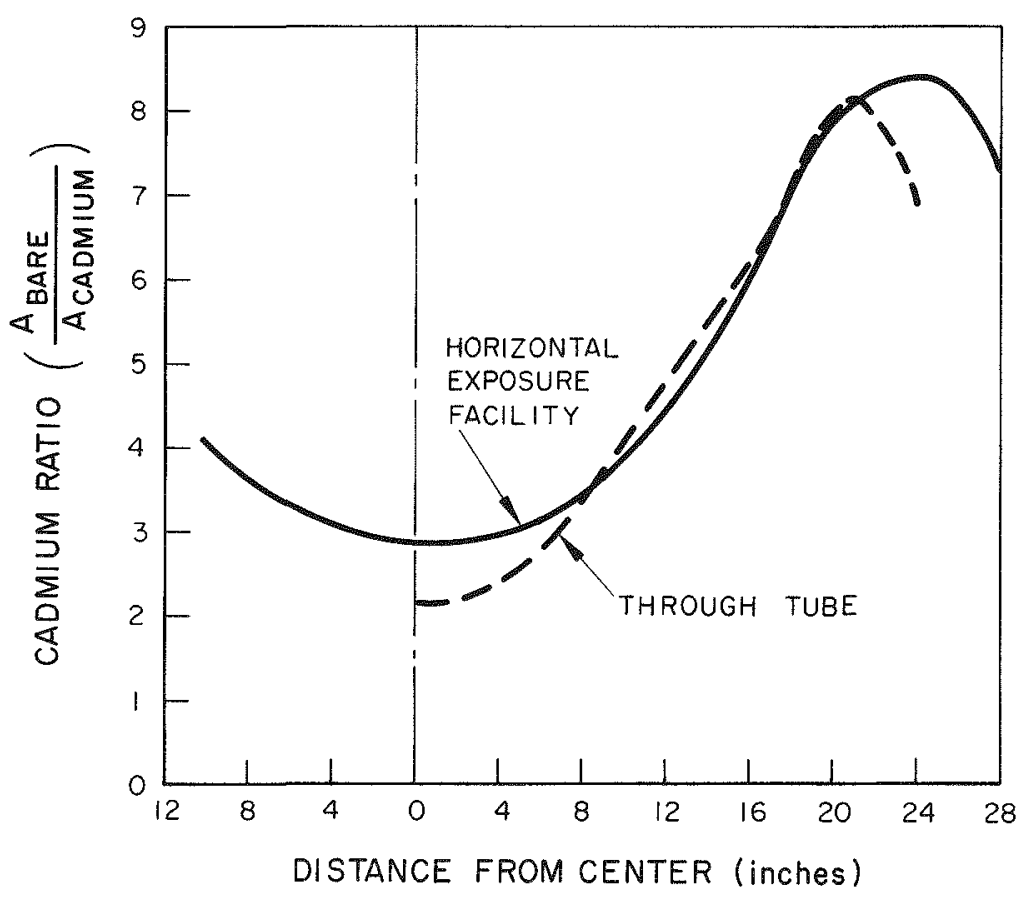

Figure 38. Cadmium Ratio in Horizontal Through-Tube and Exposure Facility for $3.2 \mathrm{msec}$ Transient 


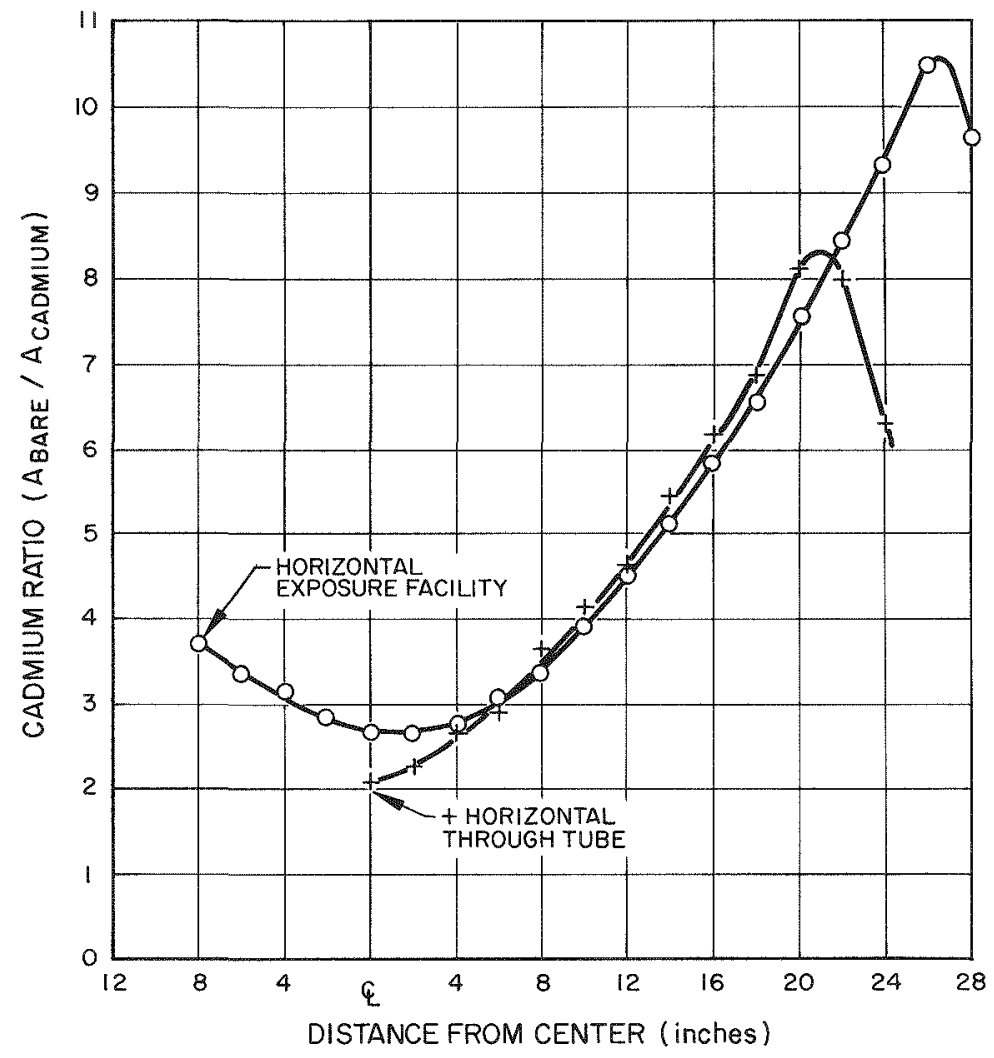

Figure 39. Cadmium Ratio in Horizontal Through-Tube and Exposure Facility for Steady-State.

$$
Q=W_{f} C_{p} \Delta T
$$

where

$$
\begin{aligned}
C_{p} & =\text { heat capacity of coolant } \\
Q & =\text { the rate of heat removal by the coolant } \\
W_{f} & =\text { the coolant flow rate } \\
\Delta T & =\text { the temperature difference of the inlet and outlet coolant. }
\end{aligned}
$$

For the KEWB reactor system this reduced to the form

$$
\mathrm{CTP}=5.08 \cdot \mathrm{F} \cdot \Delta \mathrm{V} \quad(\mathrm{kw})
$$

where

$$
F=\text { the coolant flow rate in } \mathrm{gpm}
$$

$\Delta V=$ the difference, in millivolts, of the iron-constantan inlet and outlet thermocouple potentials. 
The procedure used was to operate tire reactor at a stable power such that the micro-microammeter current reading was $0.5 \times 10^{-6}$ amps with a constant coolant flow rate of $1.16 \mathrm{gpm}$. The reactor was operated at this power level for about one $\mathrm{hr}$ to insure thermal equilibrium in the system. Frequent temperature readings were made during the calibration to obtain the best time average of the power level. Obtaining the reactor power level from the CTP determination gave the power calibration of the micro-microammeter for $0.5 \times 10^{-6}$ amps. This was then used for the calibration of all other power detecting and recording systems.

Data from a typical CTP calibration is shown in Table I and is plotted in Figure 40 .

TABLE I

COOLANT THERMAL POWER CALIBRATION DATA

\begin{tabular}{|c|c|c|c|c|}
\hline $\begin{array}{l}\text { Time } \\
\text { (min) }\end{array}$ & $\begin{array}{c}\text { Inlet } \\
\text { Coolant } \\
\text { Temp } \\
\text { (my) }\end{array}$ & $\begin{array}{l}\text { Outlet } \\
\text { Coolant } \\
\text { Temp } \\
(\mathrm{mv})\end{array}$ & $\Delta V$ & $\begin{array}{l}\mathrm{CTP} \\
(\mathrm{kw})\end{array}$ \\
\hline 11 & 0.955 & 1.540 & 0.585 & 3.45 \\
\hline 14 & 0.955 & 1.564 & 0.609 & 3.58 \\
\hline 20 & 0.960 & 1.592 & 0.632 & 3.72 \\
\hline 25 & 0.990 & 1.613 & 0.623 & 3.68 \\
\hline 28 & 1.010 & 1.629 & 0.619 & 3.67 \\
\hline 30 & 1.015 & 1.642 & 0.627 & 3.64 \\
\hline 35 & 1.030 & 1.665 & 0.635 & 3.70 \\
\hline 40 & 1.034 & 1.680 & 0.646 & 3.74 \\
\hline 44 & 1.036 & 1.686 & 0.650 & 3.81 \\
\hline 47 & 1.036 & 1.685 & 0.649 & 3.83 \\
\hline 50 & 1.040 & 1.685 & 0.645 & 3.82 \\
\hline 53 & 1.039 & 1.690 & 0.651 & 3.80 \\
\hline 56 & 1.037 & 1.690 & 0.653 & 3.84 \\
\hline 58 & 1.036 & 1.690 & 0.654 & 3.85 \\
\hline 60 & 1.037 & 1.691 & 0.654 & 3.85 \\
\hline 61 & 1.035 & 1.691 & 0.656 & 3.86 \\
\hline 63 & 1.035 & 1.691 & 0.656 & 3.86 \\
\hline 65 & 1.035 & 1.691 & 0.656 & 3.86 \\
\hline
\end{tabular}




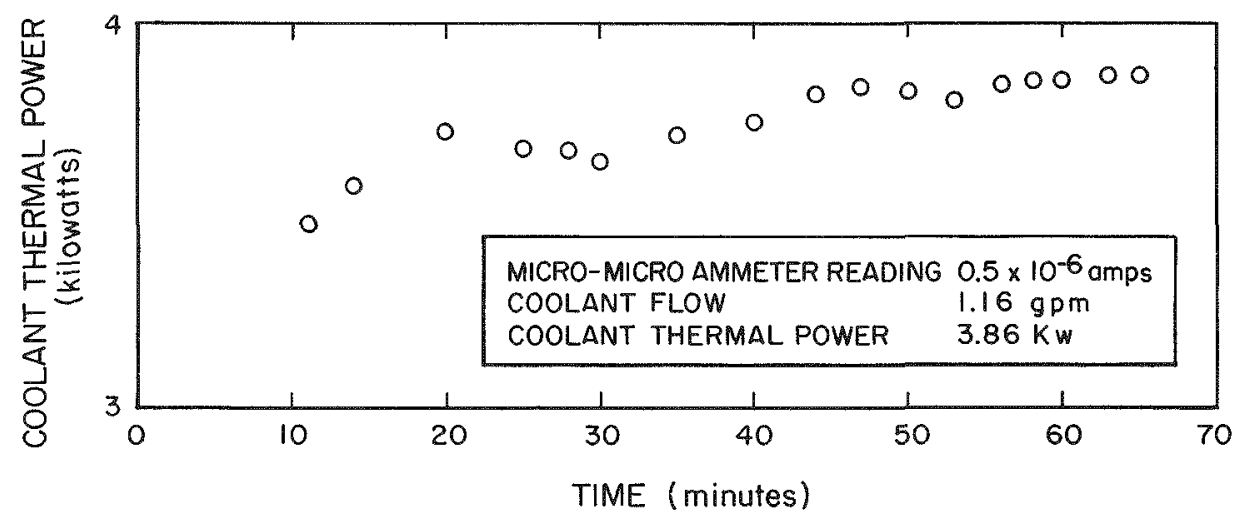

Figure 40. Coolant Thermal Power Calibration Plot. 


\section{CORE CHARACTERISTICS}

The reactor was made critical on July 13, 1956 with highly enriched uranium in the form of uranyl sulfate solution. The critical loading at room temperature was $1680 \mathrm{gm}$ of $\mathrm{U}^{235}$. This determination was obtained with $11.0 \mathrm{l}$ of fuel solution in the sphere. An additional $0.45 \ell$ of solution was added to load the reactor to $4 \%$ $(\$ 5.00)$ excess reactivity. This resulted in a fuel volume of $11.45 \ell$ and a void volume in the sphere above the solution of $2.2 \mathrm{l}$ which is approximately $16 \%$ of the spherical core volume.

For the investigation of the full core case, it was necessary to adjust the fuel volume and contained $U^{235}$ to achieve a condition of $4 \%$ excess loading with $13.65 \ell$ of solution in the core.

Since the addition of water resulted in an increase in reactivity (See Table II) it was necessary to remove fuel solution to reduce the loading and then add water until the core was full. This was accomplished by removing fuel solution containing $480 \mathrm{gm}$ of $\mathrm{U}^{235}$ and then adding water in a series of aliquots until the solution volume was 13.45 l. A control rod calibration was then made at the new solution level and the excess reactivity adjusted to $4 \%$.

Table II gives a comparison of the characteristics of the spherical core for the full and underfull cases. 
TABLE II

KEWB SPHERICAL CORE CHARACTERISTICS

\begin{tabular}{|c|c|c|}
\hline Items & $85 \%$ full core & Full core \\
\hline 1. Mass of $\mathrm{U}^{235}$ in core for critical $(\mathrm{gm})$ & 1680 & 1240 \\
\hline 2. Mass of $U^{235}$ in core for $4 \%(\$ 5)$ excess $(\mathrm{gm})$ & 1905 & 1450 \\
\hline 3. Mass of $\mathrm{U}^{238}$ in core for $4 \%(\$ 5)$ excess $(\mathrm{gm})$ & 138 & 106 \\
\hline 4. Fuel concentration at $4 \%(\$ 5)$ excess $\left(g m U^{235} / \ell\right.$ ) & 166 & 106 \\
\hline 5. Fuel enrichment $(\%)$ & 93.2 & 93.2 \\
\hline 6. Mass of sulphure in core ( $\mathrm{gm})$ & 440 & 423 \\
\hline $\begin{array}{l}\text { 7. Total mass of water in fuel solution and } \\
\text { cooling coils }(\mathrm{gm})\end{array}$ & 11,240 & 13,660 \\
\hline 8. Volume of fuel solution in core vessel $(l)$ & 11.45 & 13.65 \\
\hline 9. Mass of stainless steel in cooling coils ( $\mathrm{gm}$ ) & 2880 & 2880 \\
\hline $\begin{array}{l}\text { 10. Mass of stainless steel in control rod thimbles } \\
\text { and horizontal through-tube ( } \mathrm{gm})\end{array}$ & 2941 & 2941 \\
\hline 11. Volume of water in cooling coils $(\ell)$ & 0.68 & 0.68 \\
\hline 12. Volume of void above liquid level in the sphere $(\ell)$ & 2.20 & 0.0 \\
\hline 13. Radius of core, inside $(\mathrm{cm})$ & 15.6 & 15.6 \\
\hline $\begin{array}{l}\text { 14. Nominal thickness of stainless steel core } \\
\text { vessel (in.) }\end{array}$ & $1 / 4$ & $1 / 4$ \\
\hline 15. Control rod worth $(\$)$ & 8.65 & 9.16 \\
\hline 16. Average critical rod position (in.) & 3.00 & 3.90 \\
\hline $\begin{array}{l}\text { 17. Reflector dimensions (unmachined graphite logs) } \\
\text { (cm cube) }\end{array}$ & 142 & 142 \\
\hline 18. Average density of reflector $\left(\mathrm{gm} / \mathrm{cm}^{3}\right)$ & 1.55 & 1.55 \\
\hline $\begin{array}{l}\text { 19. Void volume in control rod thimbles and } \\
\text { horizontal through-tube }(\ell)\end{array}$ & 0.83 & 0.93 \\
\hline 20. $\mathrm{H} / \mathrm{U}^{235}$ ratio & 150 & 260 \\
\hline 21. Mass coefficient of reactivity $\left(\$ / \mathrm{gm} \mathrm{U}^{235}\right)$ & 0.014 & 0.016 \\
\hline 22. Water coefficient of reactivity $(\$ / c c)$ & 0.0027 & 0.009 \\
\hline $\begin{array}{l}\text { 23. Temperature coefficient of reactivity } \\
\text { at } 30^{\circ} \mathrm{C}\left(\$ /{ }^{\circ} \mathrm{C}\right) \\
\text { at } 80^{\circ} \mathrm{C}\left(\$ /{ }^{\circ} \mathrm{C}\right)\end{array}$ & $\begin{array}{l}-0.020 \\
-0.032\end{array}$ & $\begin{array}{l}-0.041 \\
-0.052\end{array}$ \\
\hline 24. Power coefficient $(\$ / \mathrm{kw})$ & 0.013 & 0.028 \\
\hline $\begin{array}{l}\text { 25. Gas production coefficient } \\
\left.\text { (stoichiometric } \mathrm{H}_{2}-\mathrm{O}_{2} \mathrm{STP}\right)(\ell / \mathrm{kwh})\end{array}$ & 15.6 & 18.1 \\
\hline
\end{tabular}




\section{DETAILS OF EXPERIMENTAL DATA}

The experimental program included investigation of the following parameters:

a) Amount of reactivity release,

b) Rate at which reactivity is inserted,

c) Effects of initial pressure, temperature, power, and void volume in reactor core, and

d) Interaction effects of the gas recombination system.

The amount of reactivity released has been varied from very small in puts to about $4 \% \Delta \mathrm{k}(\$ 5)$. The largest reactivity input gave rise to an asymptotic period of $2 \mathrm{msec}$. Reactivity has been inserted as a step and at various ramp rates which correspond to the withdrawal of one control rod or two, three, or four rods simultaneously. The effect of initial temperature pressure, power, and void volume in the core was investigated for various total reactivity inputs and rates of reactivity insertion.

\section{A. STEP REACTIVITY INSERTIONS}

Step inputs of reactivity were investigated for inputs up to $4 \%(\$ 5)$. The initial fuel temperature was $25^{\circ} \mathrm{C}$, initial power level $10^{-3} \mathrm{w}$, and no coolant flowing. The core atmosphere was stoichiometric $\mathrm{H}_{2}-\mathrm{O}_{2}$, and special procedures were followed to insure that the fuel solution was saturated with this atmosphere. It was noted that the lack of saturation control led to erratic results, with unsaturated transients having up to $20 \%$ higher peak powers for the slower excursions.

The transient initiation sequence is as follows: (1) The control rod positions for low power criticality, $25^{\circ} \mathrm{C}$ initial temperature, and the desired system pressure are observed and reactivity increment calculations are based on the se positions. This compensates for small reactivity fluctuations due to uncontrolled parameters. (2) The poison rod for the reactivity device is inserted in the horizontal through-tube and the reactor power allowed to decay to $10^{-3} \mathrm{w}$ or less. (3) The control rods are then withdrawn the distance required to make available the desired excess reactivity. The reactor is maintained subcritical during this control rod withdrawal by the poison rod in the through-tube. (4) A sequence timer automatically initiates the activation of the recording instruments and ejection of the poison rod. (5) The transient is normally terminated shortly after the peak power by an operator-initiated manual scram. 
Step input transients were run with both the pneumatic and mechanical reactivity devices. There was no difference in the results obtained for any stepinput investigated with low initial power levels. This is because the slowest withdrawal. that obtained with the mechanical device, was fast enough to insert the total reactivity before the reactor power level reached the readable detection level of the power recording devices. For transients initiated at higher initial power levels, the pneumatic device, with its faster withdrawal time, was used exclusively.

Data were obtained to determine the effect of total reactivity input on maximum power and maximum pressure. Figure 41 presents typical transient recordings of the power and pressure for two fuel solution volumes $(85 \%$ full and full core). It will be noted that when the core was initially filled with fuel solution, that is. when there was no void volume in the spherical portion of the core vessel, pressure transducers at the top and bottom of the core, which were both below

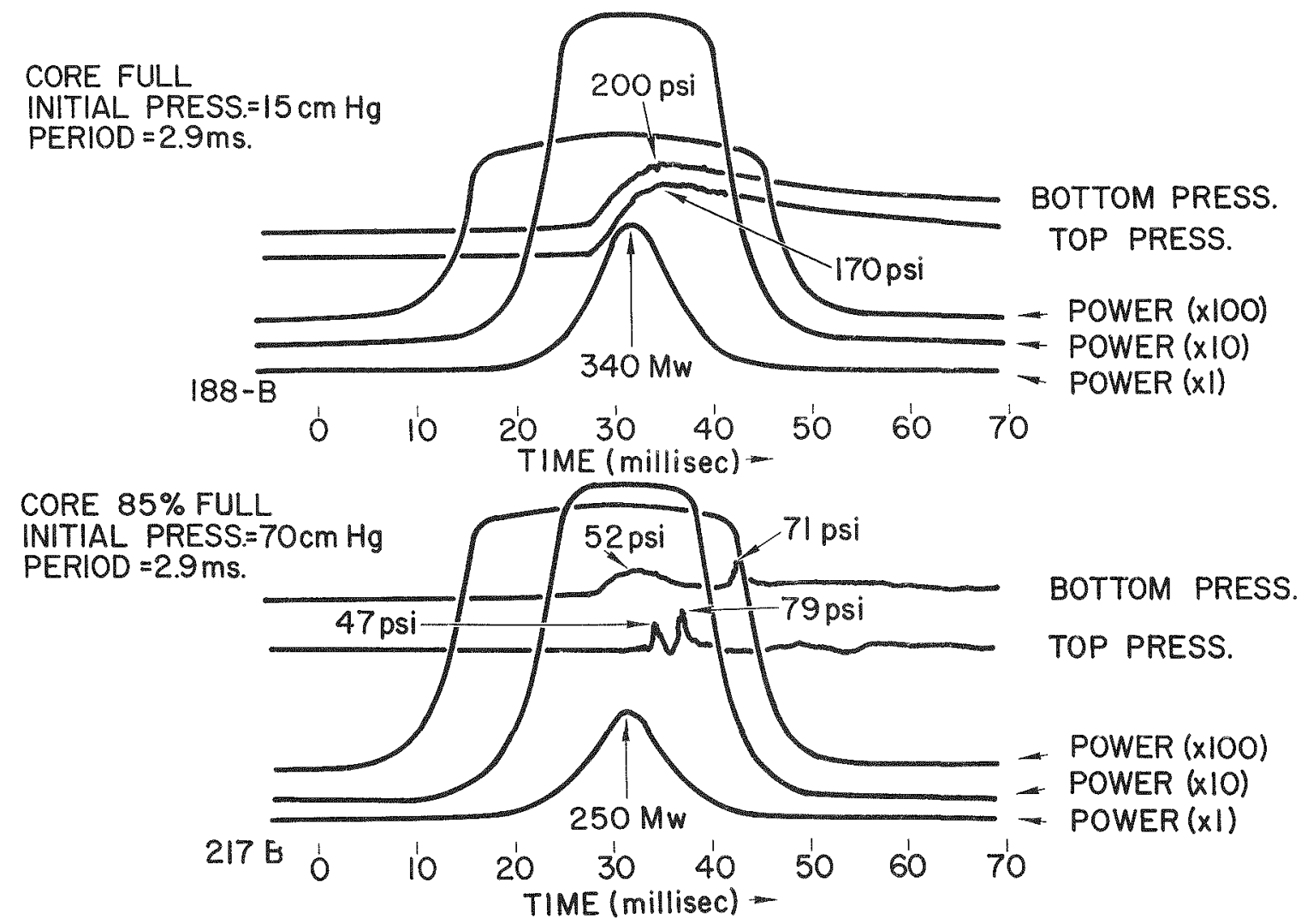

Figure 41. Typical Transient Recordings 
the surface of the fuel solution. gave essentially the same smoothly varying function. In the lower trace it may be seen that the underfull condition, where the top transclucer was initially above the fuel surface, gave rise to a similar smoothly varying function at the bottom of the core which was followed by two sharp pressure pulses at the top of the core and then a sharp pulse at the bottom. The first sharp pulse at the top of the core is believed to be caused by the rising fucl solution striking the transducer. The second sharp pulse at the top of the core and the sharp pulse at the bottom are believed to have originated when the orifice restriction between the core and overflow chamber impeded solution expansion. The time delay between these two pulses is consistent with the time required for a pressure wave to travel the distance between the pressure transducers in a liquid-gas mixture such as is found in the core vessel at that time.

In Figure 42 the maximum power achieved by the reactor following a step input of reactivity which gave rise to the periods indicated is presented. Tabular data is given in Tables III and IV. The effects of varying two of the major parameters investigated, intial pressure and initial void volume in the core vessel, are shown. For the $85 \%$ full core case (the standard loading for this type reactor) there was some pressure dependence for periods longer than prompt critical.

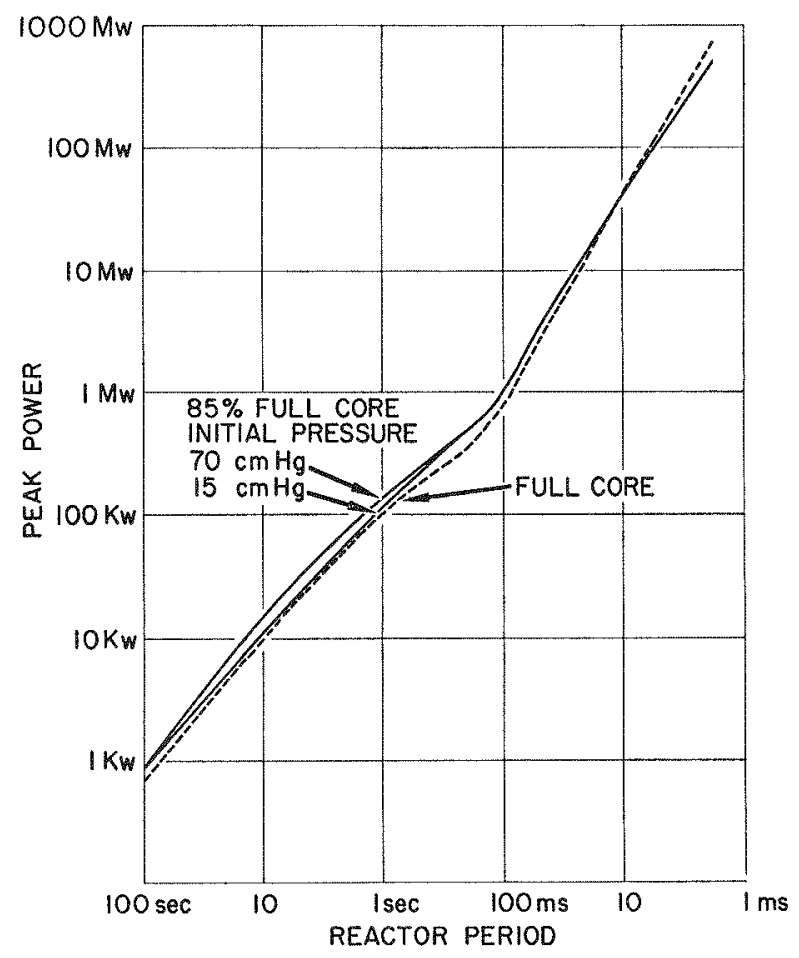

Figure 42. Peak Power vs Reactor Period 
TABLE III

SUMMARY OF DATA FOR STEP INPUT TRANSIENTS, 85\% FULL CORE.

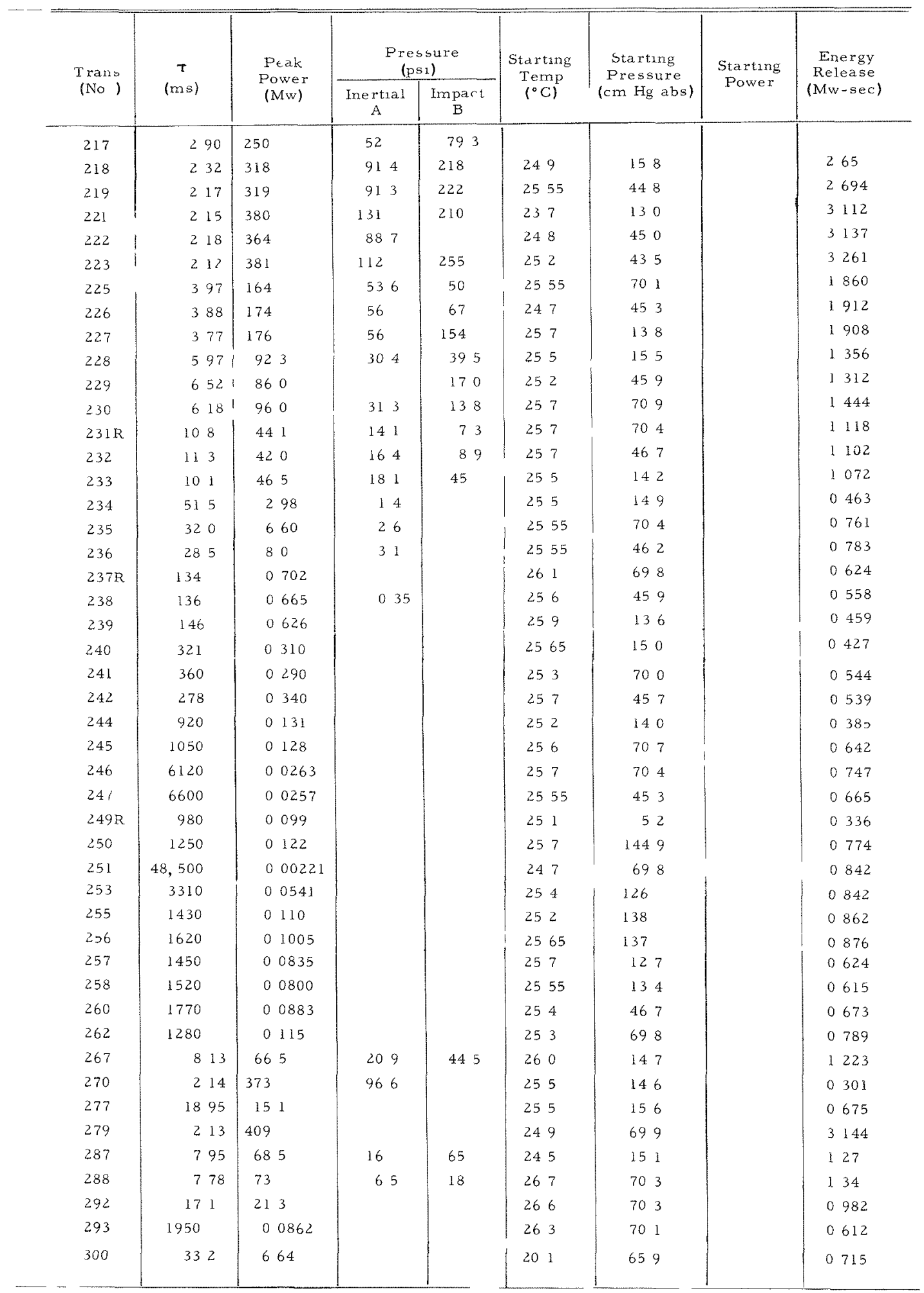


TABLE IV

SUMMARY CF DATA FOR STEP INPUT TRANSIENTS, FULL CORE

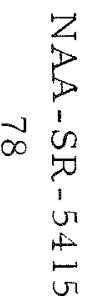

\begin{tabular}{|c|c|c|c|c|c|c|c|c|}
\hline \multirow{2}{*}{$\begin{array}{l}\text { Trans } \\
\text { (No.) }\end{array}$} & \multirow{2}{*}{$\begin{array}{c}T \\
(m s)\end{array}$} & \multirow{2}{*}{$\begin{array}{l}\text { Peak } \\
\text { Power } \\
\text { (Mw) }\end{array}$} & \multicolumn{2}{|c|}{$\begin{array}{c}\text { Pressure } \\
\text { (psi) }\end{array}$} & \multirow{2}{*}{$\begin{array}{c}\text { Starting } \\
\text { Temp } \\
\left({ }^{\circ} \mathrm{C}\right)\end{array}$} & \multirow{2}{*}{$\begin{array}{c}\text { Starting } \\
\text { Pressure } \\
(\mathrm{cm} \mathrm{Hg} \text { abs })\end{array}$} & \multirow{2}{*}{$\begin{array}{l}\text { Starting } \\
\text { Power }\end{array}$} & \multirow{2}{*}{$\begin{array}{r}\text { Energy } \\
\text { Release } \\
\text { (Mw-sec) }\end{array}$} \\
\hline & & & $\begin{array}{l}\text { Bottom } \\
\text { Inertial }\end{array}$ & Top & & & & \\
\hline 172 & 205 & 12.4 & 5.64 & 4.75 & 257 & 304 & & 074 \\
\hline 173 & 243 & 119 & 4.14 & 328 & 256 & 70.1 & & 088 \\
\hline 174 & 114 & 43.1 & 286 & 26.4 & 25.6 & 70.2 & & 1.33 \\
\hline 176 & 5.25 & 137. & 93.0 & 76.2 & 255 & 70.1 & & 2.13 \\
\hline 177 & 4.09 & 200 & 135 & 117 & 255 & 70.2 & & 260 \\
\hline 181 & 2.68 & 366 & 214 & 192 & 26.6 & 71.5 & & 3.89 \\
\hline 183 & 1.82 & 773 & 620 & 541 & 26.5 & 67.5 & & 6.38 \\
\hline 186 & 5.03 & 137 & 83.1 & 77 & 244 & 14.2 & & 2.02 \\
\hline 188 & 2.92 & 341 & 203 & 170 & $\sim 25$ & 147 & & \\
\hline 191 & 1.98 & 682 & 442 & 393 & 26.5 & 146 & & 582 \\
\hline 201 & 1010 & 0.0901 & & & 26.4 & 70.6 & & 027 \\
\hline 202 & 200 & 0.248 & & & 25.5 & 70.2 & & 0.43 \\
\hline 203 & 117 & 0.630 & & & 26.1 & 70.4 & & 0.45 \\
\hline 205 & 9.55 & 48.15 & 49.8 & 44.4 & 25.5 & 69.9 & & 1.40 \\
\hline 206 & 891 & 0.103 & & & 25.5 & 151 & & 028 \\
\hline 208 & 110 & 0.705 & & & 25.6 & 15.2 & & 0.34 \\
\hline 209 & 2.38 & 525 & & & 25.7 & 5.1 & & 4.51 \\
\hline 210 & 10.1 & 43.2 & 34.8 & 30.8 & 25.5 & 46 & & 1.23 \\
\hline 211 & 1.97 & 707 & 420 & 421 & 238 & 14.8 & & 684 \\
\hline 212 & 538 & 214 & & & 256 & 146 & & 033 \\
\hline 213 & 3020 & 00309 & & & 256 & 148 & & 018 \\
\hline 214 & 16.4 & 18.2 & 84 & 78 & 257 & 148 & & 0.82 \\
\hline 215 & 26.3 & 8.53 & 4.8 & 35 & 254 & 15.6 & & 060 \\
\hline
\end{tabular}


Under all other circumstances, for both the $85 \%$ full and full core cases, the reactor did not exhibit any sensitivity to initial system pressure.

The full core peak powers are less than those for the $85 \%$ full case down to periods of about $10 \mathrm{msec}$. For shorter periods, the full core resulted in higher peak powers. Since the full core had larger reactivity coefficients, one would expect the peak power to have been lowex in all cases; however, the energy coefficient of reactivity decreased for very short periods in the full core case. In the region where the two curves cross, significant interial pressures were beginning to be generated in the full core runs and it is probable that these pressures were responsible for the reduction of the energy coefficients of reactivity in the full core and thus gave rise to the higher maximum powers. The maximum powers achieved for $2 \mathrm{msec}$ transients were $460 \mathrm{Mw}$ for the $80 \%$ full core and $680 \mathrm{Mw}$ for the full core.

The maximum inertial pressures detected in the spherical portion of the core vessel during these step input transients are given in Figure 43, for both the full and underfull cases. No appreciable pressure pulses were seen for transients having periods longer than 10 to $20 \mathrm{msec}$. As mentioned previously, the expansion pressures in the full core case were essentially the same at top and bottom of the core vessel. The expansion pressure for the underfull core, which was seen only at the bottom of the core, was less than for the full core case. The maximum impact and reflective pressures observed in the underfull case are also given in Figure 43; they were about the same magnitude as the maximum expansion pressures for the full core.

The expansion pressure data were taken with the galvanometer recording system, using a CEC strain wire pressure transducer. The impact pressure data given were taken with the fast transient pressure system, using Statham transducers and oscilloscope recording. This system was designed to measure the pressures generated by hydrogen-oxygen explosions and has no responsetime limitations insofar as these pressure pulses are concerned. The galvanometer recording system used has frequency response limitations which lead to values for the impact data which were about $30 \%$ lower than those obtained with the fast recording system. Considerable scatter was observed in the magnitude of the first sharp pressure pulse observed at the top of the core, but in all cases it was considerably less than the impact pressure given in Figure 43. 
Since this pulse is believed to be caused by the surface of the fuel solution striking the diaphragm of the transducer, the scatter is to be expected.

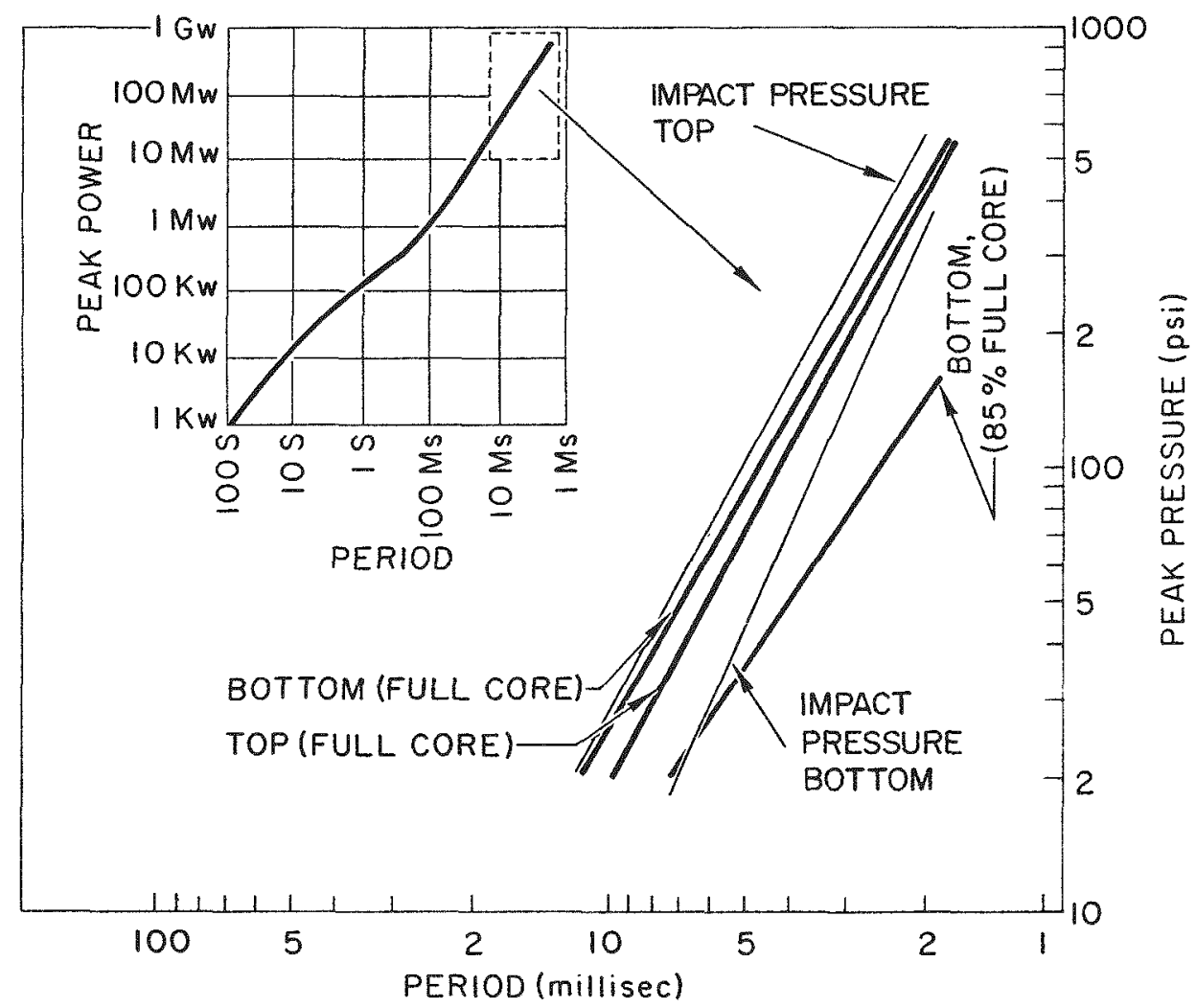

Figure 43. Peak Pressure vs Period

The maximum expansion pressure seen in the system for any initial condition was 620 psi which was recorded at the bottom of the core for the full core case. The maximum impact pressure observed was 680 psi at the top of the coxe. This is greater in magnitude than the 600 psi design pressure of some conventional aqueous solution reactors, but since it is of very short duration there is no danger of damaging the vessel. A study of the effects of sharp pressure pulses on the core vessel was conducted by M. Greenfield. The results of this study are given in Part IV of this series of reports. ${ }^{2}$

The effect of varying the initial temperature of the fuel solution was investigated for five different stable reactor periods and two initial core pressures for the underfull core. The results of these investigations are given in Figure 44 
and Table $\mathrm{V}$. The maximum power is observed to decrease slightly with increasing temperature for an initial pressure of $70 \mathrm{~cm} \mathrm{Hg}$ for all stable periods investigated. The maximum initial temperature runs were made at $90^{\circ} \mathrm{C}$, since the fuel solution boils at about $95^{\circ} \mathrm{C}$ at a pressure of $70 \mathrm{~cm} \mathrm{Hg}$.

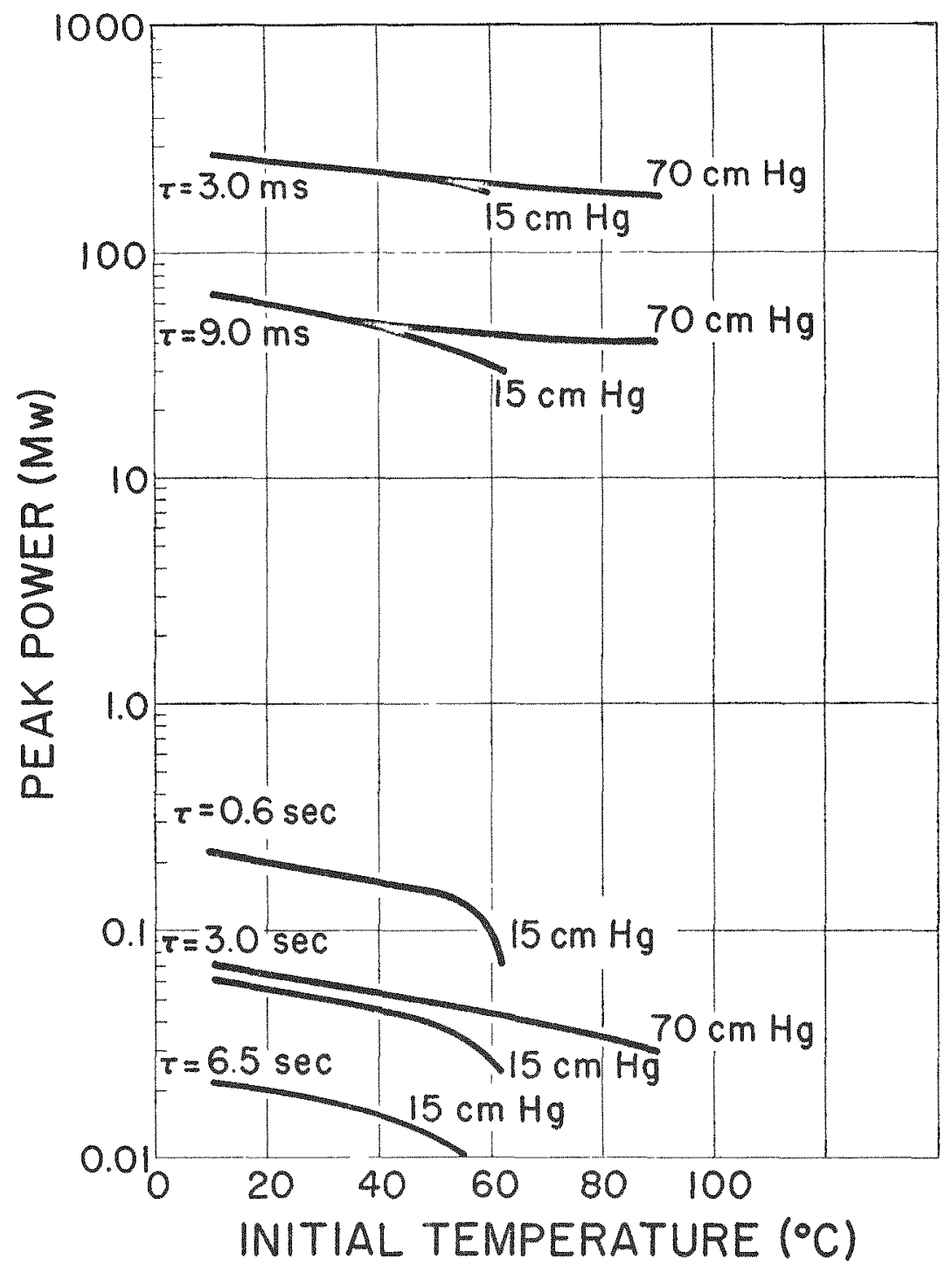

Figure 44. Peak Power vs Initial Temperature, Core Vessel $85 \%$ Full of Fuel Solution

A rather sharp decrease in peak power was noted for the $15 \mathrm{~cm} \mathrm{Hg}$ initial pressure runs at intermediate temperatures. This was to be expected since the boiling point of the fuel solution is only $61^{\circ} \mathrm{C}$ at this pressure. The temperature at which this sharp decrease in the peak power occurred increases with 
TABLE V

SUMMARY OF DATA FOR EFFECTS

OF INITIAL FUEL TEMPERATURE ON STEP INPUT TRANSIENTS, 85\% FULL CORE

\begin{tabular}{|c|c|c|c|c|c|c|c|}
\hline \multirow{2}{*}{$\begin{array}{l}\text { Trans } \\
\text { (No.) }\end{array}$} & \multirow{2}{*}{$\stackrel{T}{(\mathrm{~ms})}$} & \multirow{2}{*}{$\begin{array}{l}\text { Peak } \\
\text { Power } \\
\text { (Mw) }\end{array}$} & \multicolumn{2}{|c|}{$\begin{array}{c}\text { Pressure } \\
\text { (psi) }\end{array}$} & \multirow{2}{*}{$\begin{array}{l}\text { Starting } \\
\text { Temp } \\
\left({ }^{\circ} \mathrm{C}\right)\end{array}$} & \multirow{2}{*}{$\begin{array}{c}\text { Starting } \\
\text { Pressure } \\
\text { (cm Hg abs) }\end{array}$} & \multirow{2}{*}{$\begin{array}{r}\text { Energy } \\
\text { Release } \\
(\mathrm{Mw}-\mathrm{sec})\end{array}$} \\
\hline & & & Inertial & Impact & & & \\
\hline 99 & 8.8 & 69.2 & 11.8 & 13.0 & 9.5 & 70.1 & 1.401 \\
\hline 100 & 7.12 & 56.4 & 15.3 & 19.8 & 77.3 & 69.8 & 0.927 \\
\hline 101 & 10.74 & 33.4 & & & 61.5 & 69.9 & 0.933 \\
\hline 103 & 8.59 & 57.0 & 11.1 & 11.7 & 35.0 & 70.2 & 1.110 \\
\hline 104 & 9.68 & 36.0 & 10.1 & 14.6 & 86.2 & 70.3 & 0.751 \\
\hline 105 & 3.05 & 190.5 & 94 & 103 & 66.7 & 70.0 & 1.745 \\
\hline 106 & 2.45 & 227 & 83.5 & 119 & 93.7 & 70.0 & 2.472 \\
\hline 107 & 3.27 & 239 & 60.0 & 67.5 & 11.7 & 69.7 & 2.262 \\
\hline 122 & 2.97 & 204 & & & 57.8 & 15.2 & 2.264 \\
\hline 123 & 8.67 & 51.35 & & & 29.6 & 15.0 & 1.125 \\
\hline 126 & 9.93 & 26.8 & & & 60.1 & 15.2 & 0.656 \\
\hline 127 & 9.49 & 36.45 & & & 50.8 & 14.8 & 0.925 \\
\hline 129 & 8.82 & 64.8 & & & 12.0 & 14.9 & 1.345 \\
\hline
\end{tabular}


decreasing stable period. These results show the significant effect of vapor formation in contributing to shutdown of longer period transients and the relative decrease in this effect as the period decreases. As shown in Figure 44, the effect of initial pressure decreased as the periods decreased; and for a $3-\mathrm{msec}$ stable period only a slight defference is noted near $60^{\circ} \mathrm{C}$. Figure 45 shows the results of a similar series of transients with $1.0-\mathrm{sec}$ stable period run with the core completely filled with fuel solution. The initial core pressure for these transients was $15 \mathrm{~cm} \mathrm{Hg}$. The effect of increased initial temperature is shown to be similar for the full core case as that seen for the underfull, but was somewhat larger and occurs at lower temperatures. This is attributed to the larger reactivity coefficients that are effective for the full core with transients in this stable period region.

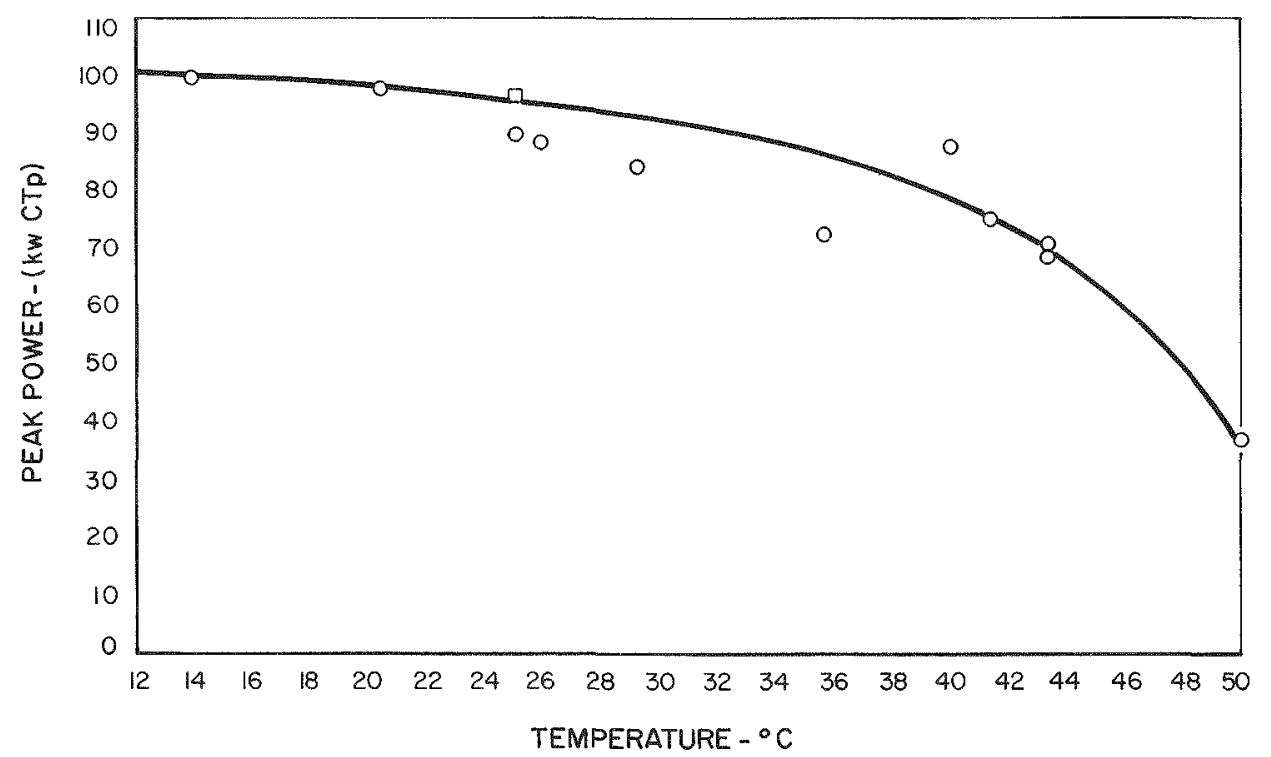

Figure 45. Peak Power vs Initial Temperature, Core Vessel Full of Fuel Solution.

The power traces have been integrated to obtain values of the energy release in the power pulses. Figure 46 shows how these energy releases vary as a function of reactor period for both the full and underfull cases. Data are given here for energy release to the time of peak power and total energy released in the burst. For periods of about 0.5 seconds it is noted that more than half the energy is released up to the time of peak power. The power pulses in this region were asymmetric in that the leading edge of the pulse is a more slowly 


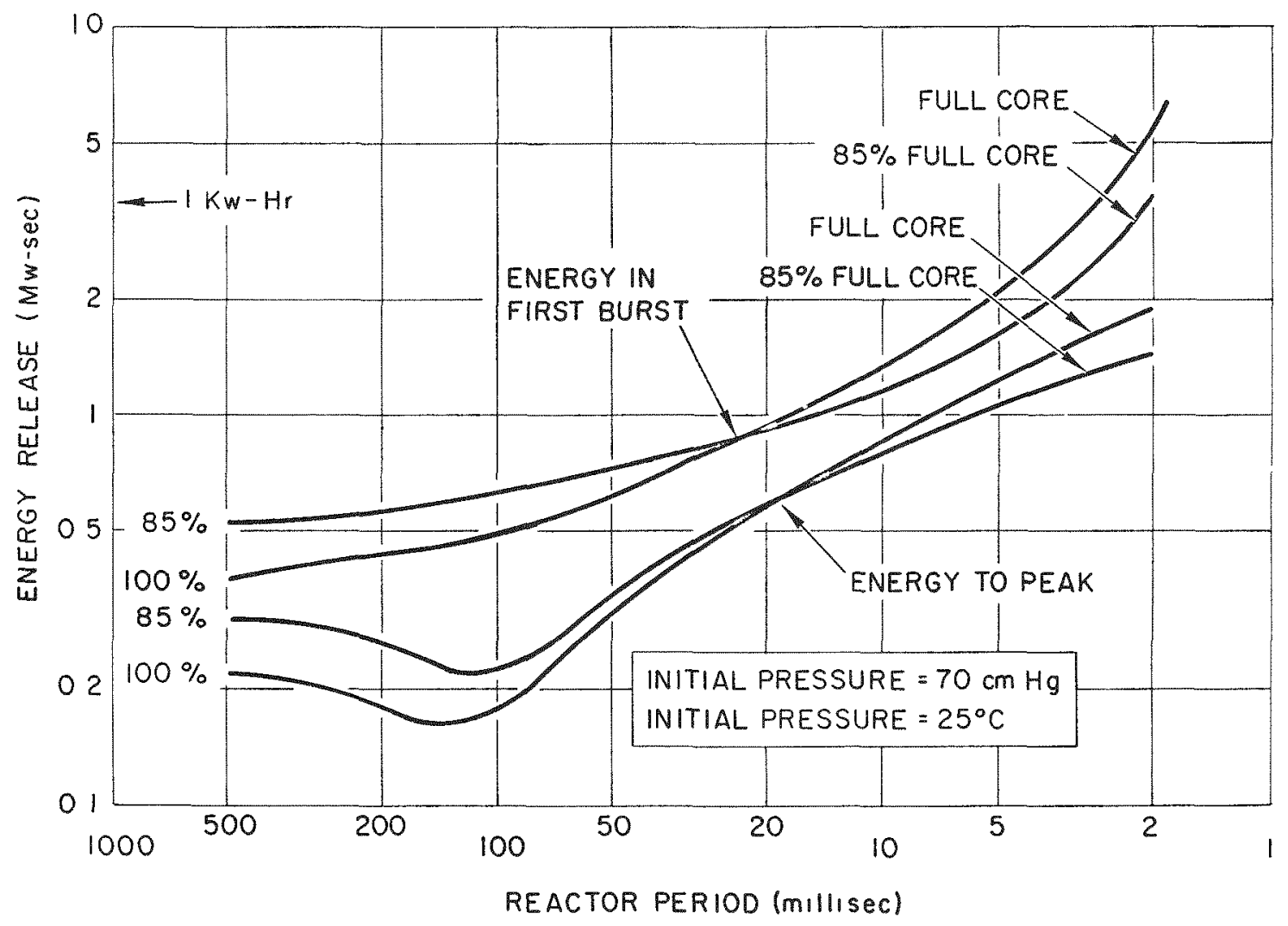

Figure 46. Energy Release vs Stable Period

varying function than the trailing edge. See Figure 47. For periods of about 200 milliseconds the pulse became symmetrical with equal energy released before and after peak power. See Figure 48 . In the region around prompt

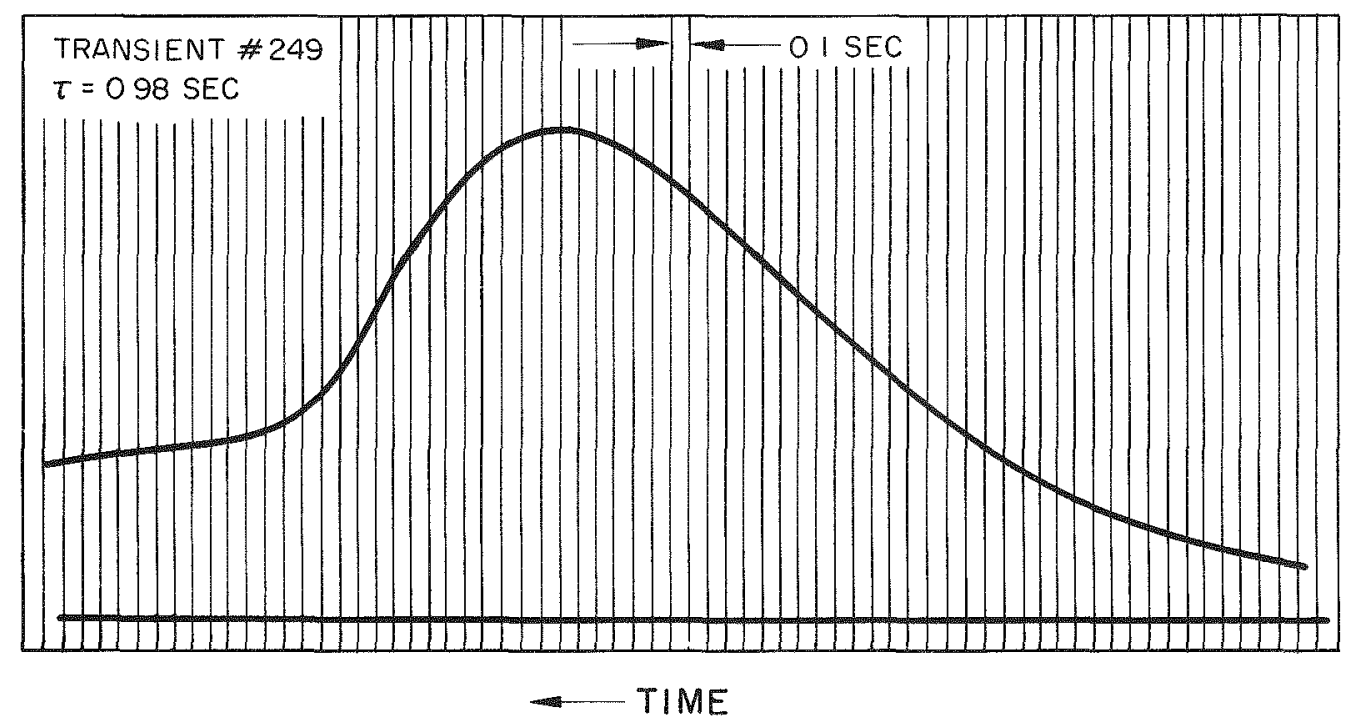

Figure 47. Oscillogram for Transient No. 249 B, Stable Period 0.98 sec. 


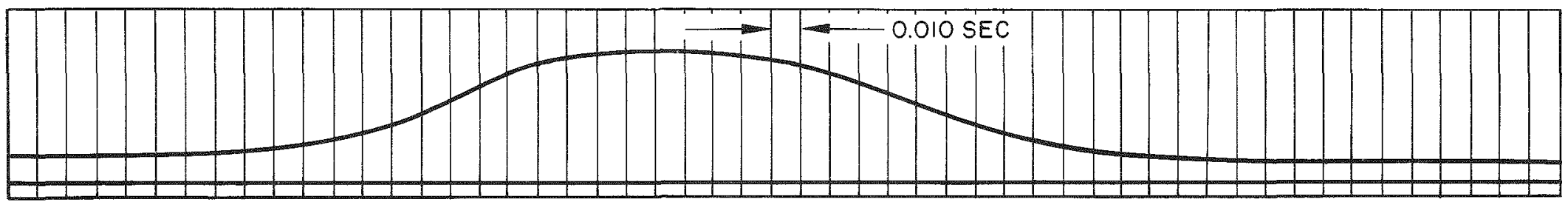

- TIME

Figure 48. Oscillogram for Transient No. 202 BR, Stable Period $200 \mathrm{msec}$

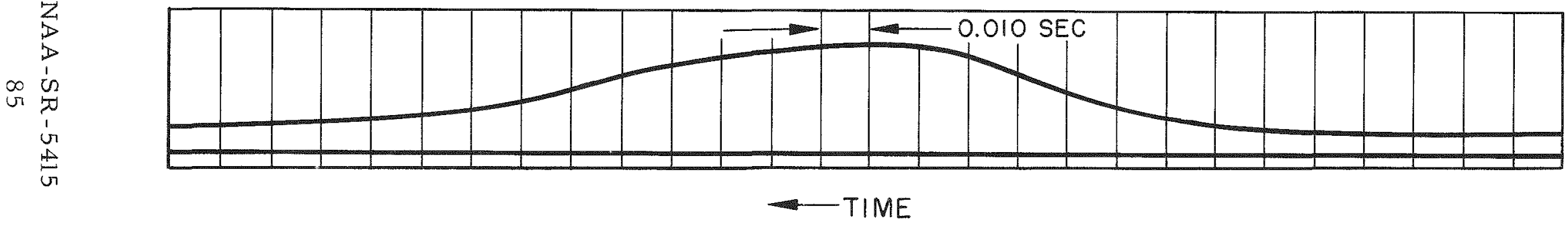

Figure 49. Oscillogram for Transient No. $204 \mathrm{~B}$, Stable Period $153 \mathrm{msec}$

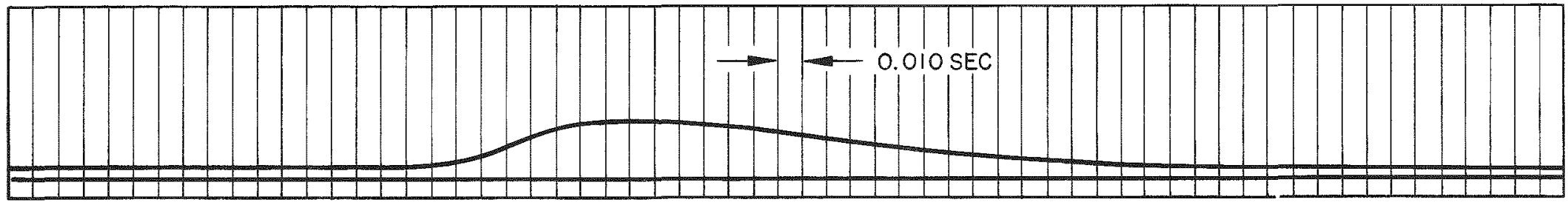

- TIME

Figure 50. Oscillogram for Transient No. $234 \mathrm{~B}$, Stable Period $51.1 \mathrm{msec}$ 
critical the pulse became asymmetric in the opposite direction, i. e. the tail of the burst is a more slowly varying function than is its leading edge. See Figure 49. Just above prompt critical ( $T=150 \mathrm{msec}$ ) at periods of about $50 \mathrm{msec}$, the situation again reversed and the burst became sharply cut off. See Figure 50 . At periods near $4 \mathrm{msec}$ the pulse became symmetrical. See Figure 51 . As the

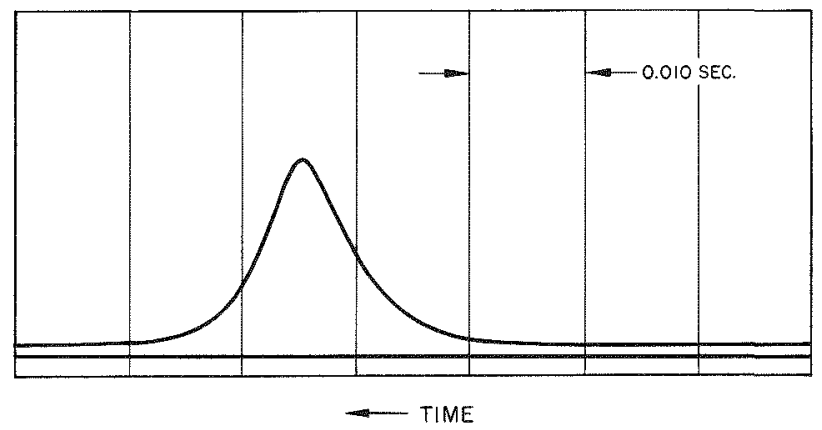

Figure 51. Oscillogram for Transient No. 226 B, Stable Period $3.8 \mathrm{msec}$ period is further decreased to a few milliseconds the pulse again became asymmetric in a fashion similar to that around prompt critical with the leading edge of the burst steeper than the trailing edge. See Figure 52. This latter asymmetry

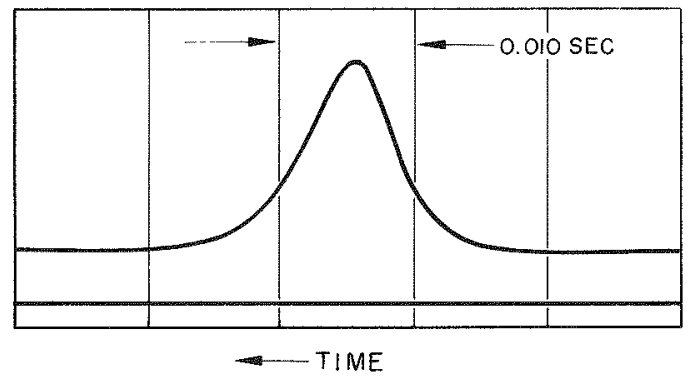

Figure 52. Oscillogram for Transient No. 190 B, Stable Period $2.12 \mathrm{msec}$ for short period excursions appears to be unique to the KEWB system among thermal reactor concepts and is believed to be caused by the graphite reflector. Although it is not conclusively proved, all available information indicates that neutrons that left the core and spent a large portion of their lifetime in the reflector had an overall effect similar to an additional group of neutrons - - they tended to lengthen the pulse decay time. This subject is discussed in more detail in Part II of this series of reports. 
The effects of initial solution volume on the energy release were as would be expected from the peak power data. For periods longer than $20 \mathrm{msec}$, the energy release was less for the full core case; and for stable periods less than $20 \mathrm{msec}$, the energy release was greater.

From these data, one must conclude also that steam formation could not play a significant role in reactor shutdown when the initial solution temperature is about $25^{\circ} \mathrm{C}$. The heat capacity of the fuel was between 15 and $20^{\circ} \mathrm{C} / \mathrm{Mws}$ for both the full and underfull cases. Therefore, boiling could not occur by the time of peak power, since the maximum temperature reached would only be $65^{\circ} \mathrm{C}$ for initial temperature of $25^{\circ} \mathrm{C}$. In addition, substantial pressures were present frequently at the time of peak power, which subdued boiling.

To investigate the effect of initial reactor power on the transient response of the reactor, a series of step reactivity input transients were run at stable powers of 1,10 , and $20 \mathrm{kw}$. The initial fuel temperature for this series of runs was set at $40^{\circ} \mathrm{C}$, since the cooling system could not maintain a $25^{\circ} \mathrm{C}$ fuel temperature at $20 \mathrm{kw}$ stable power. The initial core pressure was $70 \mathrm{~cm} \mathrm{Hg}$.

Figure 53 and Table VI present the results of these excursions. In this graph, the solid line function (noted as " $\mathrm{B}$ " series, $\mathrm{T}_{\mathrm{O}}=25^{\circ} \mathrm{C}$ ) is the result of step inputs run at negligible power and initial fuel temperature of $25^{\circ} \mathrm{C}$. The dash-line function represents this step input low initial power data normalized to $40^{\circ} \mathrm{C}$ to compare with the data taken at higher initial powers.

It is apparent from the data that there was no appreciable effect on the maximum power achieved by the reactor as a result of high starting power. This is evidence that the shut-down mechanisms which control the reactor were not influenced by the presence of pre-existent atmospheric-pressure gas voids in the fuel solution.

This series of transients was initiated by setting the control rods at the desired excess while the large poison rod of the pneumatic reactivity device was inserted in the through-tube. The reactor was then brought to stable power at the desired power level by using the poison rod as a control rod. The reactor was operated at stable power for a minimum of five minutes to allow the delayed neutrons to come in to equilibrium and the system pressure to reach $70 \mathrm{~cm} \mathrm{Hg}$, and then the transient was initiated by pneumatically ejecting the poison rod from the core. 
TABLE VI

SUMMARY OF DATA FOR EFFECTS OF INITIAL REACTOR POWER ON STEP INPUT TRANSIENTS, 85\% FULL CORE (P SERIES)

\begin{tabular}{|c|c|c|c|c|c|c|c|c|}
\hline & \multirow{2}{*}{$\begin{array}{l}\text { Trans } \\
\text { (No.) }\end{array}$} & \multirow{2}{*}{$\begin{array}{c}\text { Equivalent } \\
\tau \\
(\mathrm{ms})\end{array}$} & \multirow{2}{*}{$\begin{array}{l}\text { Peak } \\
\text { Power } \\
(\mathrm{Mw})\end{array}$} & \multicolumn{2}{|c|}{$\begin{array}{l}\text { Pressure } \\
(p \& i)\end{array}$} & \multirow{2}{*}{$\begin{array}{c}\text { Starting } \\
\text { Temp }\end{array}$} & \multirow{2}{*}{$\begin{array}{c}\text { Starting } \\
\text { Pressure } \\
\text { (cm Hg abs) }\end{array}$} & \multirow{2}{*}{$\begin{array}{l}\text { Starting } \\
\text { Power } \\
(\mathrm{kw})\end{array}$} \\
\hline & & & & Inertial & Impact & & & \\
\hline \multirow{7}{*}{ 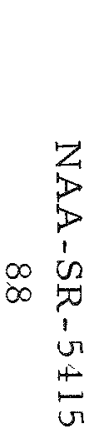 } & 1 & 33.0 & 0.362 & & & 40.3 & 70.0 & 1 \\
\hline & 2 & 38.8 & 0.352 & & & 40.5 & 70.0 & 1 \\
\hline & 3 & 21.7 & 3.79 & & & 40.3 & 70.0 & 1 \\
\hline & 4 & 25.0 & 3.125 & & & 40.5 & 70.0 & 1 \\
\hline & 5 & 21.1 & 3.58 & & & 40.2 & 70.0 & 1 \\
\hline & 6 & 9.40 & 41.8 & & & 40.3 & 70.0 & 1 \\
\hline & 7 & 2.78 & 236 & & & 40.6 & 70.0 & 1 \\
\hline & $8 R^{2}$ & 27.6 & 0.288 & & & 40.6 & 70.0 & 10 \\
\hline & 9 & & 2.34 & & & 41.2 & 70.0 & 10 \\
\hline & 10 & 10.8 & 30.8 & 12.8 & 1.08 & 40.6 & 70.0 & 10 \\
\hline & 11 & 3.37 & 198 & & & 41.6 & 70.0 & 10 \\
\hline & $12 \mathrm{R}$ & 31.2 & 0.280 & & & 44.6 & 70.0 & 25 \\
\hline & 13 & & 358 & & & 39.0 & 70.0 & 20 \\
\hline & 14 & & 2.04 & & & 42.3 & 70.0 & 20 \\
\hline & 15 & 11.2 & 28.4 & 23.7 & 7.6 & 42.8 & 70.0 & 20 \\
\hline & 16 & 3.06 & 202 & & & 40.3 & 70.0 & 20 \\
\hline
\end{tabular}




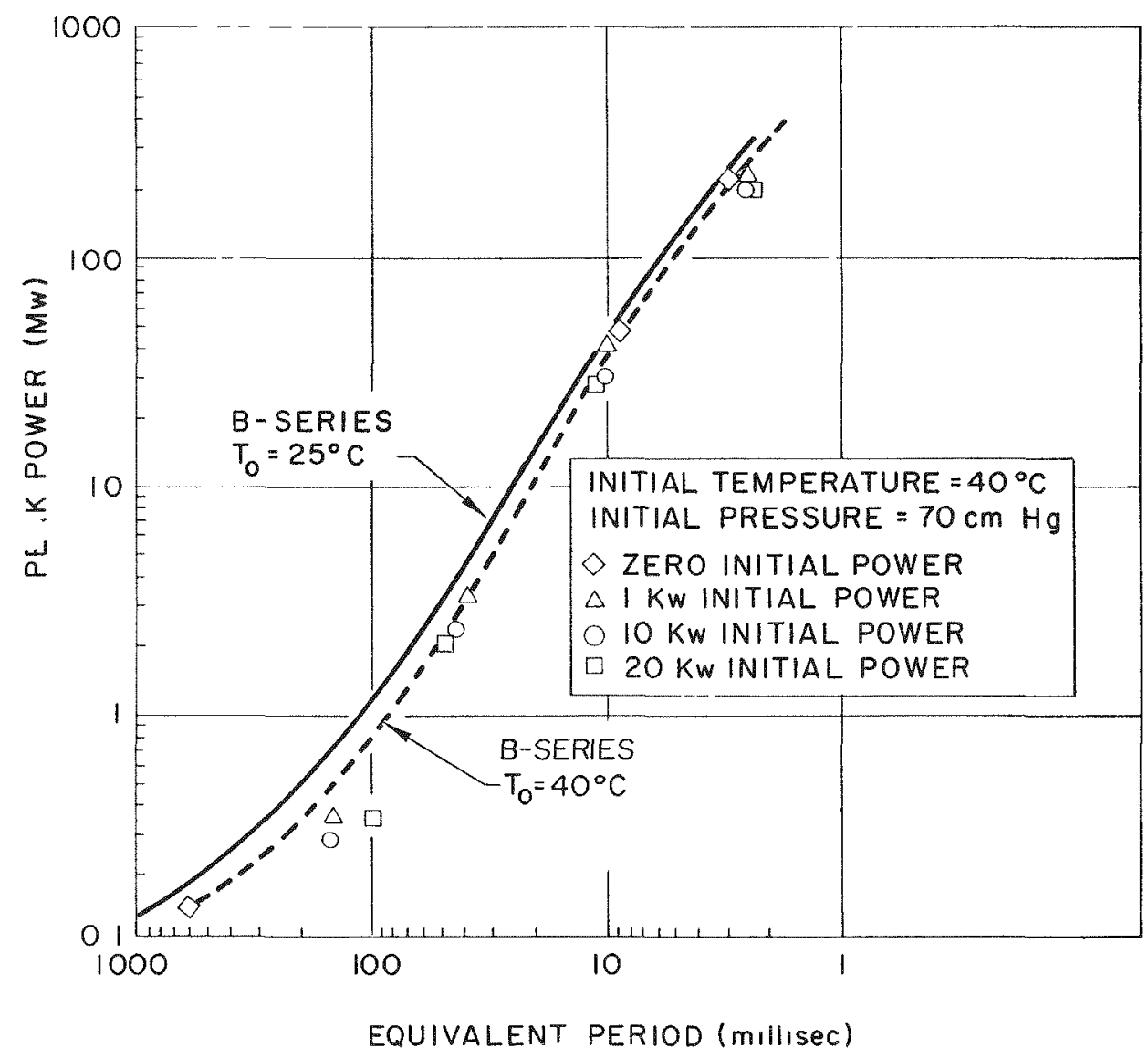

Figure 53. Peak Power vs Initial Power

It was not possible to use the conventional independent variable, stable period, in these experiments. Even with the fast poison rod ejection, the reactor did not achieve a stable period. The influence of the prompt neutron term is substantial and causes a rapid initial rise in the power. Before the reactor recovered from this initial "prompt jump", it had reached a sufficient power level so that the shutdown mechanisms were beginning to function and the power began to deviate from a simple exponential. Therefore, "equivalent" periods were used as a basis for comparing the low and high power starts. These periods corresponded to those stable periods which would have occurred in a transient initiated at low initial power based on the reactivity represented by the control rod increment used.

A number of step input transients with no coolant flow were allowed to run for several minutes after peak power to determine the long time response of the system as the fuel drains back from the overflow chamber. In all cases the 
reactor returned to a low power (below $50 \mathrm{kw}$ ) and slowly decreased further in power as the temperature of the system increased. No indication of instability or divergent oscillations was observed undex any conditions.

\section{B. RAMP REACTIVITY INSERTIONS}

A series of experiments were initiated in which the reactivity input was a linearly increasing function of time. This reactivity ramp was obtained by a programmed control rod withdrawal scheme giving ramp rates ranging from $\$ 0.04$ to $\$ 0.16 \Delta \rho / \mathrm{sec}$ and a total reactivity input up to $\$ 5.0$. These ramp rates corresponded to withdrawal of one control rod, or two, three, or four control rods simultaneously. The initial core conditions for these runs were $25^{\circ} \mathrm{C}$ initial fuel temperature, $10^{-3}$ watt initial power and no coolant flow.

A typical sequence of events was as follows:

1) A power transient occurred early in the ramp input.

2) The power fell to a low level immediately after the initial transient and then recovered slightly as the rod withdrawal continued.

3) Low amplitude, damped oscillations occurred in some cases during the time the rods were being withdrawn, but always ceased when rod motion stopped.

4) After the rod withdrawal ceased, the power level slowly decreased as the fuel temperature increased.

Since the power peak occurred before the termination of the ramp, the peak power depended on the ramp rate and was independent of the total reactivity input. The stable power level reached at the time the rod motion was stopped did depend on total reactivity input. The maximum power reached after the burst was between 40 and $60 \mathrm{kw}$ for $\$ 5.0$ total reactivity input and no coolant flow.

The peak powers observed are shown in Figure 54. The basis of comparison of these results to those resulting from step inputs of reactivity is by means of the minimum period established in the two different types of excursions. It is difficult to locate this minimum period with a high degree of accuracy for the ramp-induced excursions because the period is continuously changing. This point probably accounts for the scatter seen in the data, particularly about prompt critical. The shortest period excursions observed with rod withdrawal represent simultaneous removal of all four control rods. It can be concluded from these tests that if one established the minimum period which occurs as a 
result of rod withdrawal, the peak power obtained may be reliably predicted on the basis of an equivalent step change in reactivity. The post burst behavior

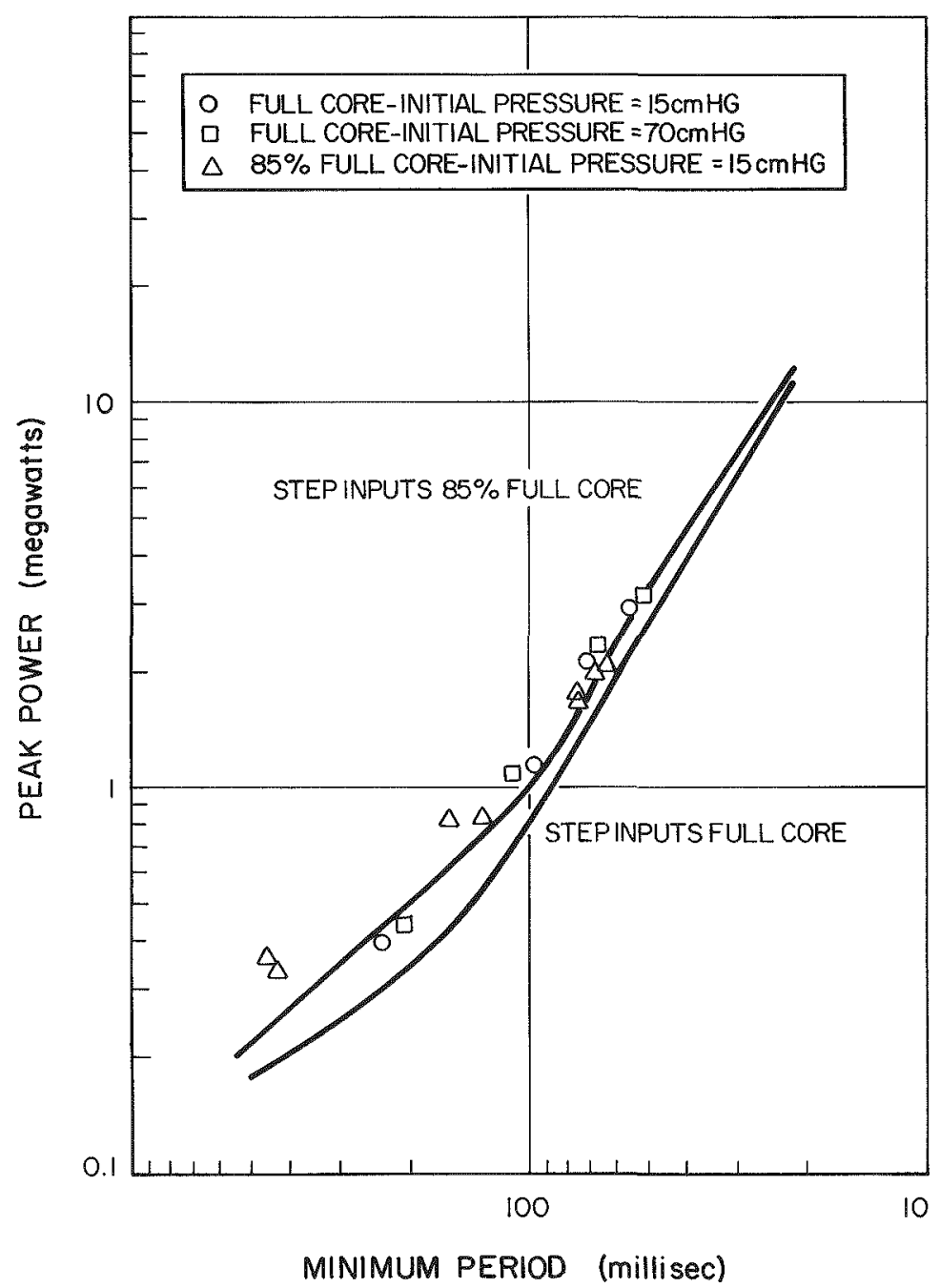

Figure 54. Peak Power vs Minimum Period, Ramp Inputs

of the reactor showed no indication of instability, even in the case of the largest reactivity input of $\$ 5.0$ which was observed over a period of $20 \mathrm{~min}$.

As indicated in Figure 53, the ramp data were taken for two initial system pressures ( 15 and $70 \mathrm{~cm} \mathrm{Hg}$ ) with the full core, and one initial system pressure $(15 \mathrm{~cm} \mathrm{Hg}$ ) for the $85 \%$ full core. Varying the initial pressure for the full core case did not give any detectable difference in the reactor behavior. Neither was there any significant difference between the full and $85 \%$ full core runs. 
Special ramp input experiments were run to determine the results of possible operator start-up accidents on a normal (underfull) operating reactor. These were:

1) A ramp transient with $\$ 3.0$ total reactivity input and $\$ 0.16 \Delta \rho /$ sec ramp rate was allowed to seek equilibrium with full coolant flow (15 g pm). The power level dropped from $2 \mathrm{Mw}$ (the maximum of the initial burst) to $20 \mathrm{kw}$ within $1 \mathrm{sec}$ after the maximum. As the ramp continued the power level rose with small damped oscillations. The maximum power reached in this interval was $200 \mathrm{kw}$ at the time the ramp input was terminated. The oscillations ceased with the termination of the ramp and the reactor reached an equilibrium power level of $160 \mathrm{kw}$, $45 \mathrm{sec}$ after the initial burst.

2) A similar ramp transient, with $\$ 5.0$ total reactivity input, was allowed to seek equilibrium with no coolant flow. The post-burst minimum power was $30 \mathrm{kw}$ and the highest post-burst power attained at ramp termination was less than $60 \mathrm{kw}$. The power decayed to $10 \mathrm{kw}$ within $3 \mathrm{~min}$ after the burst and to $6 \mathrm{kw}$ in $5 \mathrm{~min}$. The reactor was then boiling and the power level oscillated slowly between 2 and $6 \mathrm{kw}$ until the experiment was terminated 20 min after the initial power burst. Boiling at this low power compensates essentially all the reactivity input.

\section{INVESTIGATION OF HYDROGEN-OXYGEN EXPLOSIONS RESULTING FROM STEP AND RAMP INPUTS}

To complete the experimental program of the KEWB spherical core, tests were conducted to investigate the interaction of the gas recombination system and the core. These tests were designed to provide data on conditions necessary for hydrogen-oxygen ignitions and on the response of the core during such explosions.

Two groups of tests were conducted. The first group included both ramp and step reactivity inputs. Ramp inputs of $\$ 5$ at an input rate of $\$ 0.16 / \mathrm{sec}$ and $\$ 1$ at a rate of $\$ 0.04 / \mathrm{sec}$ were inserted. Step reactivity inputs resulting in reactor periods of 15,5 , and $2 \mathrm{msec}$ for low initial power and periods of 15,5 , and $3 \mathrm{msec}$ for $20 \mathrm{kw}$ starting power were also performed. 
For both step and ramp reactivity inputs there was a significant time delay between peak power and the explosion. During the power burst, large quantities of hydrogen-oxygen gas at high local pressure weregenerated, but did not explode due to the lack of an ignition source. However, when a sufficient amount of gas had diffused to the recombiner an explosion was ignited by the catalyst. In all of these tests the reactor was allowed to continue operating with full coolant flow after the burst, an equilibrium power of between 60 to $80 \mathrm{kw}$ being achieved. This permitted more gas generation and produced the worst explosion conditions for each test.

Various recombiner conditions were tested for the ramp and step inputs to find the greatest possible explosion pressures. Conditions that were varied included the initial catalyst bed temperature, recombiner aspirator pump on or off, and the gas inlet valve to the aspirator open or closed. The valve in the gas line leading directly from the catalyst bed to the core was open for all these tests.

The second group of tests simulated a normal reactor startup accident. The reactor was taken to $50 \mathrm{kw}$ on a 15 - sec period with a cold and inoperative gas recombiner.

The pressure detecting and recording system used was the fast response DADEE system described in the instrument section. Figure 13 shows a diagram of this system. For these tests, Statham pressure transducers were located in the following positions: (1) bottom of the core, (2) top of the core, (3) overflow chamber, and (4) the gas phase of the recombiner. The transducer at the bottom of the core was rendered inoperative early in the test series due to a stressed mounting condition. Replacement of this transducer was not warranted since the pressure detected below the liquid level was about one half the pressure above the liquid level and would not limit the test. Figure 15 shows the oscilloscope recording of a typical hydrogen-oxygen explosion.

\section{Results of the Tests}

The interaction of the core and the gas recombination system was found to be insensitive to a variety of startup conditions. These include core coolant flow rate, catalyst bed temperature, ramp reactivity input rate, and maximum ramp reactivity input. 
The interaction was sensitive to two other parameters. The first being the maximum step reactivity input. In the largest step inputs ( 5 to $2 \mathrm{msec}$ ), liquid was expelled from the core violently enough in the burst to carry fuel solution to the recombiner chamber. As a result, the catalyst became dampened and ignition of the gas was delayed more than normally expected. The delay allowed higher system pressures before detonation causing larger explosion pressures.

The second sensitive parameter was the gas flow in the recombination system. If the gas inlet valve to the aspirator was opened without the aspirator operating, recombiner working fluid was transferred to the core as a result of an explosion. Also, ignition was more likely to occur because the gas generated in the core diffused unhindered to the catalyst bed, whereas if the recombiner gas circulation system was in operation the diffusion of gas from the core directly to the catalyst bed would be against the established flow direction. The lack of explosions under these conditions indicated the pressure differential normally existing between core and recombiner is lessened but not reversed by the sudden evolution of gas. The maximum pressure associated with hydrogenoxygen inflammations were 450 psia in the overflow chamber and 400 psia in the core vessel. The average time from initial burst to the explosion was $25 \mathrm{sec}$. A slight resurgence of power was caused by the compression of gas voids contained in the fuel solution during the explosion.

The maximum pressures for the step reactivity inputs were 550 psia in the overflow chamber and 500 psia in the sphere. These higher explosion pressures are indicative of the delay in ignition caused by the wet recombiner catalyst.

All of the tests discussed to this point involved an initial power of approximately $1 \mathrm{mw}$. To check the sensitivity to starting power, a series of step input tests were run while operating at $20 \mathrm{kw}$ stable power. In these tests, the catalyst temperature rose rapidly after the burst due to the increased recombination required, but explosions were not initiated.

When the reactor was taken to $50 \mathrm{kw}$ stable power on a $15-\mathrm{sec}$ period with a non-operative recombiner, explosion pressures of 500 psia were observed in the overflow chamber and of 350 psia in the sphere. About $70 \mathrm{sec}$ at $50 \mathrm{kw}$ were required to produce an explosive mixture of hydrogen-oxygen gas. 


\section{Conclusion}

The maximum pressures experienced in the hydrogen-oxygen explosion tests did not endanger the integrity of the sphexical core or its recombiner. In all 25 tests conducted, the explosion pressures were less than the impact pressure for maximum step reactivity inputs. Table VII gives the initial conditions and pressure data for the runs.

\section{Interpretation of Transient Pressure Records}

The ability of the instrument systems utilized in the KEWB program to accurately record the functions being monitored was a question of critical importance, and both analytical and experimental evidence was required to formulate the answer. An example of the type of examinations made is given in the paragraphs which follow. This particular analysis was related to the recording of an $\mathrm{O}_{2}-\mathrm{H}_{2}$ explosion by a light beam galvanometer.

The shape of the pressure pulse generated by an $\mathrm{O}_{2}-\mathrm{H}_{2}$ explosion has. been shown ${ }^{10}$ to be well represented by an exponentially decaying function $\mathrm{e}^{-\mathrm{t} / \mathrm{T}}$, with $\mathrm{T}$ approximately equal to $200 \mathrm{msec}$.

The ability of a recording system to follow such rapidly varying signals depends on its time response characteristics; that is, on how well it responds to brief transients. It is possible to judge the ability of any recording channel to properly record transients by obtaining a dynamic calibration. This may be done conveniently by presenting a unit step to the recording system, and noting the response, called the indicial admittance, $A(t)$, see Figure 55. As shown in the figure, the unit step is a signal which is zero for $t=0$, and has the value unity for $t>0$. If the system can respond to this signal, the response $A(t)$ will sooner or later rise to the value unity. The function $A(t)$ is the dynamic calibration of the recording channel, and it is possible to predict the response of the channel to any signal $S(t)$ in terms of $S(t)$ and the response function $A(t)$. Frequently it is possible to represent an instrument's indicial admittance by a simple exponential rise function,

$$
A(t)=1-e^{-t / t_{0}}
$$

When this is possible, there is a simple relation between any signal $S(t)$ presented to the recording channel and the actual response $R(t)$ that is obtained. 
TABLE VII

DATA FOR $\mathrm{H}_{2}-\mathrm{O}_{2}$ EXPLOSION TESTS

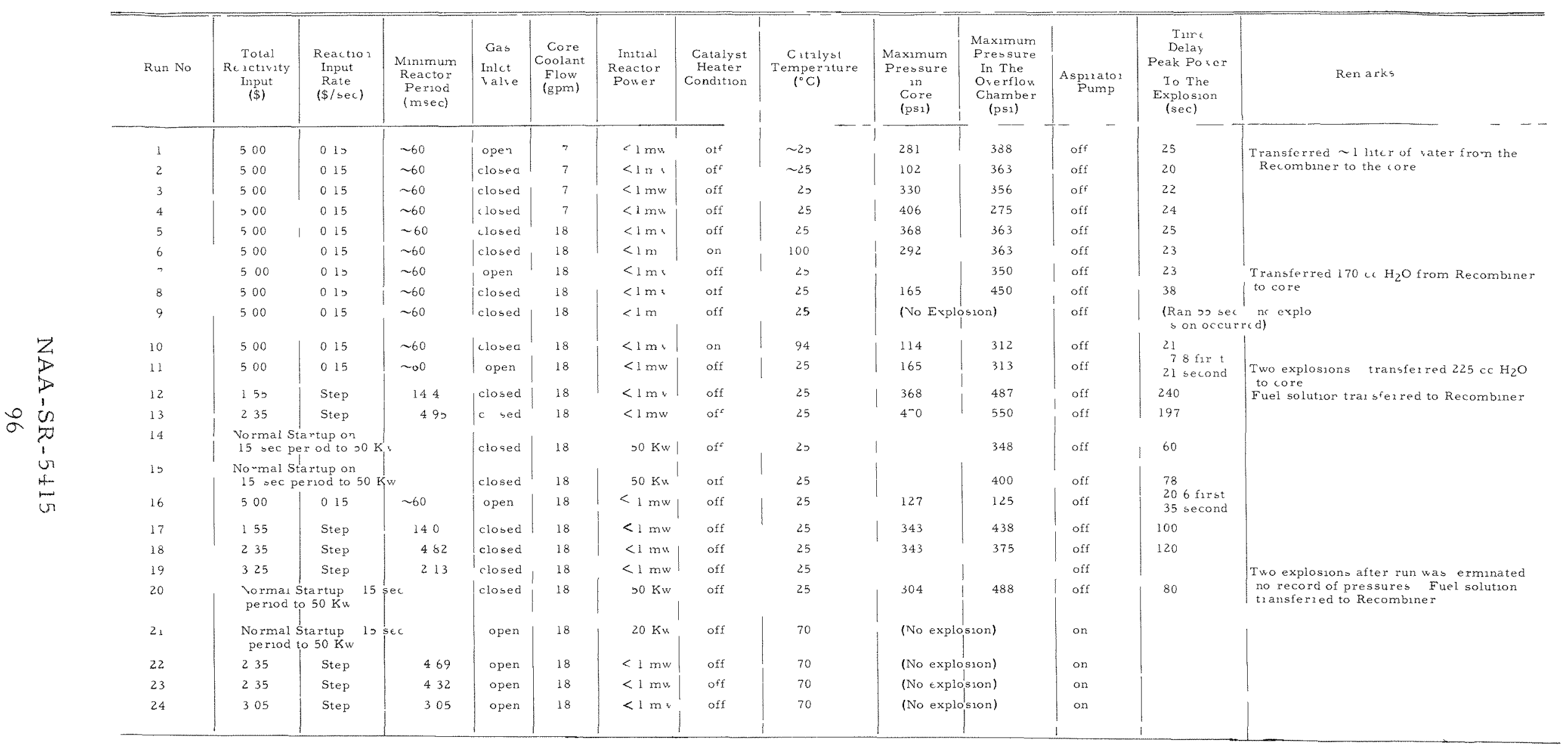




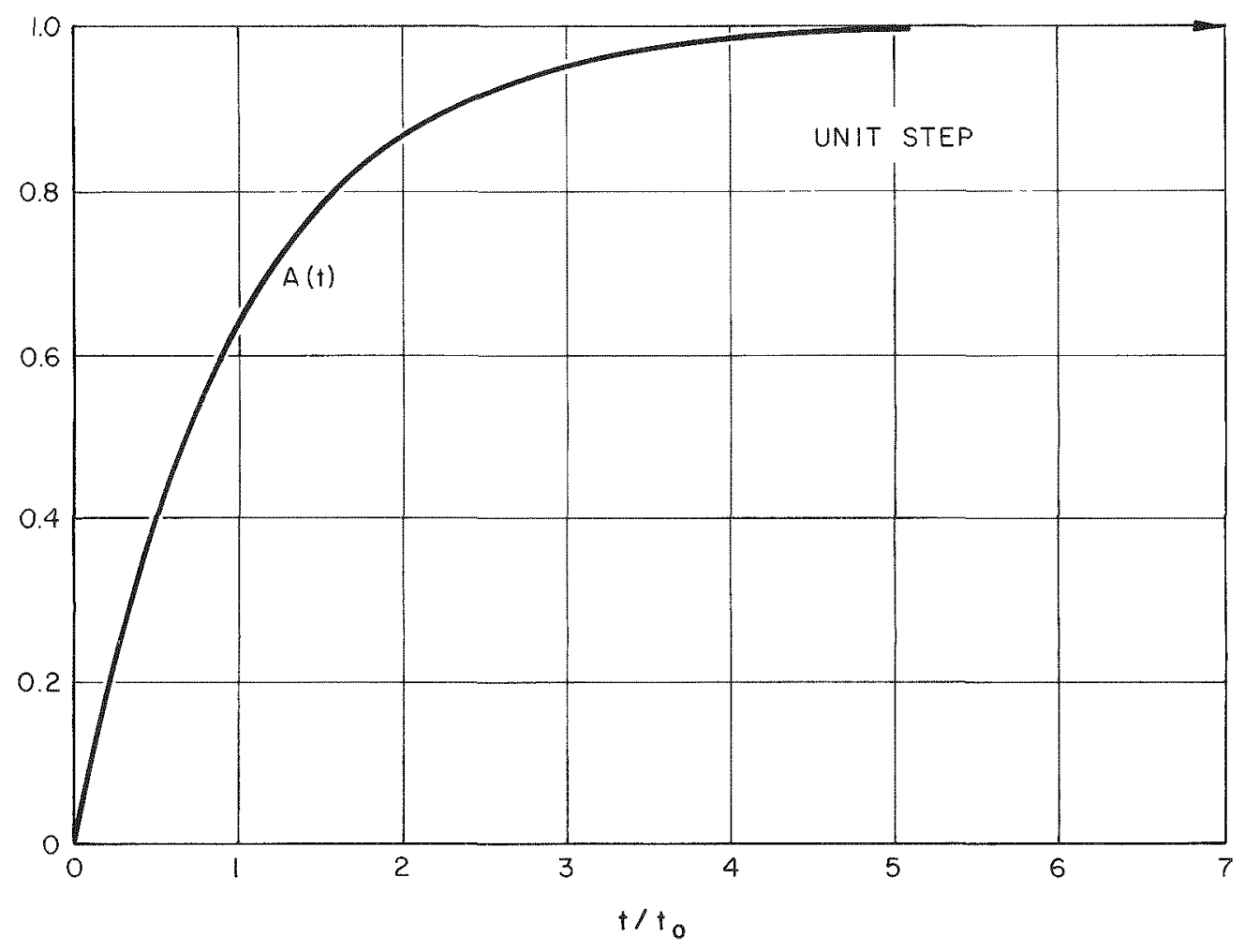

Figure 55. Plot of Unit Step and Indicial Admittance, $A(t)$

If the signal $S(t)$ is of the form mentioned earlier,

$$
S(t)=e^{-t / T}
$$

then it is possible to obtain the response function $R(t)$ in closed form. If the recording channel is a linear instrument, the relation between the signal $S(t)$, the response $R(t)$, and the indicial admittance $A(t)$ is given by the Duhamel Integral

$$
R(t)=S(t) A(0)+\int_{0}^{t} S(t) \frac{d A(t-\tau)}{d t} d \tau .
$$

If the indicial admittance $A(t)$ has the form

$$
A(t)=1-e^{-t / t_{0}}
$$

then

$$
A(0)=0
$$


and

$$
R(t)=\int_{0}^{t} S(\tau) \frac{d A(t-\tau)}{d t} d \tau=\frac{1}{t_{0}} e^{-t / t_{0}} \int_{0}^{t} S(\tau) e^{\tau / t_{0}} d \tau
$$

Differentiating both sides with respect to $t$,

$$
t_{O} R^{\prime}(t)=-\frac{1}{t_{0}} e^{-t / t_{0}} \int_{0}^{t} S(\tau) e^{\tau / t_{0}} d \tau+S(t)
$$

Eliminating the integral from Equations 9 and 10,

$$
S(t)=R(t)+t_{0} R^{\prime}(t)
$$

Since no assumptions were made about the function $S(t)$ (except that it be a "reasonable" function mathematically), Equation 11 can be applied generally when $A(t)$ can be represented by the exponential growth function $\left(1-e^{-t / t_{O}}\right)$, Equation 11 is convenient since the right hand side is expressed completely in terms of the record $R(t)$, and a computation based on the record.

As mentioned previously, if the signal $S(t)$ has the form

$$
S(t)=e^{-t / T}
$$

then one can obtain $R(t)$ as an explicit function of time.

Substituting the expression for $S(t)$ given in Equation 12 into Equation 9, one obtains:

$$
R(t)=\frac{1}{t_{0}} e^{-t / t_{0}} \int_{0}^{t} e^{-\tau / T} e^{\tau / t_{0}} d \tau
$$

Carrying out the integration,

$$
R(t)=\frac{T}{T-t_{0}}\left(e^{-t / T}-e^{-t / t_{0}}\right)
$$




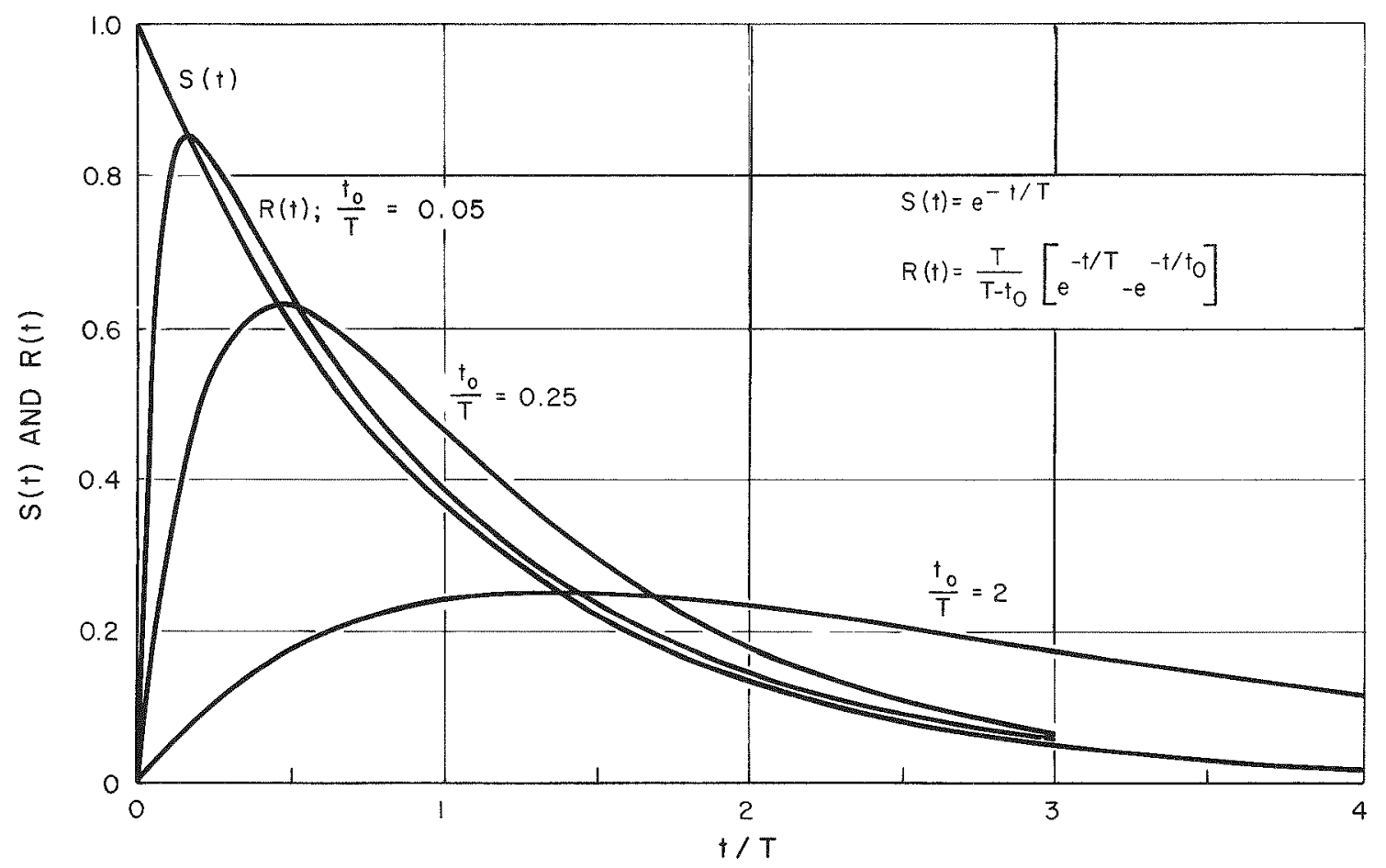

Figure 56. Signal $S(t) \underline{\text { vs }}$ Response $R(t)$

Figure 56 shows the signal $S(t)$ and the response $R(t)$ for the indicated values of $\left({ }^{t_{O}} / \mathrm{T}\right)$. The response approaches the signal more closely as ${ }^{{ }} \mathrm{O} / \mathrm{T}$ approaches zero.

It is useful to obtain the peak value of $R(t)$ as a function of ${ }^{t} 0 / T$. Then one may estimate the loss of peak response for a given ratio of the time constants.

Differentiating Equation 14 and setting it equal to zero [condition for maximizing $R(t)]$,

or

$$
\begin{gathered}
R^{\prime}(t)=\frac{T}{T-t_{0}}\left[-\frac{1}{T} e^{-t_{m} / T}+\frac{1}{t_{0}} e^{-t_{m} / t_{0}}\right]=0 \ldots(1 \\
\frac{t_{0}}{T} e^{-t^{t} m / T}=e^{-\frac{t}{t} / t_{0}}
\end{gathered}
$$

where $t_{m}$ is the time at which the maximum value $R_{m}$ occurs. 
The value of $R_{m}$ is

$$
R_{m}=\frac{T}{T-t_{0}}\left[e^{-t_{m} / T}-e^{-t_{m} / t_{0}}\right]
$$

Let $x=t_{0} / T$ and eliminate $t_{m}$ from Equations 16 and 17.

Then

$$
\mathrm{R}_{\mathrm{m}}=\mathrm{x}^{\frac{\mathrm{x}}{1-\mathrm{x}}}
$$

This is the desired function giving the peak response to be expected from a given value of $x=t_{0} / T$.

Figure 57 is a graph of Equation 18.

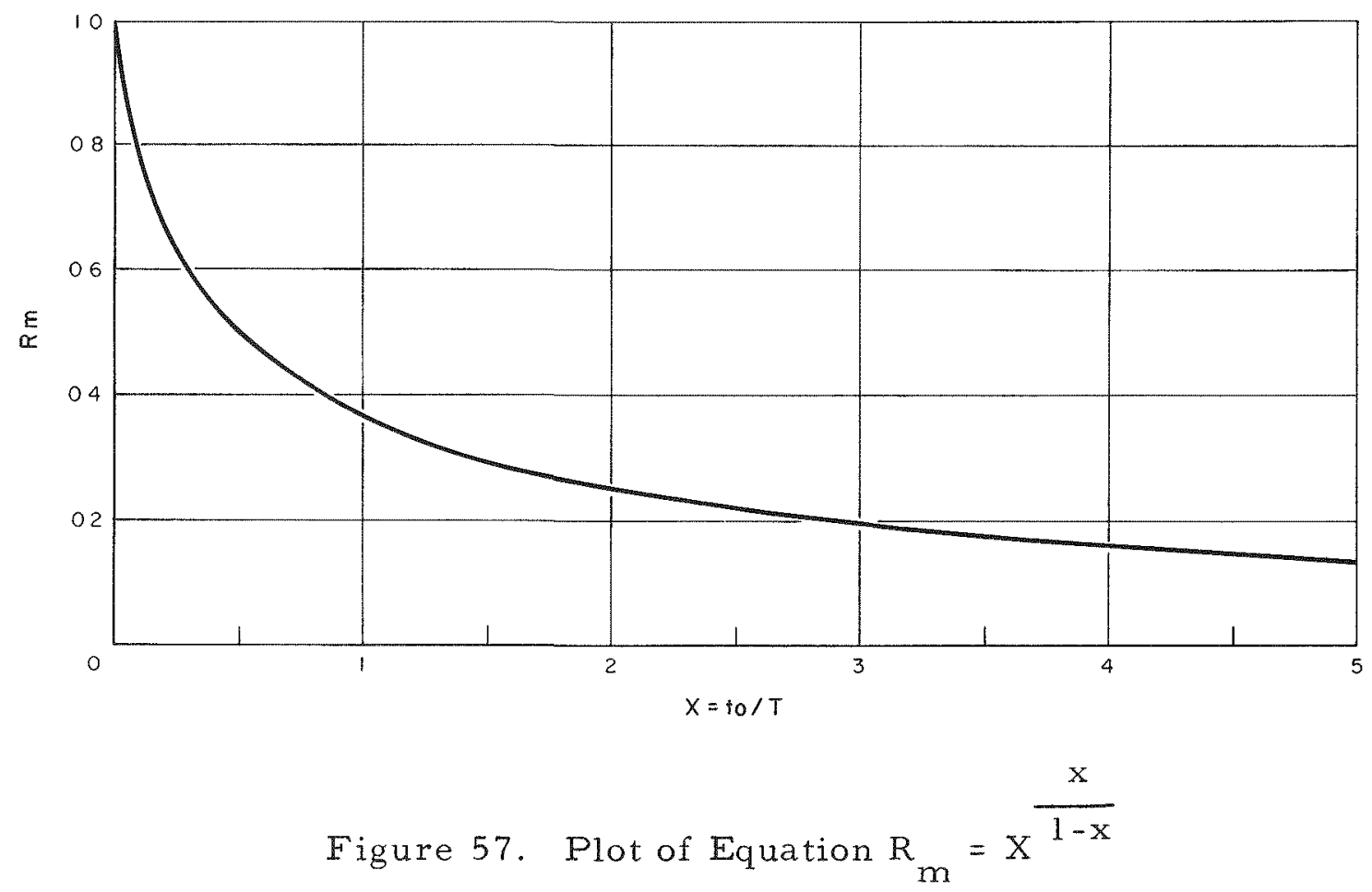

One may now estimate the loss in peak response when $\mathrm{T}=200 \mu \mathrm{sec}$ and the recording is done by the CEC recording galvanometer. The response of the latter to a unit step can be fairly well represented by the form

$$
A(t)=1-e^{-t / t_{0}}
$$

with $t_{0}=50 \mu s e c$. 
For this case, $x=\frac{50}{200}=0.25$ and $R_{m}=(1 / 4)^{1 / 3}=0.63$; that is, only $65 \%$ of the true peak would be recorded by this galvanometer.

Even though the assumed signal has its peak value $S_{0}$ at $t=0$, the instrument lag delays the peak response until the time $t_{m}$. This quantity may be computed by recasting Equation 16 into a more convenient form,

$$
e^{-t^{m} m / t}=x^{1 / 1-x}
$$

In the present case with $x=1 / 4$ and $t_{0}=50 \mu s e c$, Equation 19 leads to the value

$$
t_{m}=92 \mu s e c
$$

Thus one would expect to see records with a peak response occurring with a rise time of about $100 \mu \mathrm{sec}$.

The initial part of the graph in Figure 57 may be represented approximately by a linear relation between $R_{m}$ and $x$ for the range $0<x<0.05$ (with the error in $R_{m}$ not exceeding 1 or $2 \%$ ):

$$
R_{m}=1-3 x=1-3 t_{o / T}
$$

Thus if $t_{o / T}=0.05, R_{m}=0.85$.

By integrating Equation 8 with respect to $t$, it can be shown that

$$
\int_{0}^{\infty} R(t) d t=\int_{0}^{\infty} S(t) d t
$$

that is, a linear instrument may distort a signal, but the time integral or the area under the response curve (to $\infty$ ) will faithfully preserve the impulse of the signal. 


\section{REFERENCES}

1. R. F. Wilson, et al, "Aqueous Homogeneous Type Research Reactors," A/Conf P/1543

2. M.A. Greenfield, 'Kinetic Experiments on Water Boilers, 'A' Core Report-Part IV, Containment Aspects of Hydrogen Oxygen Explosions, "NAA-SR5418 (December 1960)

3. J. W. Flora, D. L. Hetrick, and L. P. Inglis, "Program Review of the Water Boiler Reactor Kinetics Experiments, "NAA-SR-1525 (March 15, 1956)

4. S. G. Forbes, F. Schroeder, and W. E. Nyer, "Instability in the SPERT I Reactor Preliminary Report," IDO 16309 (October 10, 1956)

5. J. W. Flora, J. W. Shortall, and W. E. Drummond, "Temperature Effect on Reactivity of the C. R. and D. Water Boiler, "LRL-148 (June 1954)

6. M. S. Dunenfeld, et al, "Kinetic Experiment on Water Boilers, 'A' Core Report - Part II, Analysis of Results, " NAA-SR-5816

7. E. R. Cohen, "Some Topics in Reactor Kinetics," A/Conf. 14/P/629 (Geneva, 1958)

8. D. P. Gamble, "A Proposed Model of Bubble Growth During Fast Transients in the KEWB Reactor, " Paper 25-3, ANS Summer Meeting (June 15, 1959)

9. J. P. Ford and J. F. Newton, "An Instrument for Extending the Frequency Response of Transducers Which Have Two Degrees of Freedom, "ISA Conference, Chicago (September 23, 1959)

10. S. P. Harris and C. F. Bumpus, Jr., "Pressure and Temperature Instrumentation for Dynamic Measurements in The KEWB Program - A Summary Report", NAA-SR-4709 (November 15, 1960) 